\title{
NOMAD, an Integrated Suite of Three Spectrometers for the ExoMars Trace Gas Mission: Technical Description, Science Objectives and Expected Performance
}
A.C. Vandaele ${ }^{1}$ - J.-J. Lopez-Moreno ${ }^{2}$ - M.R. Patel ${ }^{3,4}$ - G. Bellucci ${ }^{5}$ F. Daerden ${ }^{1}$.
B. Ristic ${ }^{1}$ - S. Robert ${ }^{1}$ - I.R. Thomas ${ }^{1}$ - V. Wilquet ${ }^{1}$ - M. Allen ${ }^{6}$ - G. Alonso-Rodrigo ${ }^{7}$.
F. Altieri ${ }^{5}$ - S. Aoki ${ }^{1}$ - D. Bolsée ${ }^{1}$. T. Clancy $^{8}$ - E. Cloutis ${ }^{9}$ - C. Depiesse ${ }^{1}$.
R. Drummond ${ }^{1}$ - A. Fedorova ${ }^{10}$ - V. Formisano ${ }^{5}$ - B. Funke ${ }^{2}$. F. González-Galindo ${ }^{2}$.
A. Geminale ${ }^{5}$ J.-C. Gérard ${ }^{11}$ - M. Giuranna ${ }^{5}$ L. Hetey ${ }^{1}$ N. Ignatiev $^{10}$.

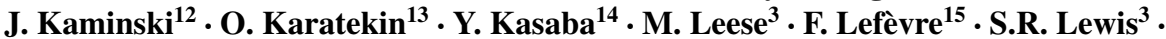
M. López-Puertas ${ }^{2}$ - M. López-Valverde ${ }^{2}$ - A. Mahieux ${ }^{5,1,16} \cdot$ J. Mason $^{3}$.
J. McConnell ${ }^{17}$ - M. Mumma ${ }^{18}$ - L. Neary ${ }^{1}$ E. Neefs ${ }^{1}$ - E. Renotte ${ }^{19}$.
J. Rodriguez-Gomez ${ }^{2}$ - G. Sindoni ${ }^{5}$ - M. Smith ${ }^{17}$ - A. Stiepen ${ }^{11}$ - A. Trokhimovsky ${ }^{10}$.
J. Vander Auwera ${ }^{20}$. G. Villanueva ${ }^{18,21} \cdot$ S. Viscardy $^{1} \cdot$ J. Whiteway $^{17}$ - Y. Willame ${ }^{1}$. M. Wolff ${ }^{8}$ the NOMAD Team

Received: 3 November 2016 / Accepted: 9 June 2018 / Published online: 19 June 2018

(C) The Author(s) 2018

Abstract The NOMAD ("Nadir and Occultation for MArs Discovery") spectrometer suite on board the ExoMars Trace Gas Orbiter (TGO) has been designed to investigate the com-

This paper is dedicated to the memory of M. Allen, V. Formisano, and J. McConnell.

ExoMars-16

Edited by Håkan Svedhem and Christopher T. Russell

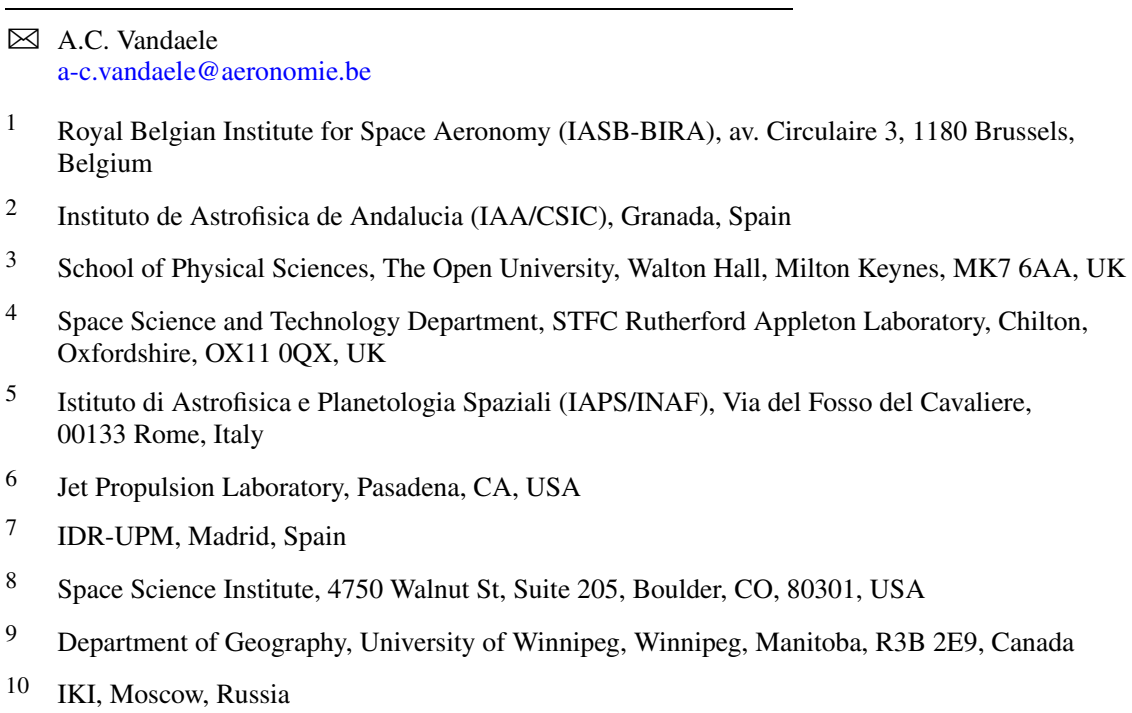


position of Mars' atmosphere, with a particular focus on trace gases, clouds and dust. The detection sensitivity for trace gases is considerably improved compared to previous Mars missions, compliant with the science objectives of the TGO mission. This will allow for a major leap in our knowledge and understanding of the Martian atmospheric composition and the related physical and chemical processes. The instrument is a combination of three spectrometers, covering a spectral range from the UV to the mid-IR, and can perform solar occultation, nadir and limb observations. In this paper, we present the science objectives of the instrument and explain the technical principles of the three spectrometers. We also discuss the expected performance of the instrument in terms of spatial and temporal coverage and detection sensitivity.

Keywords ExoMars $\cdot$ Solar occultation $\cdot$ Nadir observations $\cdot$ Mars atmosphere · Composition · Infrared $\cdot$ Ultraviolet $\cdot$ Visible $\cdot$ Spectroscopy $\cdot$ Methane $\cdot$ Dust

\section{Introduction}

NOMAD, the "Nadir and Occultation for MArs Discovery" spectrometer suite, was selected as part of the payload of the ExoMars 2016 Trace Gas Orbiter mission. The instrument will conduct a spectroscopic survey of Mars' atmosphere in ultraviolet (UV), visible and infrared (IR) wavelengths covering large parts of the $0.2-4.3 \mu \mathrm{m}$ spectral range. NOMAD is composed of 3 spectrometers (see Fig. 1): a solar occultation only spectrometer (SO-Solar Occultation) operating in the infrared $(2.3-4.3 \mu \mathrm{m})$, a second infrared spectrometer $(2.3-3.8 \mu \mathrm{m})$ capable of doing nadir, but also solar occultation and limb observations (LNO-Limb Nadir and solar Occultation), and an ultraviolet/visible spectrometer (UVIS-UV visible, 200-650 nm) that can work in the three observation modes. The spectral resolution of SO $\left(0.15 \mathrm{~cm}^{-1}\right.$ at $\left.3000 \mathrm{~cm}^{-1}\right)$ surpasses previous surveys from orbit in the infrared by at least one order of magnitude. This will allow NOMAD to considerably improve the detection limits for many trace gases, possibly discover new species, and in general largely advance our knowledge of the Martian atmospheric composition. NOMAD offers an integrated instrument combining a flight-proven concept and innovations based on existing and proven instrumentation: SO is a copy of the Solar Occultation in the IR (SOIR) instrument (Nevejans et al. 2006) on Venus Express (VEx) (Titov et al. 2006), LNO is a

\footnotetext{
11 LPAP, University of Liege, Liège, Belgium

12 Institute of Geophysics, Polish Academy of Sciences, Warsaw, Poland

13 Royal Observatory of Belgium, av. Circulaire 3, 1180 Brussels, Belgium

14 Tohoku University, Sendai, Japan

15 LATMOS, CNRS, Paris, France

16 FNRS, Rue d'Egmont 5, 1000 Brussels, Belgium

17 York University, Toronto, Canada

18 NASA Goddard Space Flight Center, Greenbelt, MD, USA

19 Centre Spatial de Liège, Liège, Belgium

20 Service de Chimie Quantique et Photophysique, Université Libre de Bruxelles, C.P. 160/09, Brussels, Belgium

21 Catholic University Of America, Washington, DC, USA
} 
Fig. 1 Spectral coverage of the three spectrometers of NOMAD, along with an indication of a typical radiance in nadir (red line) during daytime

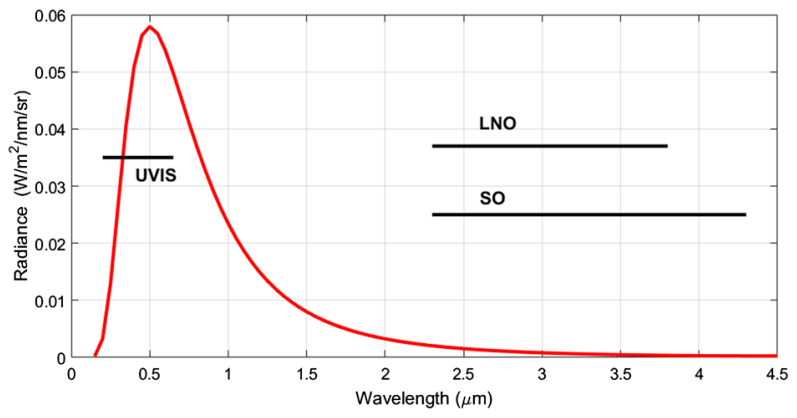

modified version of SOIR, and UVIS has heritage from the development in the context of the Humboldt lander. NOMAD will provide vertical profiling information for atmospheric constituents at unprecedented spatial and temporal resolution. Indeed, in solar occultation, the vertical resolution is less than $1 \mathrm{~km}$ for SO and UVIS, with a sampling rate of $1 \mathrm{~s}$ (one measurement every $1 \mathrm{~km}$ ), and occultations will range from the surface to $200 \mathrm{~km}$ altitude (height-dependent sensitivities for species will be presented in this paper). NOMAD will also provide mapping of several constituents in nadir mode with an instantaneous footprint of $0.5 \times 17 \mathrm{~km}^{2}$ (LNO spectrometer) and $5 \mathrm{~km}^{2}$ (UVIS spectrometer) respectively, with a repetition rate of 30 Martian days. The TGO orbit will allow NOMAD to sample a wide range of local times, hence strongly improving existing climatologies for water vapor and carbon monoxide, and developing new climatologies for e.g. HDO and methane. By providing the best-to-date measurements of $\mathrm{H}_{2} \mathrm{O}$ and, co-located and simultaneously, $\mathrm{HDO}$, hence $\mathrm{D} / \mathrm{H}, \mathrm{NOMAD}$ will contribute significantly to improve our knowledge of the Martian water cycle and the hydrogen escape process, and as such to the long-term fate of the Martian atmosphere. A highly sensitive monitoring of the well mixed, moderately long-lived gas $\mathrm{CO}$ will allow NOMAD to provide better insights in important mixing processes related to trace gases that are enriched upon condensation of the main atmospheric constituent, $\mathrm{CO}_{2}$. NOMAD will also allow for a highly sensitive diurnal monitoring of $\mathrm{CH}_{4}$ throughout 1 Martian year, allowing for the first time to assess and understand the presence or absence of this unstable organic trace gas, and in the case of confirmed presence, to provide constraints to its origin and fate.

\section{Scientific Objectives}

The scientific objectives of the NOMAD instrument can be categorized in three inter-related domains. These are compliant with and follow closely the science objectives of the TGO mission that were presented in Zurek et al. (2011). NOMAD will first of all gather information on a wide selection of trace gases and therefore help to better constrain the chemical composition of the Martian atmosphere. Then, based on these observations, climatologies of different species as well as of dust and clouds will be developed or improved and extended. Finally, the large new data sets comprising vertical profiles and mapping not only of trace gases, but also of the main constituents, temperature and dust/clouds, will be analyzed by cross-correlations and in combination with atmospheric models. This will allow for a more global understanding of the Martian atmosphere, including the source and sink processes of the different species. Table 1 lists the NOMAD scientific objectives and links these to the capabilities of the instrument and expected data. The various scientific objectives are described in detail below. 


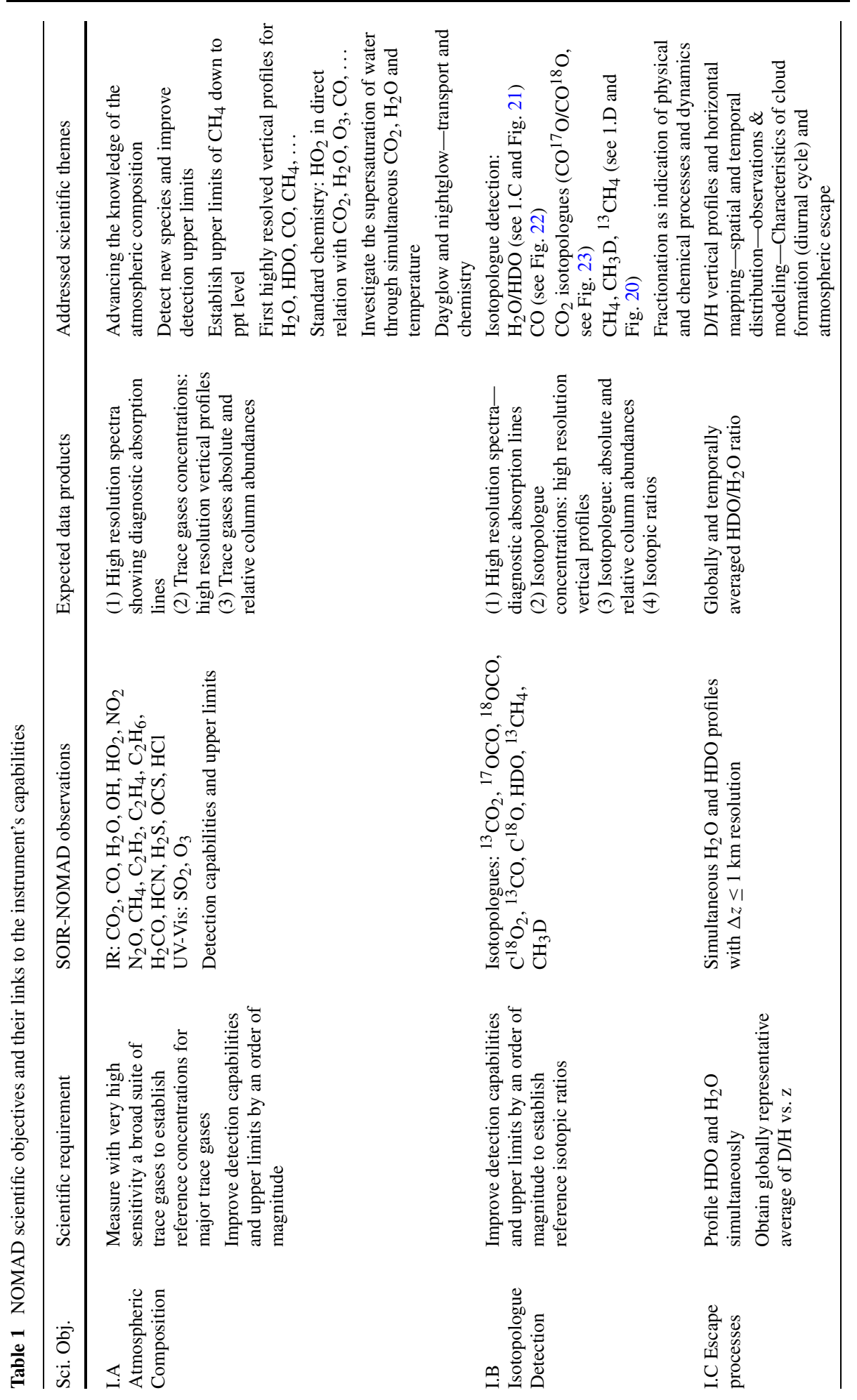




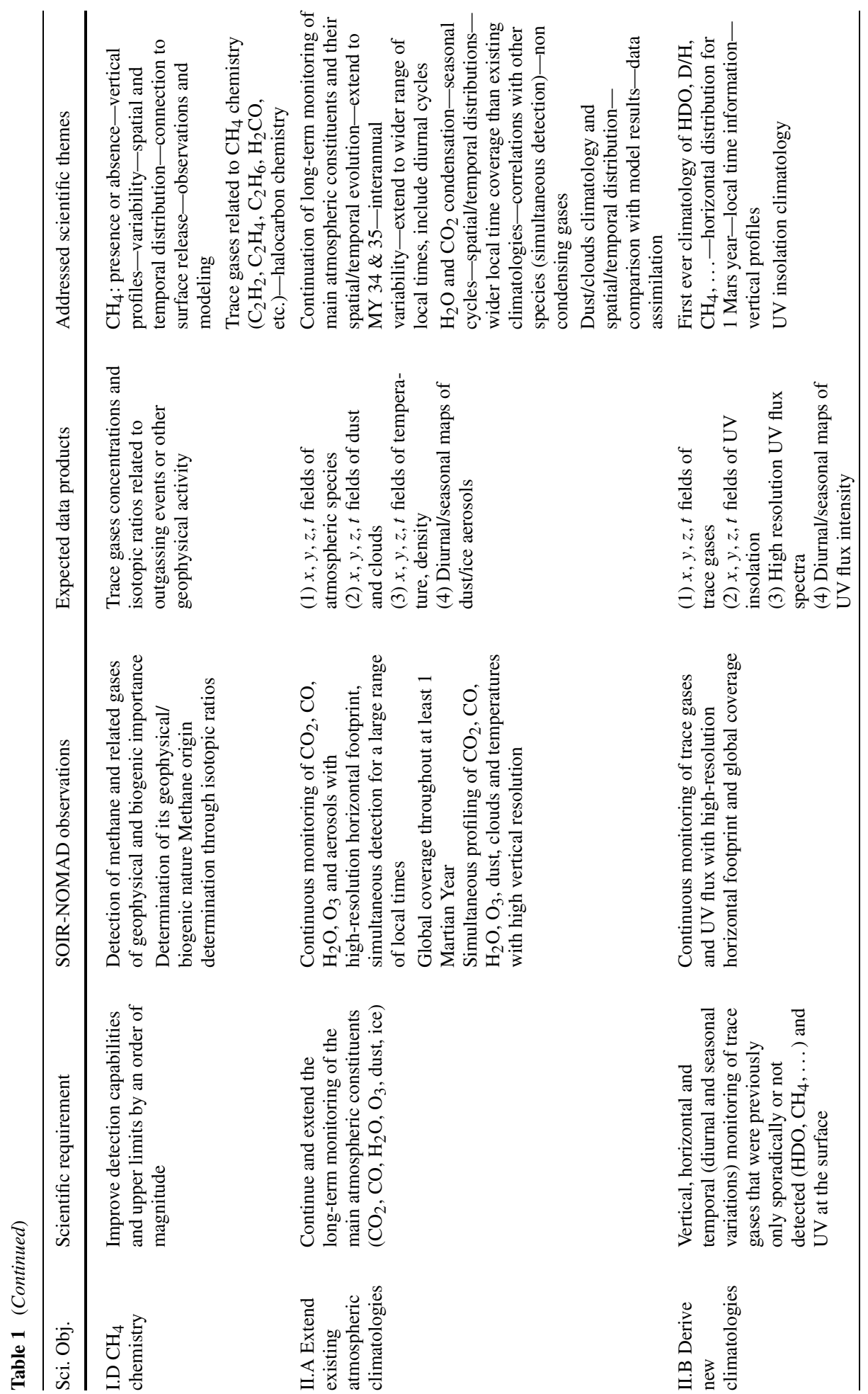




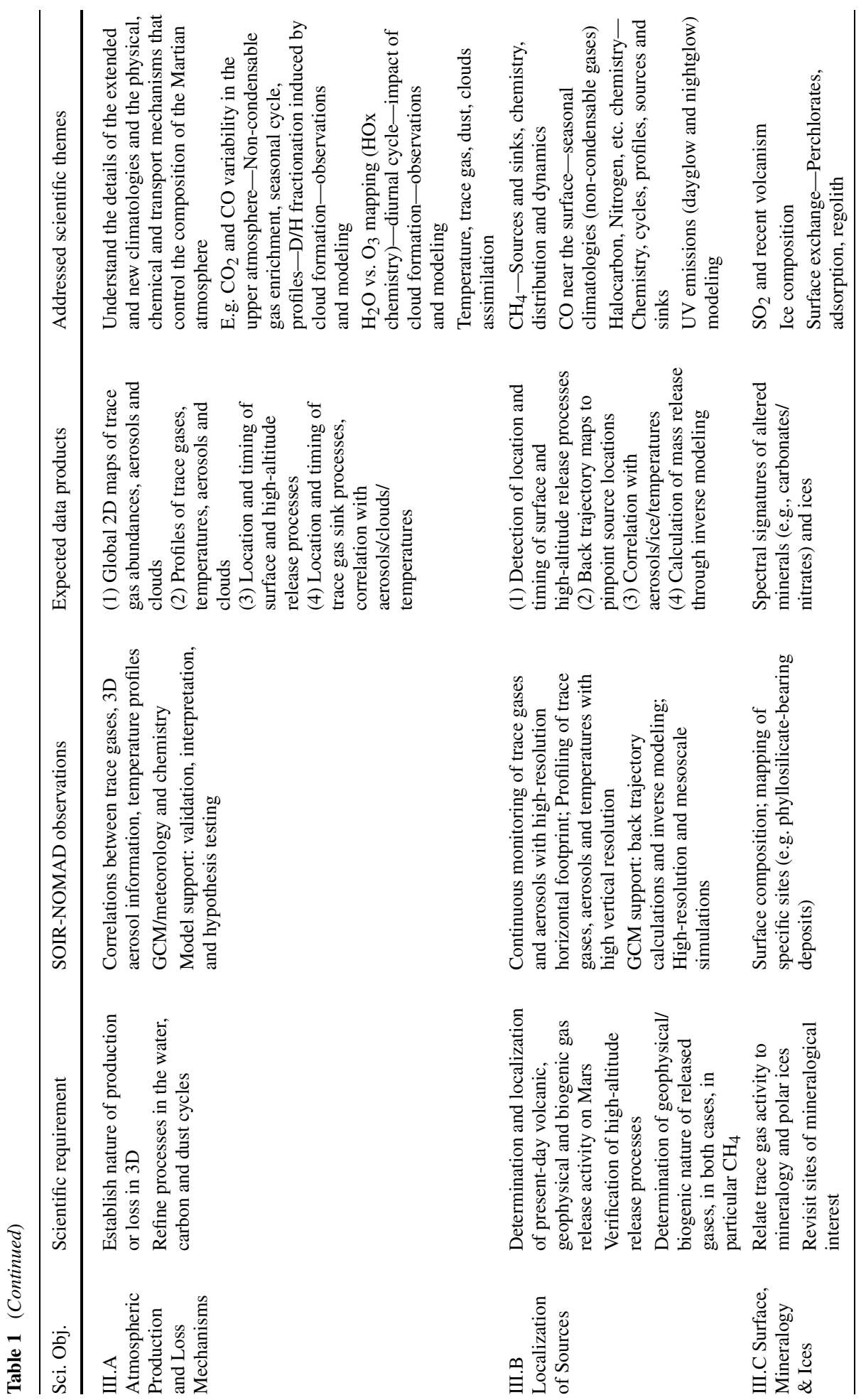




\subsection{The Chemical Composition of the Martian Atmosphere}

NOMAD will analyze the present-day chemical composition of the Martian atmosphere through the detection of a broad suite of trace gases and key isotopes. By covering UV, visible and IR spectral ranges, NOMAD ensures that a large number of species are detectable, such as $\mathrm{CO}_{2}$ (including ${ }^{13} \mathrm{CO}_{2},{ }^{17} \mathrm{OCO},{ }^{18} \mathrm{OCO},{ }^{18} \mathrm{O}{ }^{13} \mathrm{CO}$ ), $\mathrm{CO}$ (including ${ }^{13} \mathrm{CO}, \mathrm{C}^{17} \mathrm{O}$, $\mathrm{C}^{18} \mathrm{O},{ }^{13} \mathrm{C}^{18} \mathrm{O}$ ), $\mathrm{H}_{2} \mathrm{O}$ (including HDO), $\mathrm{NO}_{2}, \mathrm{~N}_{2} \mathrm{O}, \mathrm{O}_{3}, \mathrm{CH}_{4}$ (including ${ }^{13} \mathrm{CH}_{4}, \mathrm{CH}_{3} \mathrm{D}$ ), $\mathrm{C}_{2} \mathrm{H}_{2}, \mathrm{C}_{2} \mathrm{H}_{4}, \mathrm{C}_{2} \mathrm{H}_{6}, \mathrm{H}_{2} \mathrm{CO}, \mathrm{HCN}, \mathrm{OCS}, \mathrm{SO}_{2}, \mathrm{HCl}, \mathrm{OH}, \mathrm{HO}_{2}$, and $\mathrm{H}_{2} \mathrm{~S}$. The high spectral resolution of the IR spectrometers in combination with the highly sensitive and robust observation technique of solar occultation, based on the heritage of SOIR for Venus (Vandaele et al. 2008), will provide resolved spectra allowing unambiguous separation of absorption lines, ensuring therefore a high sensitivity for the search of trace gases and isotopologues. In nadir mode, the horizontal and local time distribution of the total column density of several species will be measured. A list of targeted species in nadir mode is provided in Table 2.

The NOMAD target species can be classified in the following categories:

\subsubsection{Standard Photochemistry}

Although the Martian standard photochemistry is relatively well understood from models and observations to date (see Haberle et al. 2017 and references therein), several aspects are still unknown or assumed. For a start, the Martian $\mathrm{CO}_{2}$ atmosphere is normally unstable under photolysis, but a complicated mechanism involving the minor gas water vapor, and photolysis products of both $\mathrm{CO}_{2}$ and $\mathrm{H}_{2} \mathrm{O}$, leads to a stabilization of the atmosphere. One of the key species in this process, $\mathrm{HO}_{2}$, has never been measured on Mars. $\mathrm{HO}_{2}$ is in NOMAD's target list and will be detectable in solar occultation mode. Therefore, NOMAD can not only confirm the presence of this species, but also measure it in highly resolved vertical profiles collocated and simultaneously with other relevant gases, such as $\mathrm{H}_{2} \mathrm{O}$ and $\mathrm{O}_{3}$.

Also for the first time, detailed vertical profiles of $\mathrm{CO}$ will be provided, which is another key player in the stabilization problem. Especially in the upper atmosphere, the $\mathrm{CO}$ abundances are controlled by chemistry. NOMAD will contribute to an improved understanding in this region, in combination with upper atmospheric chemistry measurements by IUVS on MAVEN.

A highly reactive species on Mars is ozone, which is formed by the reaction of atomic and molecular oxygen and is photolyzed during daytime. The destruction of ozone is strongly controlled by odd hydrogen radicals (Garcia Munoz et al. 2005; Lefèvre et al. 2004). As a result, there exists a marked anti-correlation between $\mathrm{O}_{3}$ and $\mathrm{H}_{2} \mathrm{O}$, which has been confirmed by observations of the total column density of these species (e.g. Perrier et al. 2006). The interaction between these species varies however with altitude, because it is impacted by global circulation patterns (Montmessin and Lefèvre 2013) and cloud formation (Clancy et al. 1996; Montmessin et al. 2004), especially during the aphelion season. NOMAD will be the first instrument that can fully address these complicated processes, by collocated and simultaneous high vertical resolution observations of the key species $\left(\mathrm{H}_{2} \mathrm{O}, \mathrm{O}_{3}, \mathrm{HO}_{2}, \ldots\right)$ in combination with ice clouds, through the combination of its IR and UV spectrometers. It is therefore mandatory that the TGO orbit and operations allow for a dense sampling of the aphelion season, which is the nominal plan.

\subsubsection{Water Cycle}

Water is one of the most important species in the atmosphere. It controls the stability of the atmosphere, dominates the atmospheric chemistry, and has a radiative impact through 
Table 2 The LNO and UVIS detection limits in nadir and solar occultation geometry

\begin{tabular}{|c|c|c|c|c|c|c|}
\hline \multirow[t]{3}{*}{ Species } & \multirow{3}{*}{$\begin{array}{l}\text { Current } \\
\text { Knowledge }\end{array}$} & \multicolumn{5}{|l|}{ Detection limits } \\
\hline & & \multicolumn{2}{|l|}{ SO } & \multirow{2}{*}{ 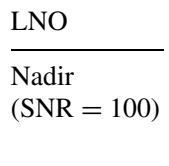 } & \multicolumn{2}{|l|}{ UVIS } \\
\hline & & $\begin{array}{l}\text { Solar } \\
\text { Occultation } \\
(\text { SNR = 2000) }\end{array}$ & $\begin{array}{l}\text { Solar } \\
\text { Occultation } \\
(\text { SNR }=3000)\end{array}$ & & $\begin{array}{l}\text { Solar } \\
\text { Occultation } \\
(\mathrm{SNR}=500)\end{array}$ & $\begin{array}{l}\text { Nadir } \\
(\mathrm{SNR}=500)\end{array}$ \\
\hline \multicolumn{2}{|l|}{$\mathrm{O}_{3}$} & $2.5 \mathrm{ppb}$ & $1.5 \mathrm{ppb}$ & $0.8 \mathrm{ppm}$ & $50 \mathrm{ppt}$ & $4.5 \mathrm{ppb}$ \\
\hline $\mathrm{CH}_{4}$ & $0-60 \mathrm{ppb}^{\mathrm{a}}$ & $25 \mathrm{ppt}$ & $20 \mathrm{ppt}$ & $11 \mathrm{ppb}$ & & \\
\hline $\mathrm{H}_{2} \mathrm{O}$ & $\begin{array}{l}<300 \mathrm{ppm} \\
\text { (variable with } \\
\text { season) }^{\mathrm{b}}\end{array}$ & $0.2 \mathrm{ppb}$ & $0.15 \mathrm{ppb}$ & $31 \mathrm{ppb}$ & & \\
\hline HDO & $\begin{array}{l}\mathrm{D} / \mathrm{H}=5.6 \\
\mathrm{SMOW}^{\mathrm{c}}\end{array}$ & $0.7 \mathrm{ppb}$ & $0.7 \mathrm{ppb}$ & $0.8 \mathrm{ppm}$ & & \\
\hline $\mathrm{CO}$ & $700-800$ ppm $^{\mathrm{d}}$ & $5 \mathrm{ppb}$ & $4 \mathrm{ppb}$ & $1.5 \mathrm{ppm}$ & & \\
\hline$[4 \mathrm{pt}] \mathrm{C}_{2} \mathrm{H}_{2}$ & $<2 \mathrm{ppb}^{\mathrm{g}}$ & $0.03 \mathrm{ppb}$ & $0.03 \mathrm{ppb}$ & $20 \mathrm{ppb}$ & & \\
\hline $\mathrm{C}_{2} \mathrm{H}_{4}$ & $<4 \mathrm{ppb}^{\mathrm{g}}$ & $0.2 \mathrm{ppb}$ & $0.15 \mathrm{ppb}$ & $70 \mathrm{ppb}$ & & \\
\hline \multirow[t]{2}{*}{$\mathrm{C}_{2} \mathrm{H}_{6}$} & $<0.2 \mathrm{ppb}^{\mathrm{e}}$ & $0.03 \mathrm{ppb}$ & $0.02 \mathrm{ppb}$ & $11 \mathrm{ppb}$ & & \\
\hline & $<0.7 \mathrm{ppb}^{\mathrm{g}}$ & & & & & \\
\hline \multirow[t]{3}{*}{$\mathrm{HCl}$} & $<3 \mathrm{ppb}^{\mathrm{e}}$ & $0.03 \mathrm{ppb}$ & $0.025 \mathrm{ppb}$ & $31 \mathrm{ppb}$ & & \\
\hline & $<0.2 \mathrm{ppb}^{\mathrm{f}}$ & & & & & \\
\hline & $<0.6 \mathrm{ppb}^{\mathrm{g}}$ & & & & & \\
\hline $\mathrm{HCN}$ & $<5 \mathrm{ppb}^{\mathrm{g}}$ & $0.03 \mathrm{ppb}$ & $0.03 \mathrm{ppb}$ & $15 \mathrm{ppb}$ & & \\
\hline \multirow[t]{2}{*}{$\mathrm{H}_{2} \mathrm{CO}$} & $<4.5 \mathrm{ppb}^{\mathrm{e}}$ & $0.04 \mathrm{ppb}$ & $0.03 \mathrm{ppb}$ & $16 \mathrm{ppb}$ & $7.5 \mathrm{ppb}$ & $150 \mathrm{ppb}$ \\
\hline & $<3.9 \mathrm{ppb}^{\mathrm{g}}$ & & & & & \\
\hline \multirow[t]{2}{*}{$\mathrm{HO}_{2}$} & $0.1-6 \mathrm{ppb}^{1}$ & $1 \mathrm{ppb}$ & $1 \mathrm{ppb}$ & $0.5 \mathrm{ppm}$ & & \\
\hline & $<200 \mathrm{ppb}^{\mathrm{g}}$ & & & & & \\
\hline \multirow[t]{2}{*}{$\mathrm{H}_{2} \mathrm{~S}$} & $<200 \mathrm{ppm}^{\mathrm{h}}$ & $4 \mathrm{ppb}$ & $3 \mathrm{ppb}$ & $1.6 \mathrm{ppm}$ & & \\
\hline & $<1.3 \mathrm{ppb}^{\mathrm{n}}$ & & & & & \\
\hline \multirow[t]{2}{*}{$\mathrm{N}_{2} \mathrm{O}$} & $<100 \mathrm{ppb}^{\mathrm{h}}$ & $0.2 \mathrm{ppb}$ & $0.2 \mathrm{ppb}$ & $83 \mathrm{ppb}$ & & \\
\hline & $<90 \mathrm{ppb}^{\mathrm{g}}$ & & & & & \\
\hline \multirow[t]{2}{*}{$\mathrm{NH}_{3}$} & $<5 \mathrm{ppb}^{\mathrm{h}}$ & & & & $1 \mathrm{ppb}$ & - \\
\hline & $<60 \mathrm{ppb}^{\mathrm{g}}$ & & & & & \\
\hline $\mathrm{NO}_{2}$ & $<10 \mathrm{ppb}^{\mathrm{h}}$ & $0.14 \mathrm{ppb}$ & $0.1 \mathrm{ppb}$ & $50 \mathrm{ppb}$ & & \\
\hline OCS & $<10 \mathrm{ppb}^{\mathrm{h}}$ & $0.3 \mathrm{ppb}$ & $0.3 \mathrm{ppb}$ & $122 \mathrm{ppb}$ & & \\
\hline \multirow[t]{4}{*}{$\mathrm{SO}_{2}$} & $<1 \mathrm{ppb}^{\mathrm{i}}$ & & & & $0.5 \mathrm{ppb}$ & $18 \mathrm{ppb}$ \\
\hline & $<2 \mathrm{ppb}^{\mathrm{j}, \mathrm{k}}$ & & & & & \\
\hline & $<0.3 \mathrm{ppb}^{\mathrm{m}}$ & & & & & \\
\hline & $<1.1 \mathrm{ppb}^{\mathrm{n}}$ & & & & & \\
\hline
\end{tabular}

${ }^{\mathrm{a}}$ Formisano et al. (2004), Krasnopolsky et al. (2004), Mumma et al. (2009). ${ }^{\mathrm{b}}$ Fedorova et al. (2008), Smith (2004), Smith et al. (2009a). ${ }^{\mathrm{c}}$ Krasnopolsky et al. (1997), Lodders and Fegley (1997), Owen et al. (1977). ${ }^{d}$ Krasnopolsky (2007), Smith et al. (2009b). ${ }^{\mathrm{e}}$ Krasnopolsky et al. (1997). ${ }^{\mathrm{f}}$ Hartogh et al. (2010). gVillanueva et al. (2013). ${ }^{\mathrm{h}}$ Maguire (1977). ${ }^{\mathrm{i}}$ Krasnopolsky (2005). ${ }^{\mathrm{j}}$ Encrenaz et al. (2011). ${ }^{\mathrm{k}}$ Nakagawa et al. (2009). ${ }^{1}$ Lefèvre et al. (2004). ${ }^{\mathrm{m}}$ Krasnopolsky (2012). ${ }^{\mathrm{n}}$ Khayat et al. (2015) 
the formation of clouds (e.g. Madeleine et al. 2012). However, the vertical profiles of water vapor have only been measured very sporadically and only for a limited range at higher altitudes (Maltagliati et al. 2011, 2013), or indirectly (Clancy et al. 2017). This is a major omission in Mars atmospheric science, which will be fully addressed by NOMAD. The detailed distribution and variability of the water profile above the planetary boundary layer (PBL) and up to the middle atmosphere, has never been measured. The complicated interactions including cloud formation and photochemistry will be accessible with the NOMAD observations. Especially the aphelion season is a very interesting time, because of the formation of the Aphelion Cloud Belt (ACB) and a low latitude ozone maximum (e.g. Clancy et al. 2016 and Perrier et al. 2006). The latter was previously explained by orbital variations in water vapor saturation altitudes (Clancy and Nair 1996; Lefèvre et al. 2004). Furthermore, the introduction of heterogeneous processes on water ice clouds (Lefèvre et al. 2008) is argued to increase ozone abundances in the presence of clouds, although more recent cloud and ozone mapping measurements by MARCI on MRO (Clancy et al. 2016) place this process into question. Water vapor profiles inferred by airglow measurements from CRISM on MRO suggest that inadequacies in modeled water vapor profiles may still play a larger role in current model-data differences for Mars ozone abundances (Clancy et al. 2017). NOMAD is planned to fully assess the aphelion cloud season at low- to mid-latitudes, both vertically and horizontally, and will contribute to further constrain the relevance of heterogeneous chemistry processes.

Previous water vapor (partial) profile measurements (Maltagliati et al. 2011, 2013) provided indication of supersaturation at high altitudes. The applied method seems however questionable as it is not evident to derive supersaturation conditions by comparing fine-scale observations in a solar occultation geometry with coarse-scale model fields. The concept of supersaturation at these altitudes was nevertheless shown to have possible far-stretching implications on the escape of water from the atmosphere (Chaffin et al. 2017). NOMAD will allow for a co-located and simultaneous observation of water vapor and temperature, providing the first direct measurements of supersaturation ratios, independent of model predictions.

NOMAD will also measure $\mathrm{HDO}$, simultaneously with $\mathrm{H}_{2} \mathrm{O}$, both vertically (profiles) and horizontally (total columns), which will provide a fascinating picture of the dynamics of the Martian atmosphere. $\mathrm{HDO}$ and $\mathrm{H}_{2} \mathrm{O}$ are fractionated by condensation and by photolysis (e.g. Bertaux and Montmessin 2001), hence their distribution is an indication of cloud formation.

The $\mathrm{D} / \mathrm{H}$ ratio may differ in water evaporating from the permanent polar cap (observable by NOMAD below $\sim 80^{\circ} \mathrm{N}$ latitude) and elsewhere on the planet. This can provide interesting insights in the long-term evolution of water on Mars, as the permanent cap is considered to be the principal or maybe the only source of atmospheric water. However, subsurface ice (Mellon et al. 2004, 2009) may also be a source of atmospheric water, possibly with a different $\mathrm{D} / \mathrm{H}$ ratio.

The different escape rates of $\mathrm{H}$ and $\mathrm{D}$ in the upper atmosphere are the clue to the long-term fate of the atmosphere, and explain why it is so different from Earth in terms of humidity. The $\mathrm{D} / \mathrm{H}$ ratio in the lower atmosphere is roughly 5.5 times higher than the value found on Earth, showing variations with seasons and latitudes (Aoki et al. 2015; Villanueva et al. 2015). This suggests that water on Mars has been lost through time, as the lighter isotope escaped more easily than the heavier one. By measuring the present $\mathrm{D} / \mathrm{H}$ ratio, one hopes to reconstruct the history of water on the planet. Simultaneous vertical profile measurements of $\mathrm{H}_{2} \mathrm{O}, \mathrm{HDO}$ and the atmospheric temperature by NOMAD will help to investigate the escape processes and evaluate upward fluxes and vertical diffusion up to 
the exobase. Combined with the MAVEN observations of D/H, obtained by direct measurement of the D and H Ly $\alpha$ emissions (Clarke et al. 2017), these observations will provide a unique way to understand the escape processes at play from the lower atmosphere up to the uppermost layers.

\subsubsection{Non-condensable Gases}

Being the main atmospheric constituent on Mars, $\mathrm{CO}_{2}$ undergoes a remarkable cycle of condensation and evaporation, leading to the formation of massive seasonal polar caps, atmospheric-surface mass exchange, and a seasonal cycle of the atmospheric surface pressure (Haberle et al. 2017 and references therein). Most trace gases however do not condense with $\mathrm{CO}_{2}$, and become enriched in terms of their volume mixing ratio (vmr). This enrichment has been observed in polar measurements of argon by GRS on Mars Odyssey (Sprague et al. 2004). From measurements of CO at lower latitudes by CRISM on MRO (Smith et al. $2009 \mathrm{~b}$ ), it was observed that towards the end of the southern summer, the polar hood that is by then fully enriched in $\mathrm{CO}$, will start to leak this enriched air towards lower latitudes. More recent research involving new data and modeling (Smith et al. 2018) highlighted that this process of transport of CO-enriched air to northern latitudes is complicated, and lags behind the nearly instantaneous planet-wide impact on the surface pressure (that is only controlled by the $\mathrm{CO}_{2}$ surface exchange). This means that large scale mixing processes of enriched air on Mars are not fully understood. NOMAD in nadir mode will monitor the column density distribution of $\mathrm{CO}$ throughout the Martian year with high spatio-temporal coverage, allowing to investigate this process with highly increased precision. The result will be relevant to all non-condensable gases.

\subsubsection{Organics}

The reports of methane observations from ground-based observatories (Krasnopolsky et al. 2004; Mumma et al. 2009), from space-borne instruments (Fonti and Marzo 2010; Formisano et al. 2004; Geminale et al. 2011), and in-situ (Webster et al. 2015) pose fundamental challenges to our understanding of the chemistry taking place in the Martian atmosphere (Zahnle et al. 2011). These studies showed high spatial and temporal variability, which cannot immediately be explained by models (Lefèvre and Forget 2009). Standard photochemical models (Summers et al. 2002) predict a lifetime for methane of 300 years, which is much longer than the mixing timescales in the atmosphere and so would imply a uniformly distributed methane in the atmosphere and no seasonal effects. Especially the data measured in 2003 and 2006 (Mumma et al. 2009) indicate that the lifetime should be much shorter (Holmes et al. 2015), perhaps as short as 200 days. The recent observations by the Mars Science Laboratory (MSL) at Gale Crater indicate a background level of 0.2-0.8 ppb (parts per billion), showing a seasonal pattern, and localized pulses of $\mathrm{CH}_{4}$ reaching $10 \mathrm{ppb}$ (Webster et al. 2013, 2015). These observations suggest that at least two different kinds of emission processes produce the background and the pulses of methane, either through geology or (bio)geochemistry related processes, or combined. $\mathrm{CH}_{4}$ is a potential biomarker on Mars Allen et al. (2006) and $\mathrm{Hu}$ et al. (2016) claimed that the high variability observed could be explained by sequestration and/or biological sources. NOMAD will deliver densely covered information on the presence and variability of methane, and on the processes related to its origin and destruction. Information on its origin may possibly be obtained through the simultaneous detection of $\mathrm{CH}_{4}$ isotopologues and higher hydrocarbons such as $\mathrm{H}_{2} \mathrm{CO}, \mathrm{C}_{2} \mathrm{H}_{4}$ or $\mathrm{C}_{2} \mathrm{H}_{6}$ (Wong et al. 
2003). Comparison of the isotopic ratios, in particular $\delta^{13} \mathrm{C}$ of $\mathrm{C}_{2} \mathrm{H}_{6}$ with that of $\mathrm{CH}_{4}$ could distinguish abiogenic $\mathrm{CH}_{4}$ from thermogenic or biogenic sources (Allen et al. 2006; Onstott et al. 2006). Although the extrapolation from Earth to Mars will complicate such an analysis, some first comparisons may be possible. Gases like $\mathrm{C}_{2} \mathrm{H}_{2}$ or $\mathrm{C}_{2} \mathrm{H}_{6}$ are also involved in serpentinization processes and will be observed by NOMAD along with $\mathrm{CH}_{4}$ and $\mathrm{H}_{2} \mathrm{O}$.

Viscardy et al. (2016) showed in a model study that the vertical distribution of $\mathrm{CH}_{4}$ can be highly non-uniform and variable after an emission from the surface. This is most interesting and was never conjectured before. NOMAD will be able to detect weak variations in the vertical distribution of $\mathrm{CH}_{4}$ as the solar occultation spectrometer of NOMAD will be extremely sensitive to $\mathrm{CH}_{4}(\sim 20 \mathrm{ppt}$, see Vandaele et al. 2015a and Table 2$)$. With the dense diurnal coverage (12 to 24 vertical profiles per sol sampling all longitudes at regular intervals), combined with similar detections by ACS's MIR spectrometer, we will not only be able to confirm the presence or absence of $\mathrm{CH}_{4}$ in the Martian atmosphere (down to ppt level) but also to monitor its variability and try to relate it to surface emissions. Therefore this finding by Viscardy et al. (2016) is highly important to NOMAD and the TGO mission, as it provides a new way to relate $\mathrm{CH}_{4}$ to surface processes. A recent modeling study by Holmes et al. (2017) investigates the interpretation of $\mathrm{CH}_{4}$ vertical profiles to be returned by the NOMAD instrument, with constraints imposed on distinguishing between different emission scenarios.

In addition, the conjectured strong sink of $\mathrm{CH}_{4}$ (Mumma et al. 2009) has opened a wide area of research in the past decade in search for such a sink process (Holmes et al. 2015; Knak-Jensen et al. 2014). NOMAD will measure the $\mathrm{CH}_{4}$ vertical profiles simultaneously with other trace gases, and dust and ice clouds, and can contribute to further understand this open problem.

\subsubsection{Geological Processes}

Although recent active volcanism on Mars has not been observed, the presence of active outgassing may still be possible (Langevin et al. 2005; Neukum et al. 2004). Major gas releases associated with volcanic outgassing are expected to be sulfuric, i.e. $\mathrm{SO}_{2}$ and $\mathrm{H}_{2} \mathrm{~S}$, which lie in the sensitivity range of NOMAD.

\subsection{Mars Climatology and Seasonal Cycles}

Continued observations are needed to better quantify the inter-annual variability and understand the physical mechanisms that govern the current Mars climate. Distinct and generally repeatable patterns occur each year in pressure, carbon dioxide deposition, temperature, aerosol (dust and water ice cloud) optical depth, and gas abundance, but there are also significant inter-annual variations (Clancy et al. 2016; Montabone et al. 2015; Smith et al. 2018). Many aspects of such climatologies are still not yet well characterized, such as local time variations, and the vertical distribution of gases and aerosols. The seasonal variations of non-condensable gases are also important (Lefèvre and Forget 2009; Smith 2009). Characterization of their seasonal and spatial variations will constrain atmospheric dynamics and the timescales for mixing in the atmosphere. By considering the full NOMAD data set, which will cover 1 Martian year, for a wide range in latitudes $\left( \pm 80^{\circ} \mathrm{N} / \mathrm{S}\right)$ and local times, we will improve and extend the existing climatologies and build new climatologies for species that were so far not or only sporadically measured. This will be achieved through the characterization of the spatial (3D) and temporal variability of trace 
gases and dust/clouds. The extension and refinement of current climatologies for $\mathrm{CO}_{2}, \mathrm{H}_{2} \mathrm{O}$, $\mathrm{CO},\left(\mathrm{CH}_{4}\right), \mathrm{O}_{3}$, and dust/clouds will occur not only by the extension into Mars Years 34 and 35 , but also and more importantly by an extension to a wider range of local times and to the vertical distribution. Moreover, many of these species will be measured at the same location and time, allowing for the study of correlations. Obviously, NOMAD will also provide new climatologies for other species, most importantly HDO, in direct combination with $\mathrm{H}_{2} \mathrm{O}$, hence also for the D/H ratio. A climatology will also be composed for UV radiation levels at the surface.

NOMAD will also improve considerably our knowledge on the clouds and dust distribution and composition. Indeed, measurement of the aerosols/dust opacity across a wide wavelength range (i.e. UV to IR) allows the optical properties (such as particle composition and shapes) and size distribution of the suspended aerosols/dust to be derived through modeling of the phase function (Wilquet et al. 2009). The presence of ice clouds (both $\mathrm{H}_{2} \mathrm{O}$ and $\mathrm{CO}_{2}$ ) will be measurable through wavelength-dependent scattering in the observed UV and IR spectra.

Data assimilation (Lewis et al. 2007; Steele et al. 2014) will bring the resulting climatologies one step further, towards fully gridded, in 3D space and time, fields that are constrained by observations, providing the most complete picture of the Martian atmosphere to date.

\subsection{Sources and Sinks of the Martian Atmosphere}

The third and final major objective of NOMAD will be to identify the sources and sinks of the trace gases measured during the mission. While the inventory of trace gases and the characterization of their spatio-temporal distribution and variability, which are provided by the first two science objectives of NOMAD, will provide a global picture of the composition of the Martian atmosphere, more work is required to understand the observed patterns and to refine the various components which play a role in the seasonal cycles.

This will be done by characterizing the production and loss mechanisms of trace gases, including the localization of trace gas sources related to outgassing, other forms of (sub)surface exchange, such as adsorption, and atmospheric production and loss processes such as chemistry and cloud formation. The simultaneous detection of many gases and aerosols will allow to do cross-correlations between the datasets and identify interesting patterns, e.g. the correlation of a gas presence with cloud presence could hint at heterogeneous chemistry. The use of models will help us refine processes in the different cycles and test hypotheses. Furthermore, we can support the characterization of sites of interest for future missions or TGO observations.

Examples of such a refinement are the processes related to the water cycle. The precipitation of large ice crystals as detected by Phoenix (Daerden et al. 2010; Whiteway et al. 2009) formed an important milestone in our understanding of Mars water ice clouds. In addition to the highly resolved vertical profiles of water vapor, from the upper atmosphere down to the top of the PBL or as close near the surface as conditions will allow for, NOMAD can complement the (localized) Phoenix findings by a more detailed picture of cloud formation. It will be possible to derive vertical profiles of water ice clouds and better understand how they impact on the water cycle.

At the surface, perchlorates were found by the Phoenix mission (Catling et al. 2010; Kounaves et al. 2010). Recent laboratory studies demonstrated the deliquescence of perchlorate under Mars surface conditions (Nikolakakos and Whiteway 2015, 2018) including the uptake of water. This process may have an impact on the local water cycle. By investigating the water vapor column for different local times, in combination with the $\mathrm{D} / \mathrm{H}$ ratio 
as an indicator of cloud formation, NOMAD may be able to exclude or confirm such processes. This is also highly relevant to the possible explanation of surface changes detected on Mars, which are possibly caused by processes involving liquid water or salts (e.g. Ojha et al. 2015).

Another species that requires a detailed assessment of sources and sinks is of course methane. While the sources of $\mathrm{CH}_{4}$ are yet unknown (although outgassing may be the most likely source, e.g. Oehler and Etiope 2017), it was already mentioned above how the conjectured unknown sink of $\mathrm{CH}_{4}$ remains an open problem. To improve our understanding of the processes controlling the possible presence of $\mathrm{CH}_{4}$ on Mars, correlations with abundances of other trace gases (notably $\mathrm{H}_{2} \mathrm{O}$, as reaction with its photolysis product $\mathrm{OH}$ is the strongest known classical sink for $\mathrm{CH}_{4}$ on Mars), as well as with dust, clouds and atmospheric state variables (temperature and others) need to be investigated. In the case of outgassing, sources must be localized and possibly related to (sub-)surface composition or mineralogy. Global circulation models will provide critical support to this search. Daerden et al. (2015) presented the first ever use of a calculated back trajectory to explain an observed phenomenon on Mars. Similar techniques can be developed for NOMAD and $\mathrm{CH}_{4}$, although the strong mixing in the PBL will complicate this. Still, models, providing wind speeds and directions, will be able to provide a first confinement of source regions of possibly observed, localized $\mathrm{CH}_{4}$ events, as they can indicate how outgassed $\mathrm{CH}_{4}$ will spread most likely. A simple option is to do a series of emission experiments in models and select the ones best corresponding to the observed distribution (forward modeling). Inverse modeling techniques, developed for Earth, could be also applied (Bauwens et al. 2016; Stavrakou et al. 2009).

The use of data assimilation (Holmes et al. 2017; Lewis et al. 2007; Steele et al. 2014) will further constrain the model simulations and provide improved wind fields to be applied in such studies, specifically by the assimilation of temperature profiles measured by the ACS TIRVIM spectrometer in nadir mode (Korablev et al. 2018).

\section{Technical Description}

NOMAD is composed of three spectrometers described in the following section. The $-Y$ face of the instrument is pointed towards the planet during nadir observations (Fig. 2), with the nadir Lines of Sight (LOS, shown by orange arrows) pointing towards the center of Mars. The solar-pointing LOS (yellow arrows) are inclined with respect to the nadir direction by $67.07^{\circ}$ through the use of periscopes. The three spectrometers have each their own optical bench, but share the same single interface to the satellite. Neefs et al. (2015) and Patel et al. (2017) contain in-depth technical descriptions of the IR and UVIS spectrometers, respectively. Below we outline each of the spectrometers, with their main characteristics summarized in Table 3. The block diagram of the complete instrument is shown in Fig. 3. NOMAD consists of the following sub-systems: the three spectrometers, which generate scientific data (SO, LNO, and UVIS spectrometers); SO, LNO, UVIS proximity electronics; SINBAD, the central processor unit, which manages all electrical power and data connections between the spacecraft and the three spectrometers; the general radiator with the thermal control system. The radiator maintains the operational temperature range for the complete instrument. The control of the temperature is achieved through a series of temperature sensors distributed inside the instrument, which can turn on and off heaters when needed.

SO has been designed for solar occultation observations, i.e. looking at the Sun through the atmosphere during sunsets and sunrises. SO is operating at wavelengths between 2.3 
Fig. 2 The NOMAD instrument, with the SO (1), LNO (2) and UVIS (3) spectrometers. The electronics is located on the underside of NOMAD (4). Lines of sight towards the Sun (yellow arrows) and in the nadir direction (orange arrows) are also indicated

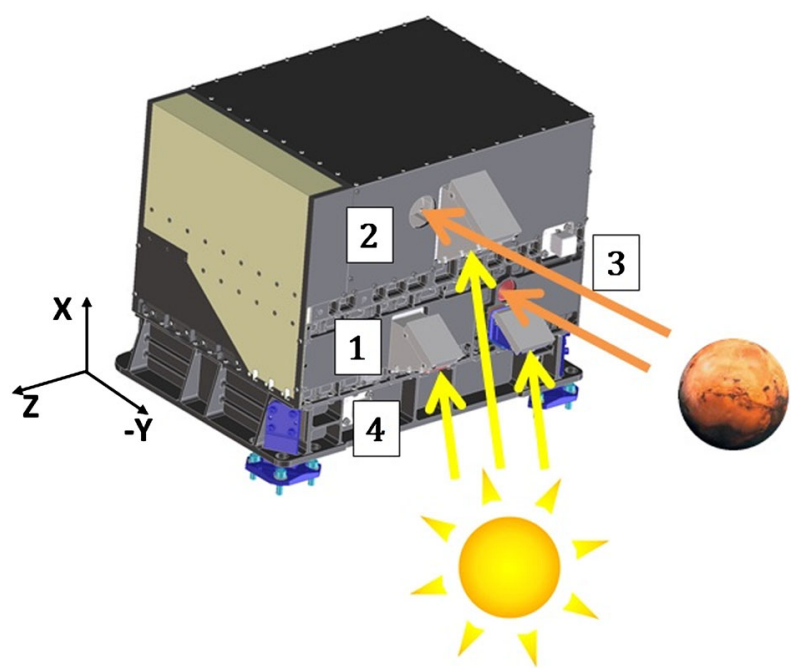

Table 3 Characteristics and performance of the three spectrometers-SO, LNO and UVIS—of the NOMAD instrument (N/A: Not applicable)

\begin{tabular}{|c|c|c|c|}
\hline & SO Spectrometer & LNO Spectrometer & UVIS Spectrometer \\
\hline Detector & $\begin{array}{l}2 \mathrm{D} \mathrm{HgCdTe} \\
320 \times 256 \text { pixel FPA }\end{array}$ & $\begin{array}{l}2 \mathrm{D} \mathrm{HgCdTe} 320 \times 256 \text { pixel } \\
\text { FPA }\end{array}$ & 2D $1024 \times 256$ pixel CCD \\
\hline $\begin{array}{l}\text { Detector } \\
\text { temperature }\end{array}$ & $88 \mathrm{~K}$ & $88 \mathrm{~K}$ & variable \\
\hline Line of Sight & $\begin{array}{l}\text { Periscope pointing } \\
\text { in Sun/Mars' limb } \\
\text { direction }\end{array}$ & $\begin{array}{l}\text { Periscope pointing in } \\
\text { Sun/Mars' limb } \\
\text { direction and nadir } \\
\text { viewing entrance }\end{array}$ & $\begin{array}{l}2 \text { telescopes pointing in } \\
\text { Sun (plus a periscope) } \\
\text { and nadir directions }\end{array}$ \\
\hline Spectral range & $2.3-4.3 \mu \mathrm{m}$ & $2.3-3.8 \mu \mathrm{m}$ & $200-650 \mathrm{~nm}$ \\
\hline Resolving power & 20000 & 10000 & \\
\hline Resolution & $0.15-0.22 \mathrm{~cm}^{-1}$ & $0.3-0.5 \mathrm{~cm}^{-1}$ & $1.2-1.6 \mathrm{~nm}$ \\
\hline $\begin{array}{l}\text { FOV }(\text { spectral } \\
\text { direction } \times \text { spatial } \\
\text { direction })\end{array}$ & $2 \operatorname{arcmin} \times 30 \operatorname{arcmin}$ & $4 \operatorname{arcmin} \times 150 \operatorname{arcmin}$ & $\begin{array}{l}2 \operatorname{arcmin} \text { circular (solar occ) } \\
43 \text { arcmin circular (nadir) }\end{array}$ \\
\hline $\begin{array}{l}\text { Spatial resolution } \\
\text { (solar occultation) }\end{array}$ & $1 \mathrm{~km}(\Delta \mathrm{z}$ at limb $)$ & $1 \mathrm{~km}(\Delta \mathrm{z}$ at limb $)$ & $1 \mathrm{~km}(\Delta \mathrm{z}$ at limb $)$ \\
\hline $\begin{array}{l}\text { Instantaneous } \\
\text { footprint (nadir) }\end{array}$ & N/A & $0.5 \mathrm{~km} \times 17 \mathrm{~km}$ & $5 \mathrm{~km} \times 5 \mathrm{~km}$ (Nadir) \\
\hline Vertical sampling & $180 \mathrm{~m}$ to $1 \mathrm{~km}$ & $180 \mathrm{~m}$ to $1 \mathrm{~km}$ & $<300 \mathrm{~m}$ \\
\hline
\end{tabular}

and $4.3 \mu \mathrm{m}$ (2320 to $\left.4350 \mathrm{~cm}^{-1}\right)$, using an echelle grating with a groove density of approximately 4 lines/mm in combination with an Acousto-Optical Tunable Filter (AOTF). Figure 4 (top panel) illustrates the schematics of the SO spectrometer, which is also represented in 3D in Fig. 5 (top panel). The light entering the instrument, and passing through the spectrometer entrance slit, is guided via a parabolic mirror onto a diffraction grating, operating in Littrow configuration. The same parabolic mirror then focuses the optical beam to produce an intermediate image. Finally, a set of relay optics projects the intermediate image onto an 


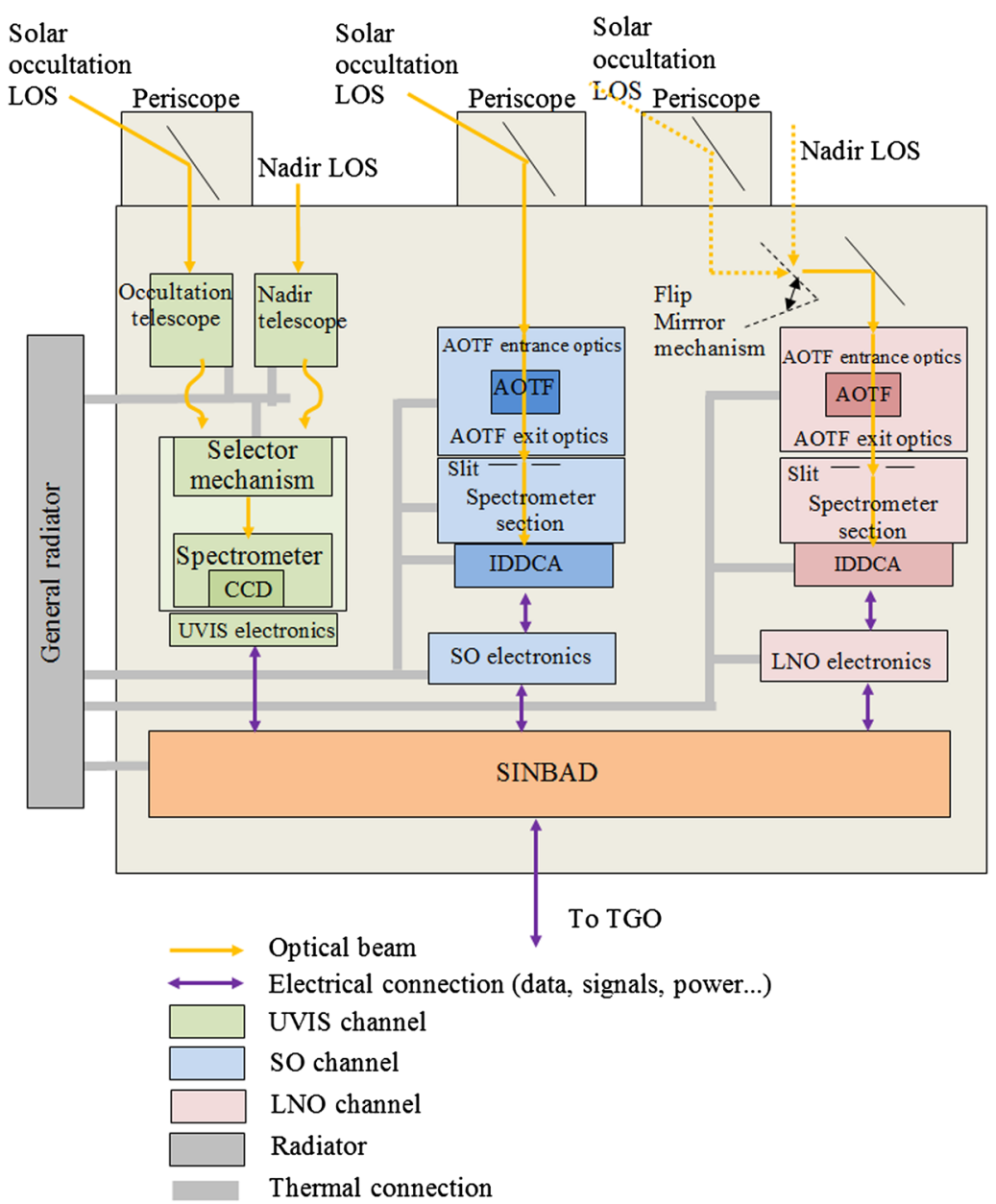

Fig. 3 Schematics of the NOMAD instrument which consists of the following sub-systems: the three spectrometers, which generate scientific data (SO, LNO, and UVIS spectrometers); their proximity electronics; SINBAD, the central processor unit, which manages all electrical power and data connections between the spacecraft and the three spectrometers; the general radiator and the thermal control system

Integrated Detector Dewar Cooler Assembly (IDDCA). The AOTF is a passband filter that selects a spectral window corresponding to the desired diffraction order. The width of the selected spectral windows varies from 20 to $35 \mathrm{~cm}^{-1}$ depending on the selected diffraction order. The function of the AOTF entrance optics is to reduce the diameter of the incoming beam, to match the aperture of the AOTF. The AOTF exit optics images the beam onto the slit, which is the entrance of the spectrometer section and which defines the FOV of the spectrometer. The SO electronics consists of proximity electronics mounted next to the SO IDDCA, a radiofrequency driver unit next to the AOTF and an electronic unit mounted below the SO base plate. The SO electronics interfaces with SINBAD.

The optical layout of the LNO spectrometer $(2.3$ and $3.8 \mu \mathrm{m}$, bottom panels of Figs. 4 and 5) is very similar to that of SO. The main operational difference is that the LNO spectrometer is capable of both nadir and solar occultation observations. LNO can switch from 

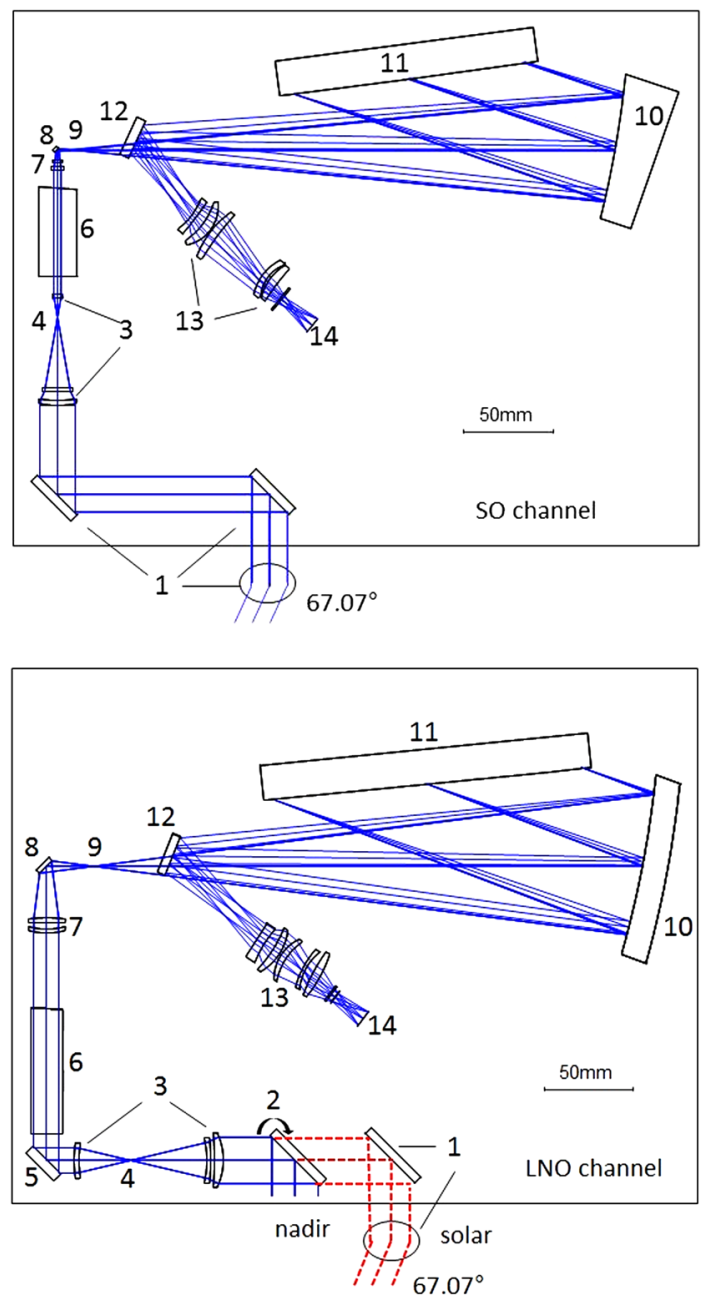

Fig. 4 Schematics of the SO (top panel) and LNO (bottom panel) spectrometers. The entrance of the SO spectrometer is a periscope consisting of three flat mirrors (nr. 1, top). The LNO spectrometer has two entrance apertures: (1) The solar entrance is a periscope with two flat mirrors (nr. 1, bottom), one inside the base plate, one protruding and tilting the beam by $67.07^{\circ}$ (out of the figure plane); (2) The nadir entrance consists of one single flat flip mirror (nr. 2, bottom). This mirror is driven by a motor and can be placed inside the beam. The front-end optics of the spectrometers is followed by the AOTF entrance optics (nr. 3). In the intermediate image plane of the entrance optics, a diaphragm (nr. 4) is placed that limits the FOV of the system in order to reduce scattering and ghost images, and to prevent overlap between order 1 and order 0 of the AOTF. In the LNO spectrometer, an additional folding mirror (nr. 5) had to be inserted between the AOTF entrance optics and the AOTF. An AOTF (nr. 6) selects the order from the incoming light beam that corresponds to a RF signal applied to the crystal, and outputs this small fraction of the beam towards the AOTF exit optics (nr. 7). All other orders are blocked. Via a small folding mirror (nr. 8), the AOTF exit optics creates an image of the scene (Sun or surface of Mars) on the spectrometer entrance slit (nr. 9). An off-axis parabolic mirror (nr. 10) serves as collimating lens in the spectrometer section and offers a parallel light beam to the echelle grating (nr. 11). After dispersion of the light by the grating, the beam passes again by the parabolic mirror (nr. 10), now serving, together with the detector optics (nr. 13), as imaging lens. Via a folding mirror (nr. 12), the beam is projected on the detector (nr. 14) that has its optical axis parallel to the overall optical axis of the spectrometer 

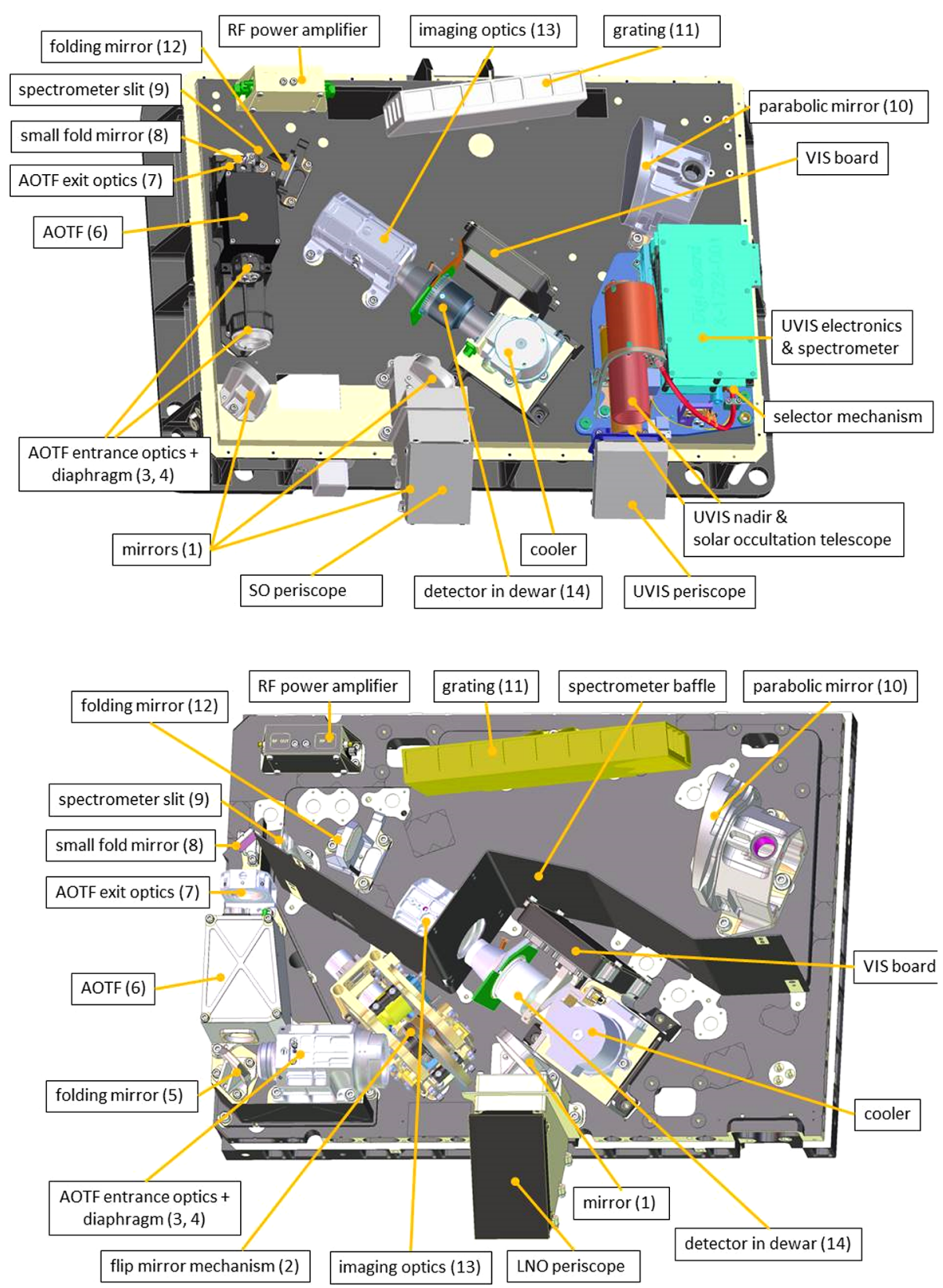

Fig. 5 3D views of the SO (top) and LNO (bottom) spectrometers, showing the physical position of the optical elements

one line of sight to the other by operating a mirror mechanism. When the mirror is 'in' the optical path, the LNO LOS is pointed towards nadir $(-Y)$. When the mirror is 'out' of the optical path, the LNO LOS is pointed towards the limb and can perform measurements during solar occultations. Using this boresight of the LNO spectrometer will also allow limb 
observations. The flip mirror, driven by a motor, has a fail-safe mechanism that puts it permanently 'in' the optical path (nadir setting) in case of motor failure. LNO will handle the large dynamic range between solar and nadir observations by adjusting the integration time and the number of accumulations.

Some modifications were implemented to increase the signal throughput as well as to reduce the thermal background of the instrument: decreasing the highest wavelength limit of the sensitivity of the detector to reduce the impact of thermal noise (from $4.3 \mu \mathrm{m}$ for SO to $3.8 \mu \mathrm{m}$ for LNO); use of optical elements with lower f-number; increasing the length of the slit from 30 arcmin to 150 arcmin in the spatial direction and from $2 \operatorname{arcmin}$ to $4 \operatorname{arcmin}$ in the spectral direction; using a larger AOTF crystal; cooling down the spectrometer as much as possible and using longer integration times, appropriate pixel binning, and accumulating spectra. All these modifications led to a higher throughput and a higher signal to noise ratio (SNR).

The FOVs of SO and LNO have been chosen to achieve adequate spatial resolution either in solar occultation (resolution and sampling should be lower than $1 \mathrm{~km}$ ) and nadir observations (instantaneous footprint should not be larger than $1^{\circ}$ by $0.3^{\circ}$ or $60 \mathrm{~km}$ by $17 \mathrm{~km}$ ). The slit of the SO spectrometer has therefore been chosen to be a 2 arcmin (spectral direction) by 30 arcmin (spatial direction) rectangle. The 2 arcmin ensures that SO achieves an instrument line profile resolution of $0.15 \mathrm{~cm}^{-1}$ at $3000 \mathrm{~cm}^{-1}$, corresponding to a resolving power $\lambda / \Delta \lambda$ of 20000 , while the 30 arcmin have been imposed by the apparent diameter of the Sun at Mars (varying along the orbit of Mars around the Sun between 19 to 23 arcmin, with an average value of $21 \mathrm{arcmin}$ ). The size of the slit of the LNO spectrometer has been chosen to be a compromise between increasing the signal entering the instrument and limiting the footprint size. With a $4 \times 150 \operatorname{arcmin}^{2}$ rectangular slit, LNO reaches a spectral resolution of $0.3 \mathrm{~cm}^{-1}$ and a resolving power of $\lambda / \Delta \lambda \sim 10000$ at $3000 \mathrm{~cm}^{-1}$ and an instantaneous footprint of $0.5 \times 17 \mathrm{~km}^{2}$. Note that we expect the resolution to vary linearly across the wavelength range of both SO and LNO, as was observed for the SOIR instrument (Mahieux et al. 2008), for which the resolution varied from $0.12 \mathrm{~cm}^{-1}$ at $2300 \mathrm{~cm}^{-1}$ to $0.25 \mathrm{~cm}^{-1}$ at $4000 \mathrm{~cm}^{-1}$.

Both detectors of SO and LNO are actively cooled HgCdTe Focal Plane Array and are made up of 320 pixels along the spectral axis and 256 rows in the spatial direction (MARSMW K508HSM, Sofradir). Ten minutes before an occultation or before a nadir overpass starts, the detector used for the observation is cooled down to a temperature of about $88 \mathrm{~K}$. In SOIR on Venus-Express, the standard K 508 Stirling cooler from RICOR was used. This device has a high reliability and has been proven to be successfully used in space also on several other missions. However, its Mean Time To Failure (MTTF) is 8000 hours, which is sufficient for the SO spectrometer of NOMAD, but not for LNO. Not only lifetime (in hours) is an issue for these devices, but also the number of on/off-cycles has to be taken into account. At the time of selection, RICOR was developing a new generation of his popular K 508 cryocooler series (K 508 N) with predicted MTTF of 20000 hours. However, performance of the $\mathrm{K} 508 \mathrm{~N}$, and especially lifetime, were not sufficiently proven and an alternative was offered to fulfill the NOMAD requirements (both for a SO and a LNO scenario and both for MTTF and on/off cycles). The K 508 HSM (High Speed Motor) is derived from the standard K 508 by modifying the stator coil winding of the motor. All other mechanical parts are kept strictly identical. The K 508 HSM has an increase in reliability due to a lower operating pressure that decreases the radial constraints on the compressor's ball bearings, a critical part with regard to lifetime degradation. The loss of power, due to the lower pressure, is compensated by the higher rotation speed of the motor resulting in similar cooldown times as the K 508 at slightly higher power consumption. 


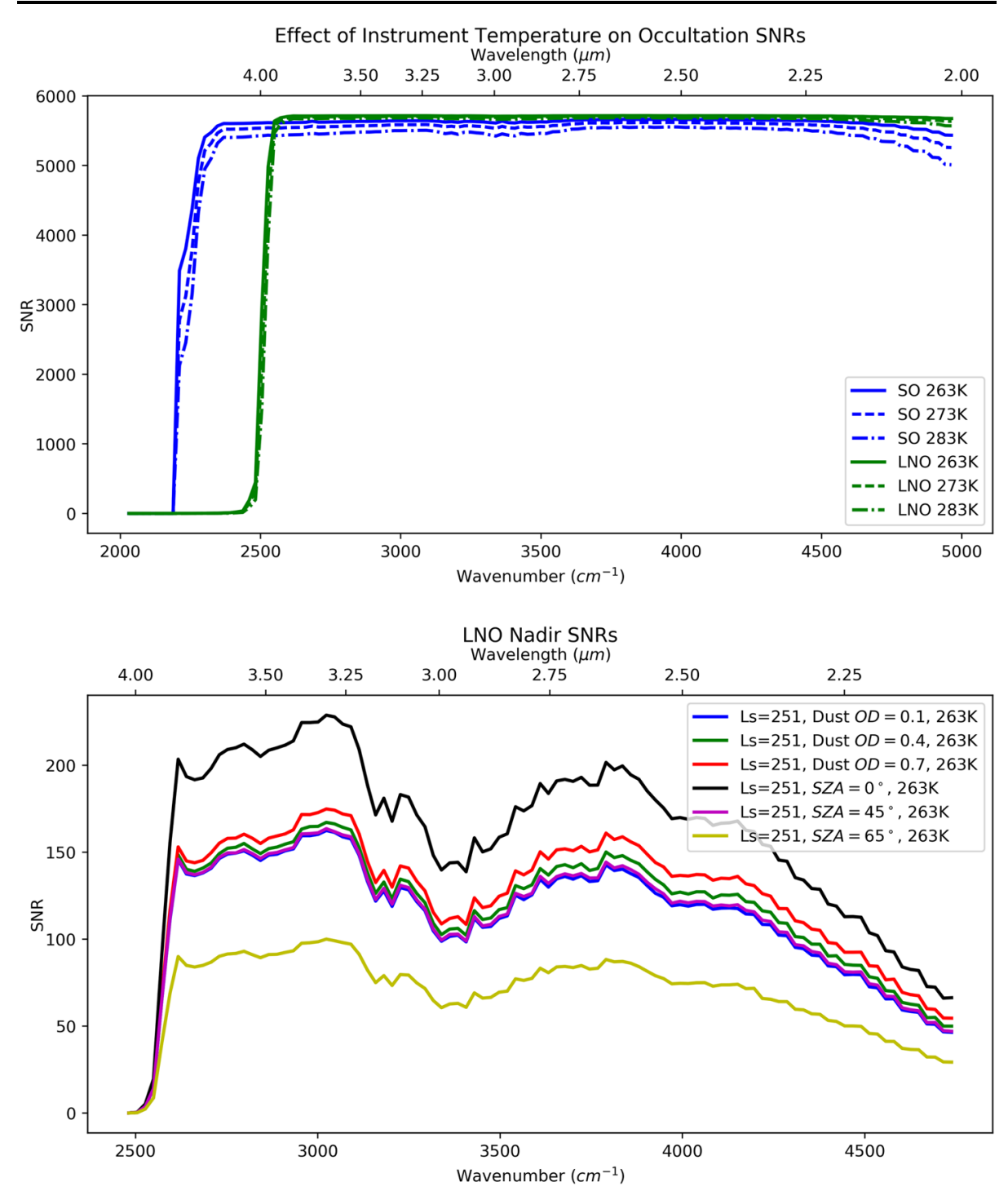

Fig. 6 Overview of the expected SNR for the SO and LNO spectrometers in solar occultation and nadir mode respectively, from Thomas et al. (2016). Top: the SNR in solar occultation mode assumes no dust extinction and an optimal integration time matched to the instrument sensitivity; values are given for three different temperatures of the instrument $(263 \mathrm{~K}, 273 \mathrm{~K}, 283 \mathrm{~K})$. Bottom: SNR of nadir observations by LNO for a range of observation conditions: dust optical depth $=0.1,0.4$, and 0.7 or solar zenith angles of 0,45 , and $65^{\circ} ; L_{\mathrm{S}}=251^{\circ}$ [close to Sun], assuming a planetary albedo of 0.242 and all 144 detector pixels are binned for a Mars observation of 15 seconds duration

Most of the mechanical elements, and especially those close to the optical path, have undergone a space qualified optically black anodization. This limits scattering of light and keeps the influence of thermal background as low as possible.

An intensive study of the different sources of noise, and their effect on the performance of the SO and LNO spectrometers has been reported in Thomas et al. (2016). Figure 6 
Fig. 7 Layout of the UVIS spectrometer: the entrance slit (S), the aperture (A), the collimating mirror (M1), the diffraction grating $(\mathrm{G})$, the focusing mirror (M2), the 2nd order filter (F) and the detector (CCD)

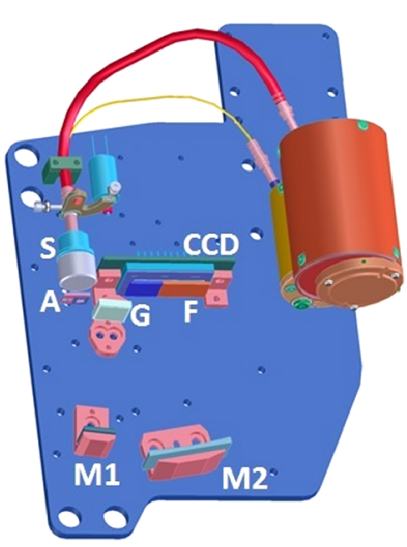

gives the SNR values for the SO and LNO spectrometers, at the central wavelengths of the orders, for typical integration times and for three different temperatures of the instrument $(263 \mathrm{~K}, 273 \mathrm{~K}, 283 \mathrm{~K})$. For SO and LNO operating in solar occultation mode the figure gives the single pixel SNR values (no binning, no accumulations). For the LNO spectrometer working in nadir mode, the signal considered was the Sun radiation being reflected on the surface of Mars. The pixels from one detector column have been binned over the slit height (144 pixels) and individual spectra have been accumulated over the duration of a measurement (15 s). These numbers have been obtained after considering the effect of the different optical elements composing the spectrometers on the incoming radiation and an estimation of the detector noise for typical observations (solar occultation or nadir observations) under different observing conditions (impact of the solar zenith angle, of the dust loading, of the surface reflectivity; see Thomas et al. 2016 for the full detailed analysis). In the case of solar occultation measurements, the noise is shot noise limited while in nadir measurements, the noise will be due to the thermal background (radiation emitted by the optical elements themselves). Hence the observation strategy is different for solar occultation than for nadir measurements, as will be explained further in the next section.

The UVIS spectrometer is based on the conventional Czerny-Turner configuration $(\mathrm{Cz}-$ erny and Turner 1930). Figure 7 illustrates the basic layout of the spectrometer while Fig. 8 illustrates the different elements composing the spectrometer. The light enters the instrument through telescopes connected to optical fibers which transport the light to the selector mechanism placed just before the entrance slit of the spectrometer. Each telescope is equipped with an extension tube limiting stray light from outside the FOV to enter the instrument. The spectrometer is an imaging system with a magnification equal to 1 . More details on the instrument can be found in Patel et al. (2017). The spectral range is very broad (200$650 \mathrm{~nm}$ ) with optimized performance in the UV range. The blaze angle and incidence angle are chosen to achieve the highest reflectance of the first diffraction order at $220 \mathrm{~nm}$. A 2nd order filter solves the issue of the overlap between the 1st and the 2nd diffraction orders of the grating. The solar FOV of UVIS ( 2 arcmin circular) has been chosen to ensure a vertical resolution better than $1 \mathrm{~km}$, while the nadir FOV of 43 arcmin (circular) is compatible with an instantaneous footprint of $5 \times 5 \mathrm{~km}^{2}$. The slit width is $65 \mu \mathrm{m}$ which corresponds to a spectral resolution $<1.6 \mathrm{~nm}$. UVIS has one periscope for the solar (narrow field) telescope and a cut-out hole in the NOMAD cover for the nadir viewing telescope. UVIS switches between nadir and solar viewing angles by alternating which optical fiber is placed in front of the spectrometer slit through the use of the selector mechanism selecting either the occul- 

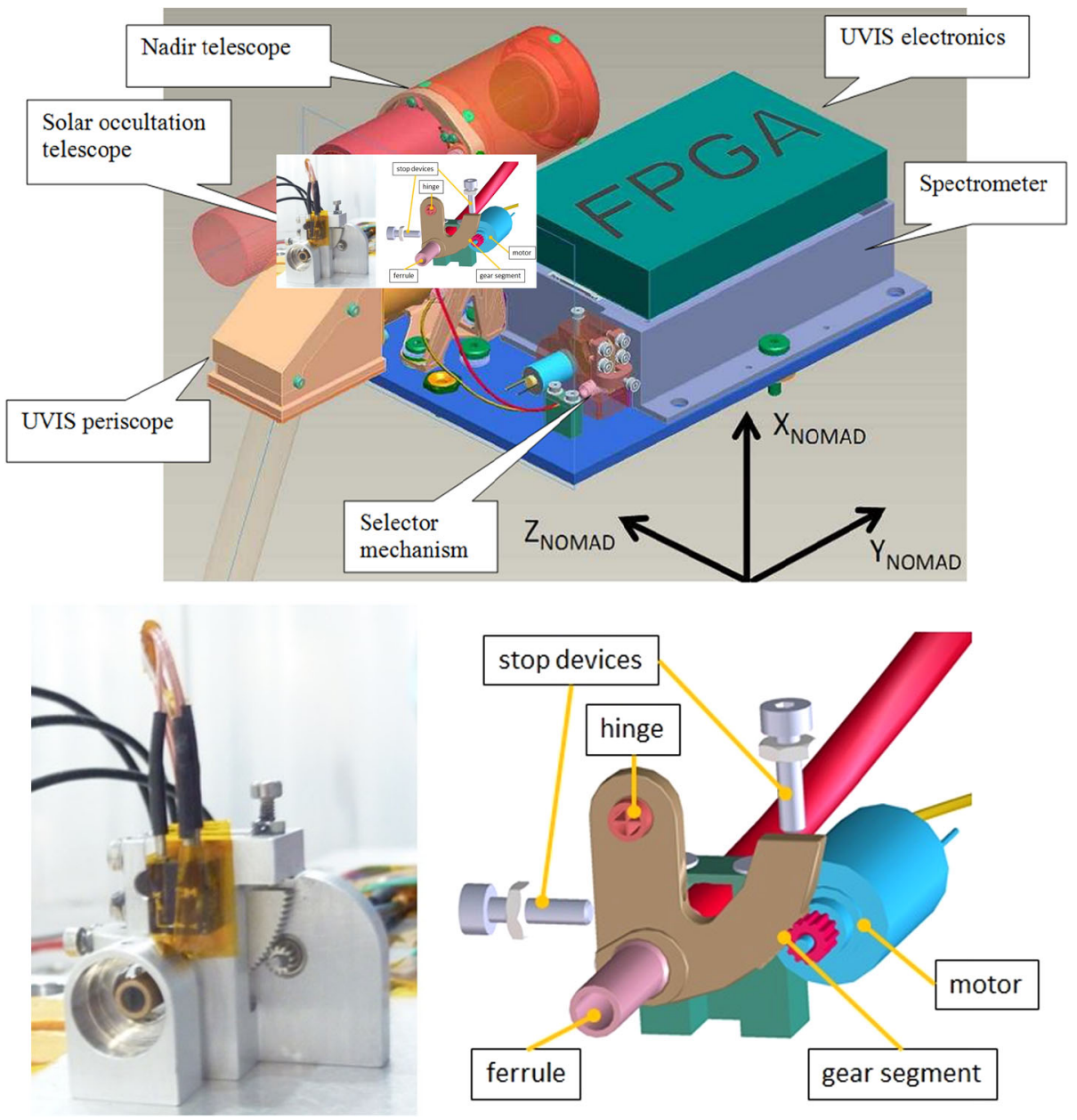

Fig. 8 Overview of the different elements composing the UVIS spectrometer. Top panel: the two entrance telescopes (for nadir and solar occultation respectively, each equipped with a tube, preventing straylight from outside the wanted FOV to enter the instrument), the periscope in front of the solar occultation telescope, the fibers transporting light from the telescopes to the selector mechanism, the spectrometer section, and the proximity UVIS electronics. Bottom panels: focus on the selector mechanism

tation telescope fiber (narrow field) or the nadir telescope fiber (wider angle). The selector mechanism is a rotating motor mechanism with established space heritage from the GAP instrument on the Beagle-2/Mars Express mission (Towner et al. 2004). The baseplate on which all optical elements are mounted, has been manufactured from carbon fiber composite to ensure low mass and sufficient stiffness with minimal thermal expansion. The cover of the instrument incorporates a series of baffles to limit stray light to reach the detector. The detector is an e2V CCD30-11 having an image area of $26.6 \times 6.7 \mathrm{~mm}$, using an array of $1024 \times 256$ pixels with $26 \mu \mathrm{m}$ pixel pitch. No active cooling system is coupled to the detector. The analysis of the radiometric performance of the UVIS spectrometer has been carried out for solar occultation and nadir observations (Vandaele et al. 2015b). Some results are shown in Fig. 9 for both types of observations and typical conditions of measurements. 

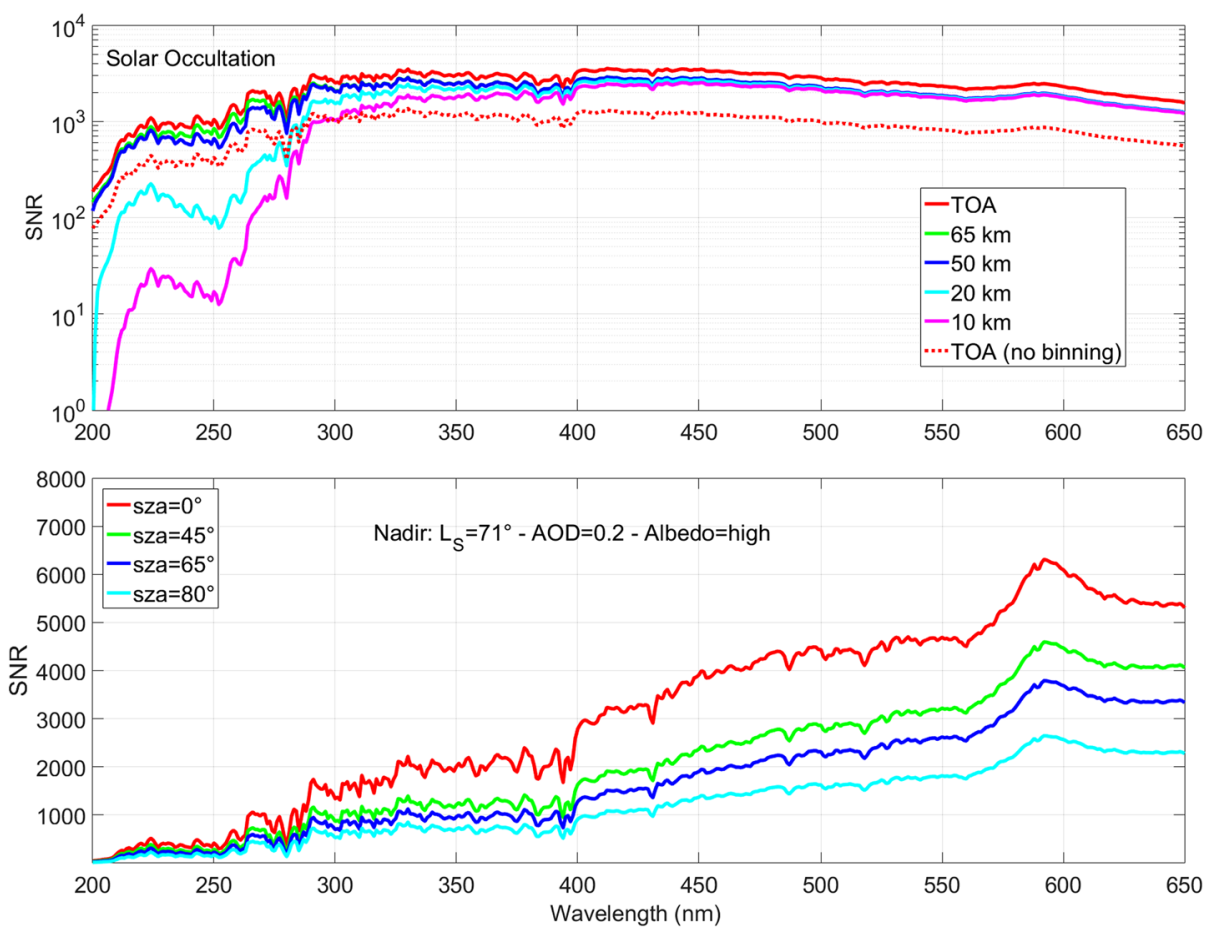

Fig. 9 Overview of the SNR levels reached with the UVIS spectrometer from Vandaele et al. (2015b): (Top) in solar occultation and for different tangent heights probed (TOA: Top Of the Atmosphere); and (Bottom) for a typical nadir observation at four different solar zenith angles (at $L_{\mathrm{S}}=71^{\circ}$, with a high reflectivity surface and with an optical depth for dust of 0.2 , integration time of $15 \mathrm{~s}$, sum over 64 rows). See Vandaele et al. (2015b) for the details of the simulation

\section{Science Implementation}

The ExoMars Trace Gas Orbiter (Svedhem 2017) arrived at Mars in October 2016 and is now orbiting the planet in a very elongated orbit slowly reducing its apocenter to reach its final orbit, probably in March 2018. At that time, the science phase will start. The TGO science orbit should be near-circular (eccentricity of 0.0069), varying between 380 and $430 \mathrm{~km}$ above the planet's surface, with an inclination of $74^{\circ}$, such that the ground track repeats after 373 orbital revolutions (or 30 sols) with one orbital period being approximately 2 hours long (12 orbits in one sol). This is the so-called 373/30 track, i.e. 373 orbits in a 30 sols repeat cycle. The flown orbit will not be actively corrected to match that repeat cycle so that after 373 orbits the ground track nominally always coincides. A drift may build up with time because there is no requirement to match the ground track exactly. This orbit will provide optimum coverage of the surface and solar occultation possibilities for the science instruments, while still allowing the spacecraft to relay data from the different assets now on the planet, as well as from future landers and rovers, in particular those of the ExoMars 2020 mission. The spacecraft will follow a complex set of maneuvers (Svedhem 2017) to point the different instruments towards the surface (nadir observation on the day and night sides of the planet) and allow NOMAD and ACS to point to the Sun during solar occultation observation (two such observations, ingress and egress, are possible for each orbit). 
NOMAD will make use of different observation modes to fulfill its scientific objectives, such as solar occultation, nadir observations, and limb measurements. Solar occultation observations will provide high vertical resolution $(<1 \mathrm{~km})$ profiles of the structure and composition of the atmosphere, while nadir observations will provide vertical column maps of the relevant species. In the following, we will not dwell too much on limb measurements (same geometry as in solar occultation but with the Sun outside of the FOV), since up to now such observations are still not part of the baseline sets of observations supported by the spacecraft. Besides these scientific observational modes, NOMAD will also perform a series of calibration and alignment observations. These include dark sky observations, lineof-sight misalignment calibrations, determination of optimized integration times for the different detectors, spectral and AOTF bandpass calibration using solar lines, detector readout calibration, as well as the radiometric calibration of the nadir spectrometers (Vandaele et al. 2015a). Already a series of calibration observations have been carried out during Near Earth Commissioning, Mid Cruise check out and the two Mars Capture Orbit sessions which were allocated in November 2016 and March 2017. These observations are being analyzed to obtain the latest characterization of the instrument, complementing the measurements performed in the laboratory before integration on the spacecraft.

NOMAD is built as a 3D mapping instrument, designed to make as many measurements as possible without exceeding the allocated data volume. For nominal science, NOMAD will typically perform 4 measurements per orbit: Solar occultation during egress (SO+UVIS); dayside nadir (LNO+UVIS); Solar occultation during ingress (SO+UVIS); nightside nadir (LNO+UVIS). A typical orbit sequence is shown in Fig. 10. NOMAD therefore permits the full exploitation of the orbit.

Solar occultation measurements are the primary type of measurements for NOMAD. They deliver the highest SNR, allowing the instrument to meet its science objectives. Typically, there will be two occultations of $\sim 4-17$ minutes each per 2-hour orbit, leading to a total measurement time of around 100-400 minutes per day depending on the $\beta$ angle. At sunset, the recording of spectra starts well before the occultation occurs (the solar spectrum outside the atmosphere is used for referencing), and continues until the line of sight crosses the planet. At sunrise, the recording of spectra continues well above the atmosphere to provide the corresponding reference. Transmittances are obtained by dividing the spectra measured through the atmosphere by the reference spectrum recorded outside the atmosphere (Trompet et al. 2016). In this way, transmittances become independent of some instrumental characteristics, such as the absolute response or the aging of the instrument and in particular of the detector. From a $74^{\circ}$ inclined orbit, the latitudes covered in solar occultation range from $88^{\circ} \mathrm{N}$ to $90^{\circ} \mathrm{S}$ (see Fig. 11) with good revisit time at various solar longitudes, while nadir observations will provide global coverage (in terms of latitude/longitude and local times). This is illustrated in Figs. 12 and 13, which show some typical orbit tracks for a period of 10 days and 1 day respectively.

Figure 11 represents the seasonal coverage of solar occultations over one Martian year. The gaps between the eclipse seasons vary between 4 and 16 days during which grazing solar occultations could be performed (occultations for which the minimum tangent height is above the Martian surface). In one Martian year, there are approximately 8244 orbits, i.e. 687 days/year*12 orbits/day, and each possibly giving 2 solar occultation profiles. In Fig. 11, 7006 orbits are shown during which full solar occultation occur ( $\beta$ angle $\leq 63.5^{\circ}$, occultations reaching the surface) leaving 1240 orbits with possible (near) grazing occultations and calibration periods. The equatorial region and mid-latitudes between $\pm 45^{\circ}$ are not sounded very frequently (only $25 \%$ of all observations, i.e. 1752 out of 7006 total solar occultation orbits). In fact, the distribution is $6 \%, 15 \%, 25 \%$ and $51 \%$ for latitudes between $\pm 15^{\circ}, \pm 30^{\circ}$, 

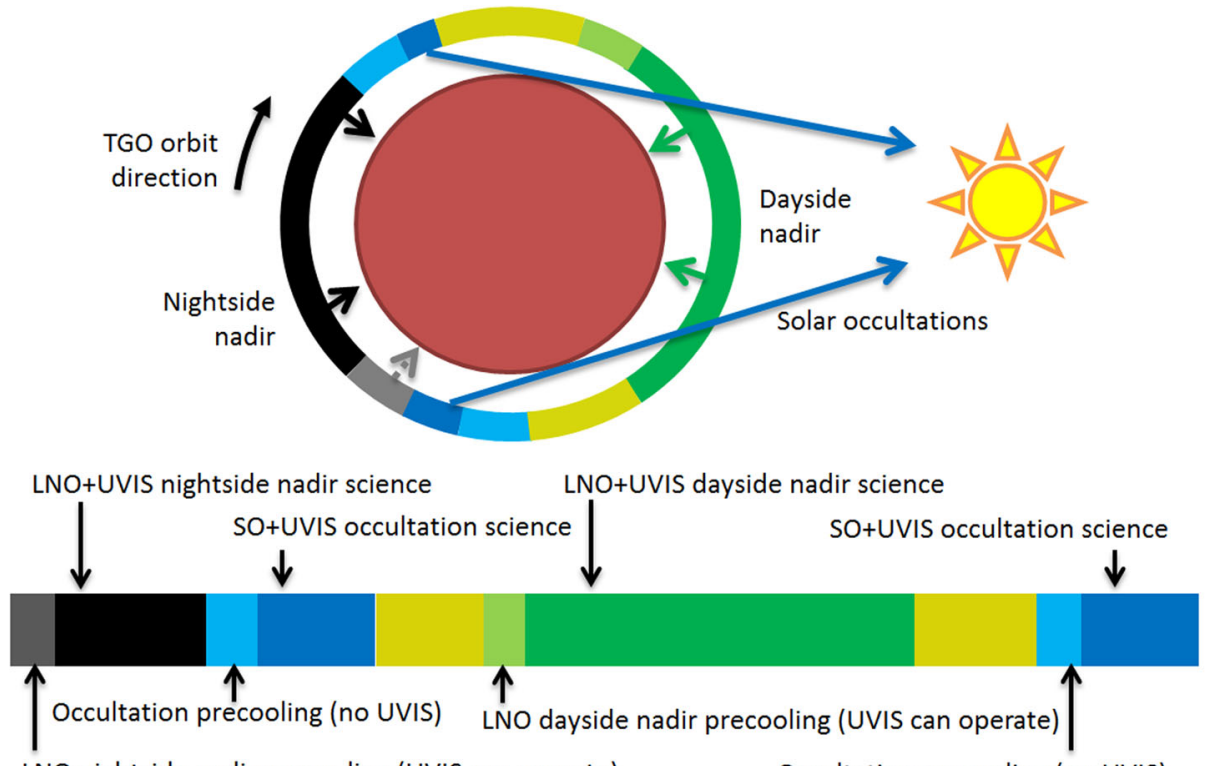

LNO nightside nadir precooling (UVIS can operate)

Occultation precooling (no UVIS)

Gold $=$ Poor nadir surface illumination angles. Potential off periods to cool instrument

Fig. 10 A typical observation sequence for a standard orbit, showing which spectrometers can operate at each step. The solar occultation events occur at specific times, and so these drive the timings of all observations. Note that this only applies when the beta angle is small-at increasing angles, the occultations increase in duration and move to lower latitudes, until there is insufficient time to run a nightside nadir measurement between them. The off-periods will be placed strategically to avoid loss of coverage of certain regions

$\pm 45^{\circ}$ and $\pm 60^{\circ}$, respectively. This means that the polar latitudes (both $\mathrm{N}$ and $\mathrm{S}$ ) are sounded about $50 \%$ of the time.

Figure 14 shows the evolution of the eclipse and solar occultation durations, as well as the beta angle, as a function of the solar longitude during 1.5 Martian year. The eclipse duration is the time during which Mars is fully occulting the Sun as seen from the TGO spacecraft, while the solar occultation duration is the time during which the solar line of sight crosses the atmosphere from $250 \mathrm{~km}$ tangential height at the limb until the surface. The higher the beta angle the shorter the eclipse duration and the longer it takes to perform a solar occultation observation (and vice-versa). The occultation duration is rather short $\sim 4-6$ minutes at low beta angles, and reaches $\sim 10-17$ minutes at high beta angles. In the latter case, the ingress and egress measurements will possibly have to be merged leading to a total measurement time of approximately $40-45$ minutes per solar occultation observation. The precooling duration of the IR-spectrometer is not included here and is typically set to 10 minutes prior to the start of a science measurement. However, this value can be modified in-flight if necessary. Simulations showing how the beta angle affects solar occultation and nadir measurements are shown in Figs. 12 and 13. The majority of occultations will occur at high latitudes and small beta angles, but a non-negligible number also occur in equatorial regions. An example of this is shown in Fig. 15 on which the location of the NASA Curiosity Rover is indicated.

The solar occultations occur down to the surface for beta angles less than $63.5^{\circ}$, though NOMAD requests to operate during solar occultations that occur up to beta angles of $67^{\circ}$ 


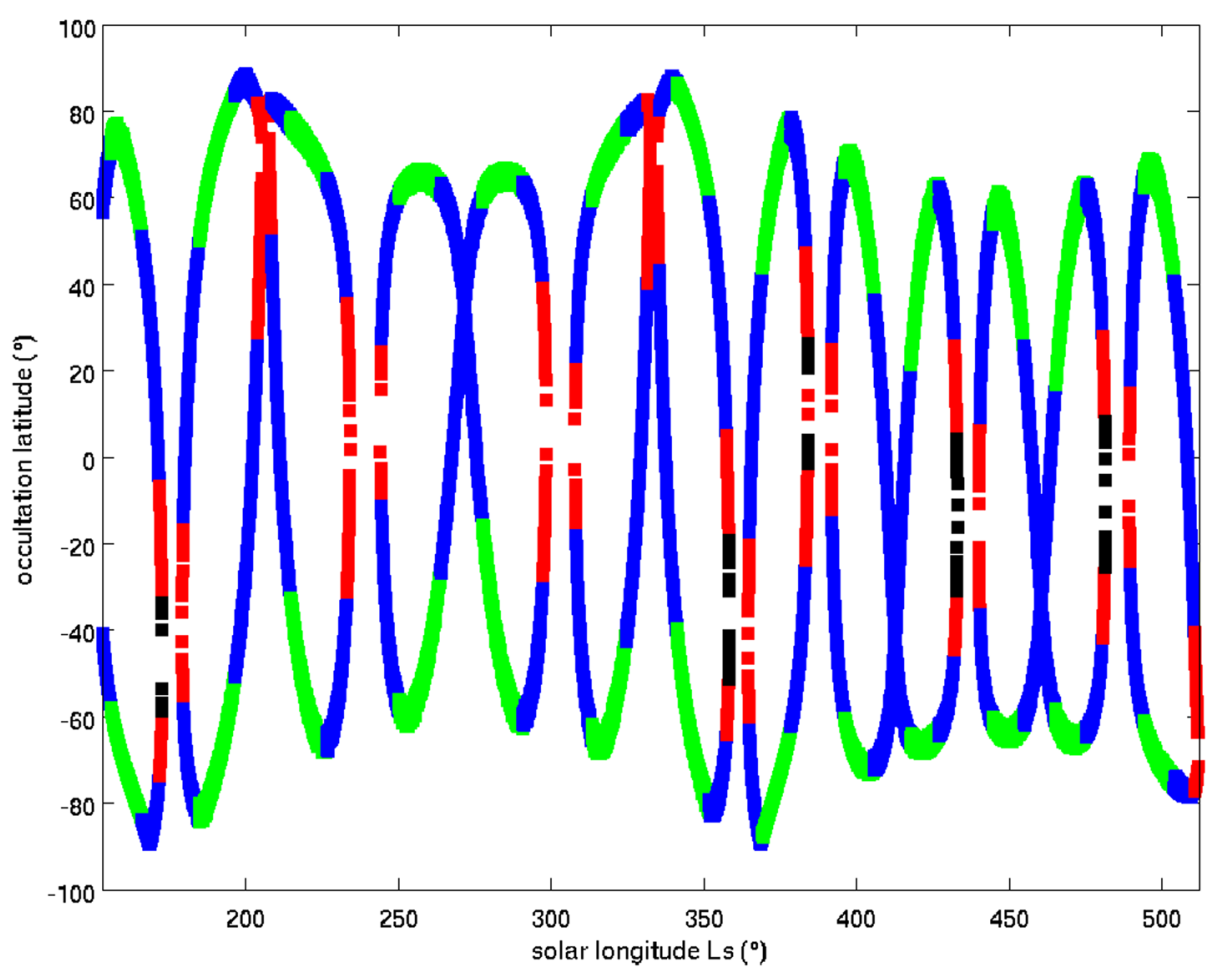

Fig. 11 Plot of the seasonal coverage of solar occultations spanning 1 Martian year. The latitudes probed by solar occultations are taken for a tangential height $0 \mathrm{~km}$ i.e. taken at penumbra start (ingress) or penumbra end (egress) times. We assumed 1 April 2018, $L_{\mathrm{S}}=152^{\circ}$, MY34 as the end of the aerobraking phase and start of the Mars commissioning phase until 16 February $2020, L_{\mathrm{S}}=152^{\circ}$, MY35. Color represents the beta ( $\beta$ ) angle values: $\beta<30^{\circ}$ (green), $30^{\circ}<\beta<60^{\circ}$ (blue), $60^{\circ}<\beta<63.46^{\circ}$ (red), and $\beta>63.46^{\circ}$ (black)

where the lowest altitude reached will be $100 \mathrm{~km}$. These are the so-called near grazing occultations where the Sun is partially occulted by Mars, or grazing occultations during which the Sun probes the atmosphere, but is never actually occulted by Mars. At beta angles higher than $67^{\circ}$, the solar occultations cannot be performed. Calibration sessions will therefore be scheduled in these periods.

UVIS always measures a full spectrum, so telecommands only need to specify which optical fiber should be positioned at the input of the spectrometer, and to properly select the integration time and pixel binning. Other properties, such as detector readout and power characteristics, are pre-programmed to their optimal values. UVIS can perform observations with an integration time of $1 \mathrm{~ms}$ to $15 \mathrm{~s}$ (larger values only constrained by footprint size and saturation). To limit data rate when using short integration times, spectra can be accumulated on board to create a higher SNR spectrum.

SO and LNO spectrometers can record several spectral windows, up to 6, each having a width ranging from 20 to $35 \mathrm{~cm}^{-1}$, in one measurement cycle. The duration of this cycle is different for solar occultation and nadir observations, because the levels of light recorded in these modes greatly differ. Typically, the cycle is of $1 \mathrm{~s}$ for solar occultation and $15 \mathrm{~s}$ for nadir observations.

The central wavelength of the AOTF bandpass of the IR spectrometers is selected by the radiofrequency $(\mathrm{RF})$ applied to the transducer. The bandwidth-22 and $24 \mathrm{~cm}^{-1}$ for the SO 

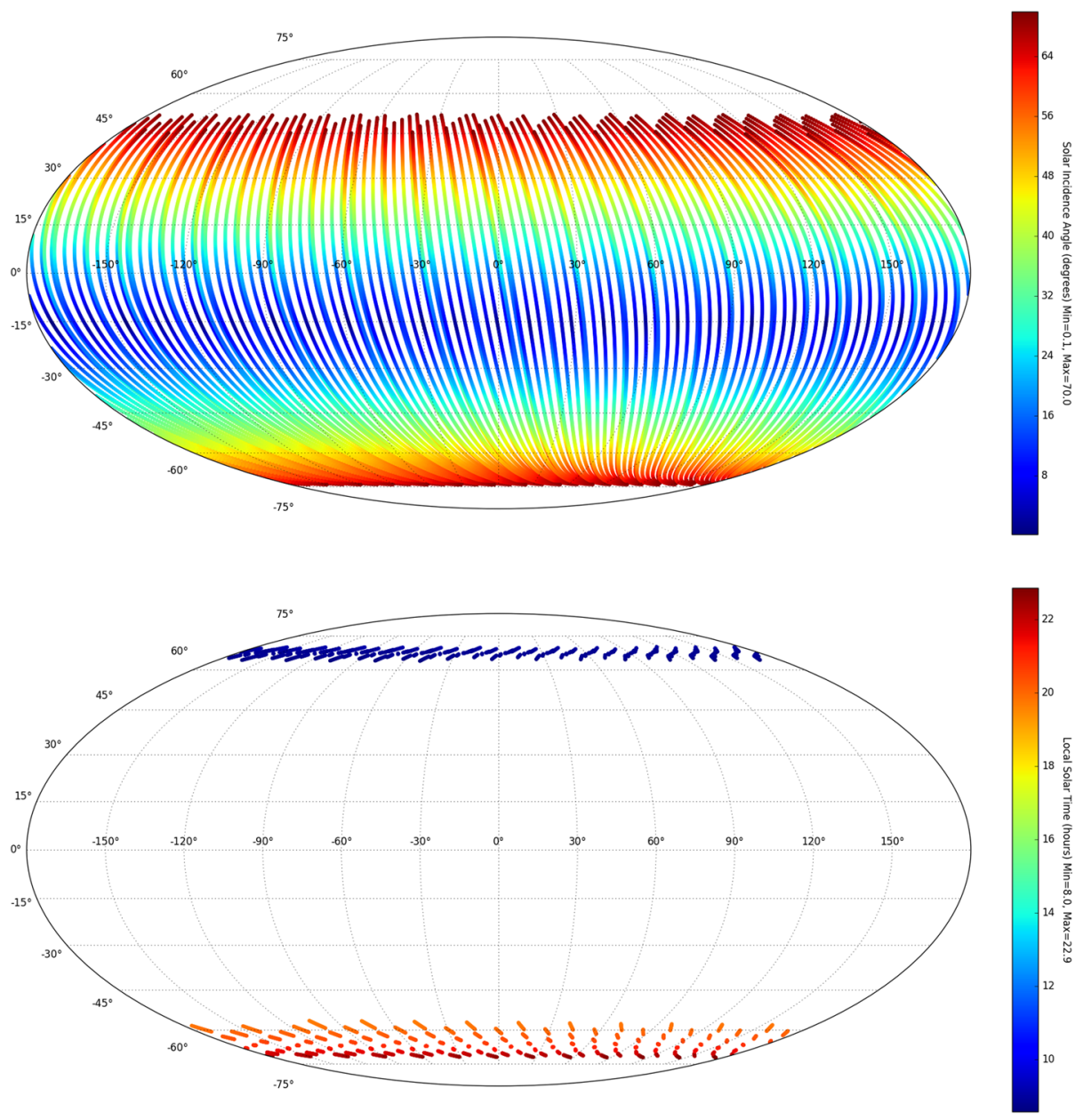

Fig. 12 Results of a 10-day orbit simulation where the beta angle is low. Top: dayside nadir coverage, showing how the solar zenith angle varies across the nadir groundtrack. Here a cut-off at $70^{\circ}$ was applied, hence no polar coverage or nightside nadir observations are plotted. In reality, the cut-off will be varied to avoid large gaps in coverage. Bottom: solar occultation coverage for the same 10 days, where the color denotes the local solar time, which here is around $10 \mathrm{am}$ or $10 \mathrm{pm}$ for this period

and LNO respectively-is close to the width of one order of diffraction of the echelle gratings. When no radiofrequency is applied, light entering the crystal will just pass through following the zeroth order path. The entrance slit of the spectrometer is placed at the 1 st order location (one of the two polarizations in fact) which is slightly off the zeroth order direction. The slit serves as a zeroth order trap for all light that is not exactly aligned with the 1st order. In this configuration, the detector only sees radiation generated after the AOTF (from the slit onwards). This setting can be used to perform background and dark current measurements (hereafter called 'dark' observations), for on-ground subtraction from the measured spectra. Typically, this option will be used in solar occultation: one of the 6 spectral AOTF settings in each measurement cycle will be dedicated to this dark observation, leaving only 5 settings for atmospheric measurements. A typical observation sequence is illustrated in Fig. 16. 

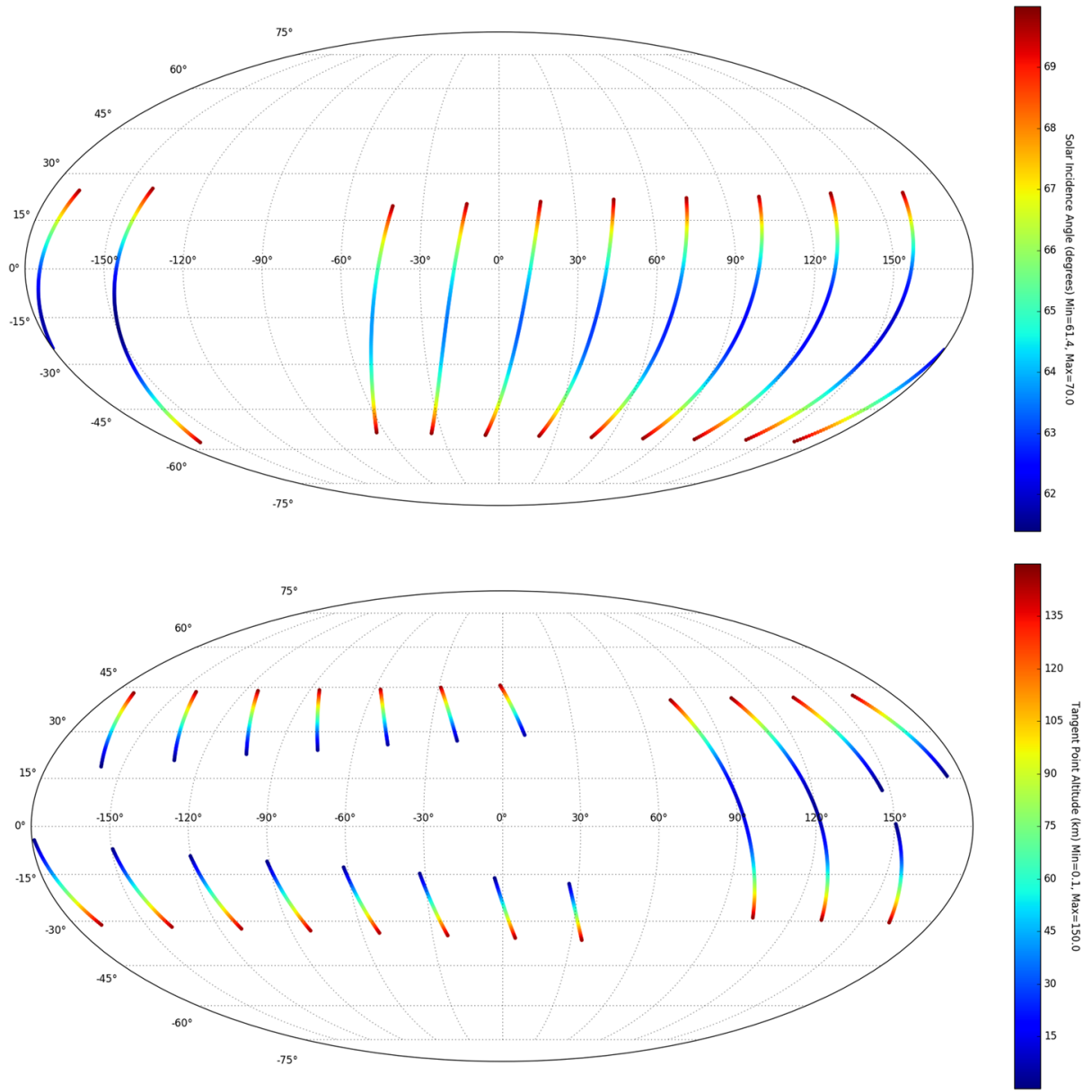

Fig. 13 Results of a 1-day orbit simulation where the beta angle is high. Top: dayside nadir coverage, showing how the solar zenith angle varies across the nadir groundtrack. Due to the higher beta angle, the surface solar incidence angles are much greater here, with a minimum value of $61^{\circ}$, which reduces the reflected nadir signal and hence negatively affects the LNO and UVIS nadir SNRs. Again, a cut-off of $70^{\circ}$ was applied, hence no polar coverage or nightside nadir observations are plotted. Bottom: solar occultation coverage for the same day, where the color here denotes the altitude of the tangent point i.e. the altitude where the occultation field of view is closest to the surface of the planet. The occultations begin around $30^{\circ}$ latitude and move westward. The higher beta angle here means that the solar occultations are longer, covering a large groundtrack. On the tenth orbit, the distance between the occultations reduces so that the two occultations join together-from this point, the tangent altitude does not reach zero, and hence they become grazing occultations

In nadir mode, however, LNO will use a second option; i.e. using half the available measuring time to perform an atmospheric measurement and half for a dark current measurement (see Figs. 16 and 17). This mode was used on board SOIR. On board background subtraction will be necessary for nadir observations because of the high expected level of thermal noise which will be the main contribution to the signal. Removing the dark on board will improve the dynamical response of the detector signal transmitted. It does halve the integration time, however, which reduces the SNR. 


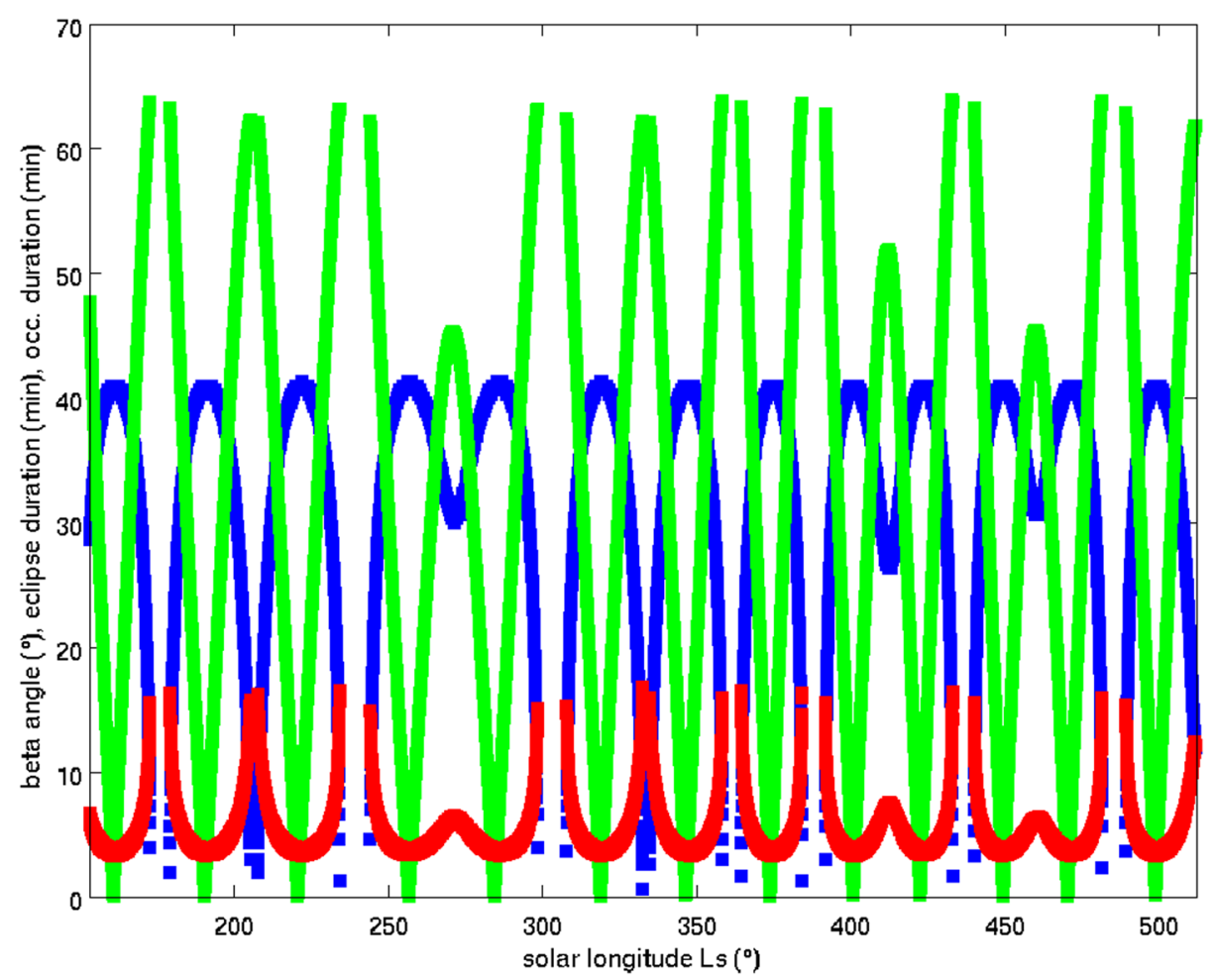

Fig. 14 Evolution of the eclipse duration (blue), the solar occultation duration (red) and the beta angle (green) in function of the solar longitude during 1.5 MY (MY34 and half of MY35). The higher the beta angle the shorter the eclipse duration and the longer it takes to perform a solar occultation observation (and vice versa)

Building on our expertise with SOIR, we have introduced another modification in the setting of the AOTF frequencies: there is now the possibility to switch to a second set of 6 spectral domains at a given moment during the observation. In the case of solar occultation, this means that from the top of the atmosphere down to e.g. $60 \mathrm{~km}$ we can observe more abundant gases or more intense absorption bands and then switch to detection of less abundant gases at an altitude where the optical path is longer and we have more chance of detecting them. Figure 18 illustrates a typical observation sequence during solar occultation.

Figure 19 illustrates the pointing achieved by all three spectrometers when pointing to the Sun or to the planet (nadir). The "suntracking" pointing mode will be used during the solar occultation measurements. The spacecraft (S/C) will track the Sun position throughout the observation. During an occultation, the slit orientation will stay inertially fixed throughout the whole pointing duration, being perpendicular to the limb at $30 \mathrm{~km}$ altitude. The nadir pointing mode will be used for night and dayside nadir observations. The $\mathrm{S} / \mathrm{C}-Y$-axis is pointed to the Mars center, while $\mathrm{S} / \mathrm{C}+Z$-axis is perpendicular to the Sun direction, with the Sun incident on the $-X$-panel. There will be a continuous nadir tracking through the pointing block. Note that for power consumption limitation, SO and LNO cannot operate together any longer, as was initially proposed.

The instantaneous fields of view (IFOV) of both IR spectrometers when observing in solar occultation are limited by the apparent size of the solar disk (average value of 21 arcmin, 


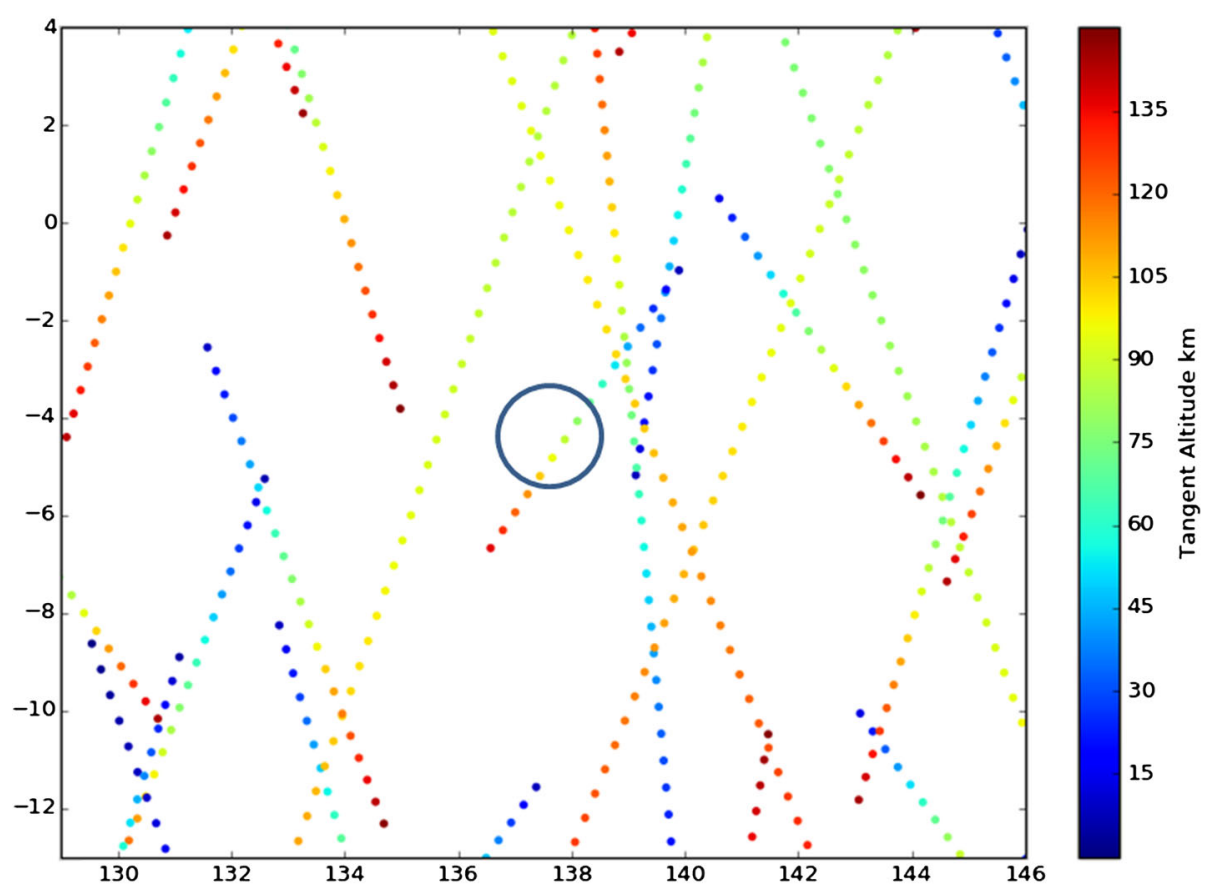

Fig. 15 Typical groundtrack coverage for solar occultation measurements near the location of the NASA Curiosity Rover landing site $\left(4.5^{\circ} \mathrm{S}, 137.5^{\circ} \mathrm{E}\right)$, for a 12 -month simulation period from May 2018 . Even close to the equator, the number of solar occultations is significant

varying along the orbit of the planet around the Sun from 19 to 23 arcmin) and by the slit width ( 2 arcmin for SO and 4 arcmin for LNO, the long side of the slit being perpendicular to the limb), whereas for UVIS it is only limited by the size of the aperture ( 2 arcmin circular). The instantaneous fields of view of the SO and LNO slits at the limb are thus $1 \times 12 \mathrm{~km}$ and $2 \times 12 \mathrm{~km}$, respectively. However, the vertical resolution and sampling are governed by the number of rows binned, as explained in Table 4 . A total of 24 spectra can be transmitted to Earth per cycle of observation due to downlink limitation. So, if 6 different wavelength intervals are recorded, only 4 spectra per such interval can be downloaded. As shown in Table 4, this can be 4 single rows, 8 rows binned by 2, or all 24 rows illuminated binned by 6 . The instantaneous field of view of each of these spectra corresponding to one bin varies from $0.5 \mathrm{~km}$ (single rows) to $3 \mathrm{~km}$ ( 24 rows binned by 6). Binning 2 rows into one spectrum for download ensures the $1 \mathrm{~km}$ resolution promised by NOMAD. The maximum vertical descent velocity of $1.2 \mathrm{~km} / \mathrm{s}$ will delineate the sampling rate and the final FOV. The maximum vertical displacement of $1.2 \mathrm{~km}$ in a second means that there is an overlap between bins sampled in consecutive measurements of the same spectral window (Vandaele et al. 2015a).

In nadir observations, the instantaneous field of view of the LNO slit ( $4 \operatorname{arcmin} \times$ 144 arcmin) corresponds to a footprint of $0.5 \times 17 \mathrm{~km}^{2}$, and that of UVIS (43 arcmin) to $5 \mathrm{~km}^{2}$. The velocity of the spacecraft is approximately $3.4 \mathrm{~km} / \mathrm{s}$ projected on the ground (3386 km Mars radius, altitude $400 \mathrm{~km}$, orbital period $7100 \mathrm{~s}$ ). This implies that, in $15 \mathrm{~s}$, the slit spans $51 \mathrm{~km}$ across the surface. The nadir observation mode therefore provides vertical columns with spatial footprints varying from $0.5 \times 68 \mathrm{~km}^{2}$ up to $17 \times 51 \mathrm{~km}^{2}$ for LNO, 


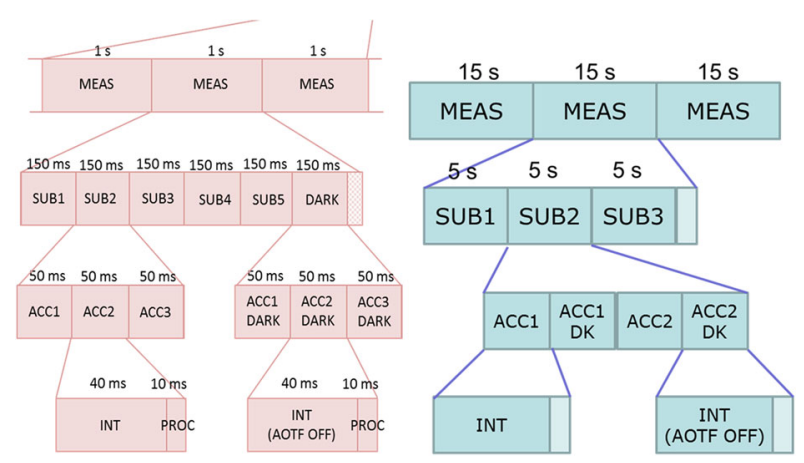

Fig. 16 (Left) Typical solar occultation observation with six spectral windows (different AOTF settings called SUB1, SUB2 etc.), one being 'dark'. The cycle is $1 \mathrm{~s}$, leading to $150 \mathrm{~ms}$ per AOTF setting, and therefore 3 accumulations (ACC1, etc.) for an integration time of $40 \mathrm{~ms}$ plus $10 \mathrm{~ms}$ readout (PROC). For each setting, the integration time is determined based on the saturation limit of the detector (depending on the observed signal and the sensitivity of the instrument in the selected diffraction order) and the number of co-added measurements is imposed by the total time of one observation. (Right) Typical nadir observation with three spectral windows (different AOTF settings). The cycle is $15 \mathrm{~s}$ leading to $5 \mathrm{~s}$ per setting. For each setting, the measurement is composed of the succession of two atmospheric observations and two dark observations, which are directly subtracted on board

\section{Along track on Mars}

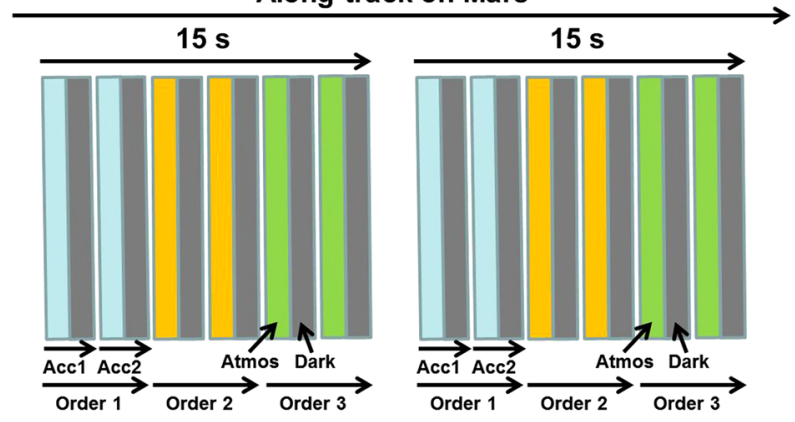

Fig. 17 Typical nadir observation sequence with a 15 s cycle and three different AOTF settings (or orders). Each measurement is a succession of an 'atmospheric' one (blue, yellow and green) and a 'dark' one (gray), the latter being subtracted on board. Several accumulations are co-added for each order. Here two are shown (Acc1, Acc2) but more can be accumulated depending on the integration time and the total AOTF settings selected

depending on the orientation of the spacecraft, and of $5 \times 56 \mathrm{~km}^{2}$ for UVIS (for observation time $\sim 15 \mathrm{~s}$ ). As the $\mathrm{CO}_{2}$ column abundance is retrieved at the same time, systematic error sources are eliminated and mixing ratios can be determined.

The data rate of SO and LNO are relatively fixed, but during periods when the data rate is higher, UVIS can take spectra more rapidly; whilst for periods where the data rate is lower, either the nightside nadir observations can be omitted or the spectrometers can be run at a lower measurement rate. The nightside nadir measurements are scheduled to be planned at low beta angles periods when the eclipse duration is rather long. During this period, there will be sufficient time to perform nadir nightside measurements between two solar occultation observations. 
Fig. 18 Solar occultation sequence with two sets of settings 'Science 1' and 'Science 2', allowing for the optimization of the selection of the measured orders as a function of altitude

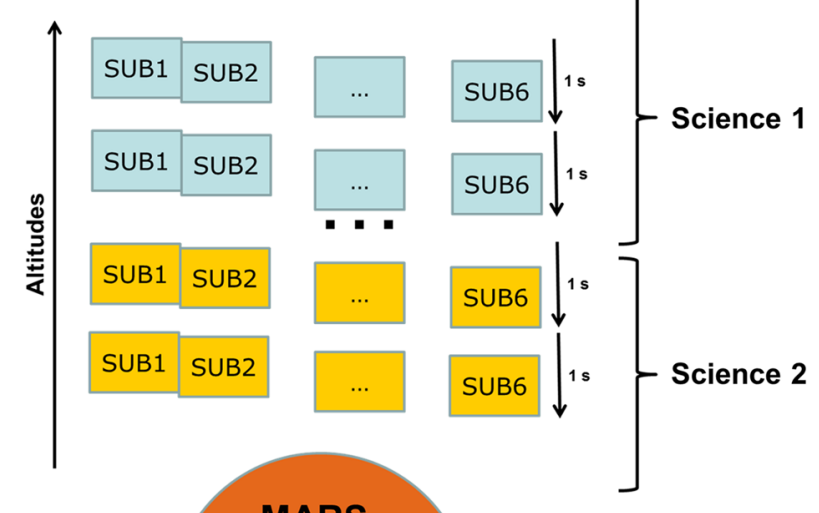

MARS
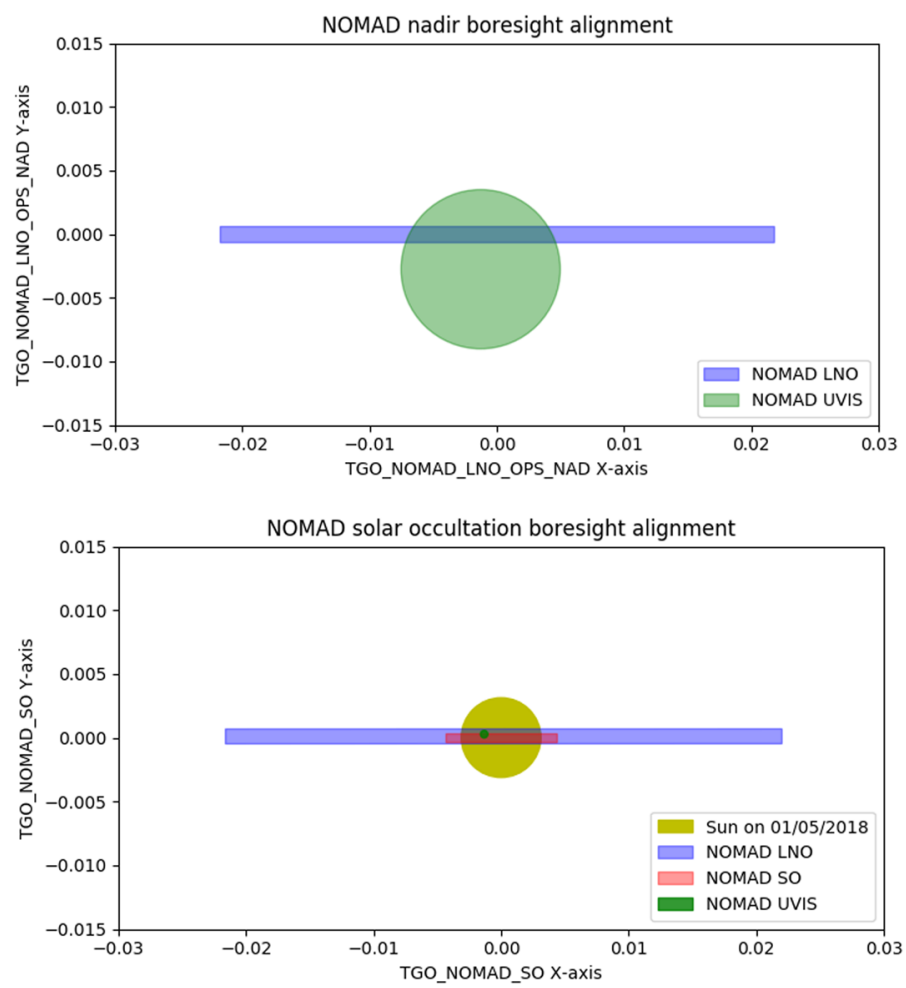

Fig. 19 NOMAD nadir (top) and solar occultation (bottom) boresight alignment, showing the very good internal alignment of the different spectrometers

By carefully matching instrument capability to the expected data volumes, NOMAD can operate nominally and continuously throughout the majority of the mission. This is further improved if the allocated portion of on-board storage $(128 \mathrm{~Gb})$ on TGO is used, which would allow NOMAD to continue operating nominally for 3-4 months while downlink rates reach the minimum during solar conjunction periods. If data rates are limited, either the number 
Table 4 The instantaneous field of view (IFOV) for SO for different binning options, for the baseline concept of 6 AOTF settings per observation

\begin{tabular}{llll}
\hline $\begin{array}{l}\text { \# of AOTF } \\
\text { settings }\end{array}$ & $\begin{array}{l}\text { \# of IR spectra/frequency } \\
\text { Maximum integration time }\end{array}$ & $\begin{array}{l}\text { Rows read-out } \\
\text { from IR detector }\end{array}$ & $\begin{array}{l}\text { SO IFOV of } \\
\text { each spectrum }\end{array}$ \\
\hline $\begin{array}{l}6 \text { (baseline, } \\
5+1 \text { 'dark' } \\
\text { setting) }\end{array}$ & 4 & 4 single rows & $0.5 \mathrm{~km}$ \\
& $160 \mathrm{~ms}$ & 8 rows binned by 2 & $1 \mathrm{~km}$ \\
& & 12 rows binned by 3 & $1.5 \mathrm{~km}$ \\
& 16 rows binned by 4 & $2 \mathrm{~km}$ \\
& 20 rows binned by 5 & $2.5 \mathrm{~km}$ \\
\end{tabular}

of diffraction orders of the IR spectrometers can be reduced or the measurement time can be increased e.g. the data rate can be halved by running 3 diffraction orders every second or 6 diffraction orders every 2 seconds. This can be reduced further for periods with very low Mars-Earth transmission rates. However, as explained above, NOMAD could operate for several months using TGO's on-board storage.

Similarly, the UVIS spectrometer has two principal modes of operation. In the typical operating mode ( $0.33 \mathrm{~s}$ per measurement), a vertically-binned full spectrum is measured at 20-bit resolution. If data transmission is limited, the measurement rhythm can be reduced so that fewer spectra are returned per second.

If higher data rates are available, SO and LNO cannot typically utilize the extra available bandwidth. However, UVIS can be run at a higher temporal resolution up to a limit imposed by the NOMAD central processing unit, or can be run in "full frame" mode, where the signal values for each pixel are returned individually, which increases the spectrometer's SNR.

The scheduled payload observations could be impacted by the regular wheel-off-loadings periods ( 1 orbit per day) and orbit correction maneuvers ( 2 orbits per month needed for one correction). Also, the NOMAD thermal constraints have to be met respecting the 80 minutes ON, 40 minutes OFF thermal cycle in a 2-hours orbit. This means that the nadir dayside observations need to be shortened to fit this thermal cycle profile. It also means that the nightside nadir observations will need to be skipped most of the time to stay within NOMAD thermal constraints to have a sufficient cool-down period.

\section{Expected Performance}

Initial studies of the performance of NOMAD were published in Vandaele et al. (2015a) and Robert et al. (2016), in which detection limits for most trace gases were determined for solar occultation and nadir observations. These studies were based on the latest optical models of the three NOMAD spectrometers (Thomas et al. 2016; Vandaele et al. 2015b), using best estimates of the SNR. The Near Earth Commissioning (NEC), Mid-Cruise Checkouts (MCC) observations as well as these performed during the two Mars Capture Orbit sessions (MCO) will help in updating these optical models by considering calibration data obtained under real space conditions. Note however, that, because of the presence of the Entry, Descent and Landing Demonstrator Module (EDM) and the absence of Mars, thermal conditions during NEC and MCC were not comparable to those under which science observations will be conducted, since the EDM was located just above our instrument preventing the NOMAD radiator to dissipate heat in an optimal manner. Similarly, because the highly elongated orbit 
prevailing during the two MCO periods was very different to the final quasi-circular orbit, thermal conditions during these observations were again not similar to the ones which will be attained during the science orbit. The final updates of the optical models, and therefore the values of SNR and associated detection limits, will need re-investigation when in nominal science orbit after aerobraking.

NOMAD is expected to improve significantly our knowledge of the composition of the Martian atmosphere, since the detection limits for several species will be improved in some cases by more than an order of magnitude. Table 2, summarizes the results obtained in Vandaele et al. (2015a) and Robert et al. (2016) for nadir observations, while Figs. 20, 21, 22, 23 illustrate the detection limits obtained in solar occultation. The detection limits were determined for UVIS considering a SNR of 500 for both viewing geometries (Vandaele et al. 2015b). The detailed SNR analysis performed on LNO nadir observations considered the contribution of the solar radiation reflected from the planet's surface under different Martian conditions: when Mars is at aphelion (farthest away from the Sun) or at perihelion (closest to the Sun), considering different surface albedos, different angles of the Sun illumination, and different dust loadings (Thomas et al. 2016). The SNR can vary hugely depending on the combination of factors listed above, therefore an SNR of 100 has been considered in the following analysis.

For solar occultation observations with $\mathrm{SO}$, the detection limits were determined assuming a one-second cycle with 6 different spectral windows and a spectral resolution of $0.15 \mathrm{~cm}^{-1}$. The detailed SNR study (Thomas et al. 2016) revealed that for typical conditions, values around 5000 were obtained (Fig. 6). Real SNRs will be reduced by the presence of dust and aerosols, and therefore a value of 2000 should be considered for the SO spectrometer when operating in solar occultation mode. Likewise for LNO in occultation mode, an SNR value of 3000 should be considered, which corresponds to the larger slit of LNO compared to that of SO.

The impact of dust or clouds was not included in the preliminary investigation of the detection limits performed in Robert et al. (2016), although their impact was considered in the SNR studies for the three spectrometers (Thomas et al. 2016; Vandaele et al. 2015b). Dust has a very different effect on solar occultation compared to nadir observations. This effect depends on the composition, form and optical properties of the aerosols considered. This is illustrated in Figs. 24 and 25, where several spectra are shown for different atmospheric dust loadings for solar occultation and nadir observations, respectively. In solar occultation, dust and clouds will mostly reduce the level of sunlight reaching the instrument by extinction, whereas in nadir observations, the situation is more complex and depends highly on the optical properties (single scattering albedo, phase functions) governing the interaction of light and the aerosols. All the simulations in nadir shown here were obtained using a full scattering scheme adapted to Martian conditions (Drummond et al. 2011; Vandaele et al. 2008; Vandenbussche et al. 2013). The model includes Rayleigh scattering and aerosol properties (i.e. single scattering albedo, optical depth and aerosol scattering matrix provided as Legendre polynomials) which are wavelength-dependent. These optical quantities were calculated based on the vertical number density distribution from Smith (2004) and Esposito et al. (2007). The dust refractive index is from Ockert-Bell et al. (1997) and the grain size distribution is from Clancy et al. (2003). The Sun irradiance has been considered here as a blackbody at the temperature of 5967K, the value most compatible with recent SOLSPEC observations (Bolsée et al. 2017). The surface is considered to be Lambertian, characterized by a constant, wavelength-independent, albedo.

The impact of the dust loading on the detectability of several species during solar occultation has been investigated further. Results are shown in Fig. 20 for methane and other 

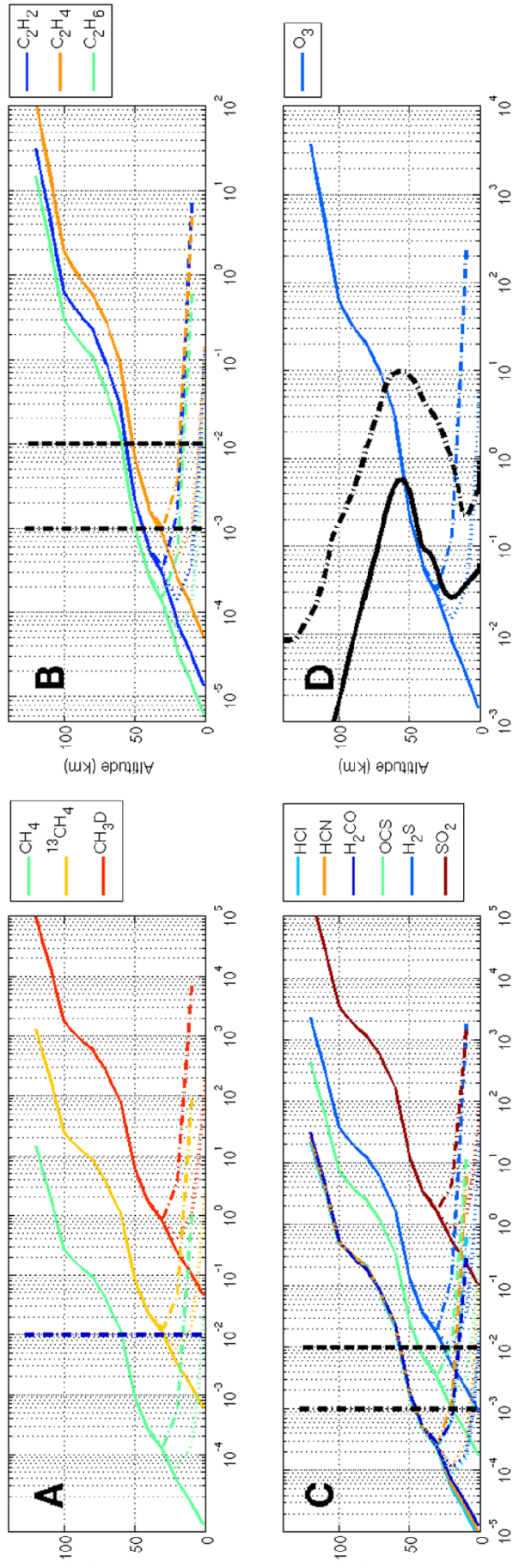

(uप्र) әрп!!|

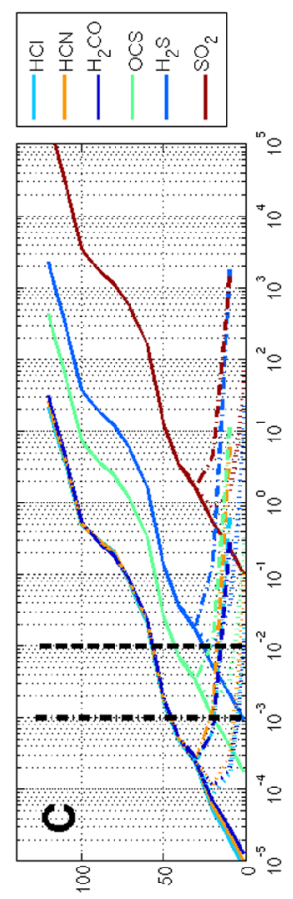

(Uत्र) әpm!||।

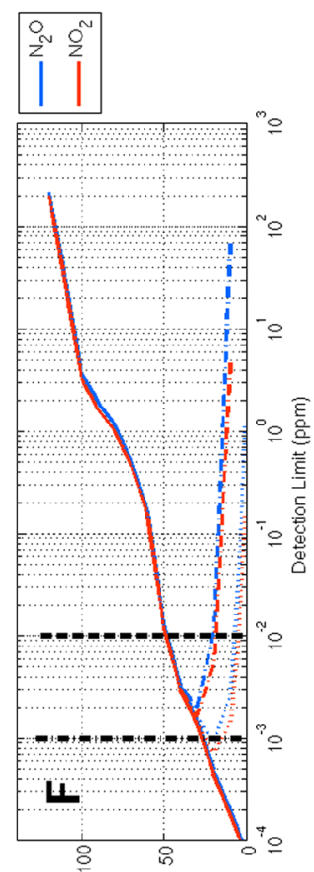

(uत्र) əpm!!||
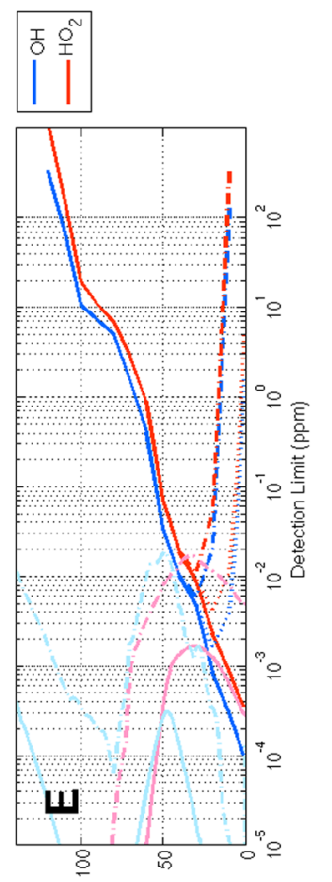

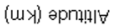

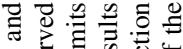

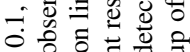

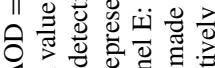
记艺造远

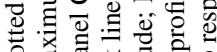
음 0 웡 II ใิ « क्षे

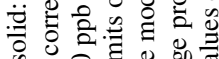

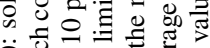

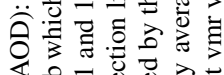

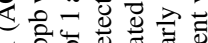

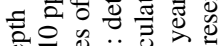

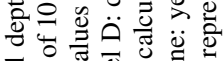
ฮี

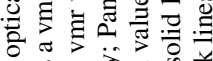

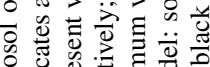

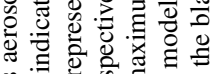

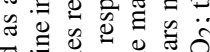

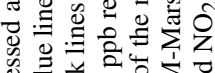

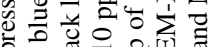

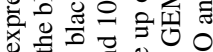

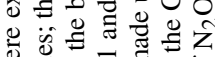

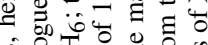

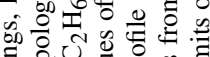

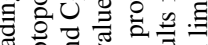
。․ㅇำ

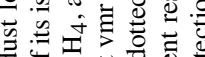

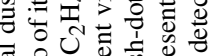

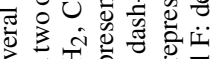

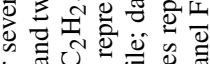

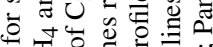

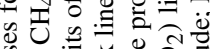

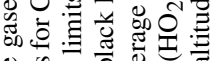

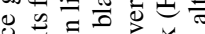

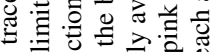

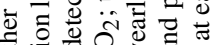

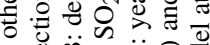

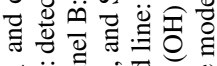

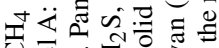

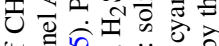
पै

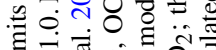

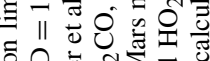

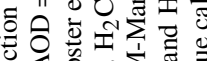

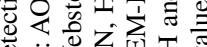

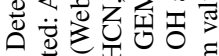

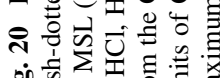

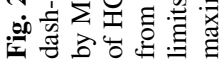




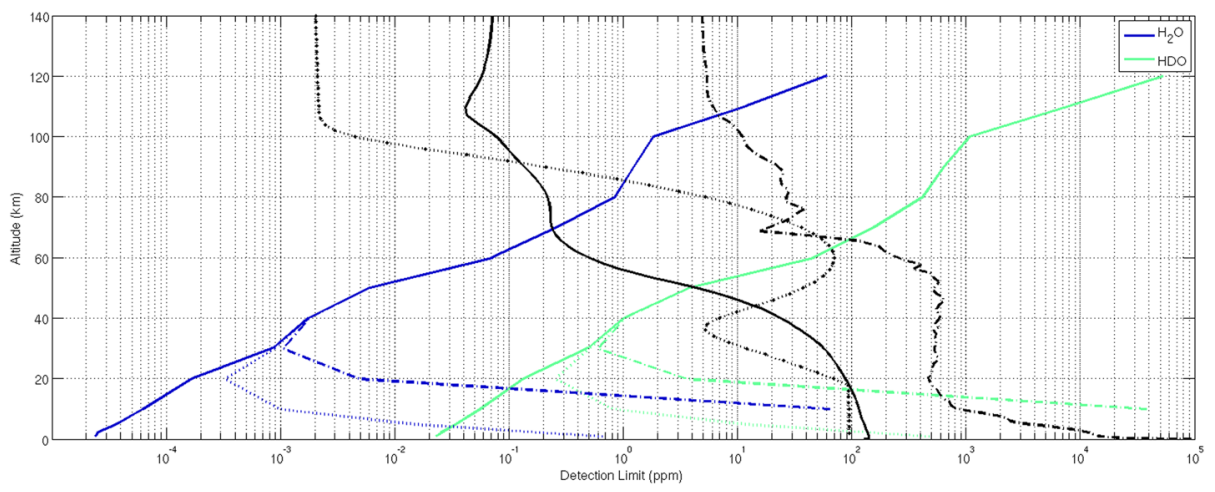

Fig. 21 Detection limits of $\mathrm{H}_{2} \mathrm{O}$ and its isotopologue $\mathrm{HDO}$, considering an enrichment of 5.6 of HDO compared to the SMOW value on Earth. The detection limits are given for several dust loadings, here expressed as Aerosol Optical Depth (AOD): solid: $\mathrm{AOD}=0.0$, dotted: $\mathrm{AOD}=0.1$, and dash-dotted: $\mathrm{AOD}=1.0$. The black lines represent results from different models: solid is the yearly average obtained by GEM-Mars; dashdotted: profile made up of the maximum value calculated by the model at each altitude; dotted: profile used in Chaffin et al. (2017) as being representative of the high-altitude water profiles observed by SPICAM (Maltagliati et al. 2011)

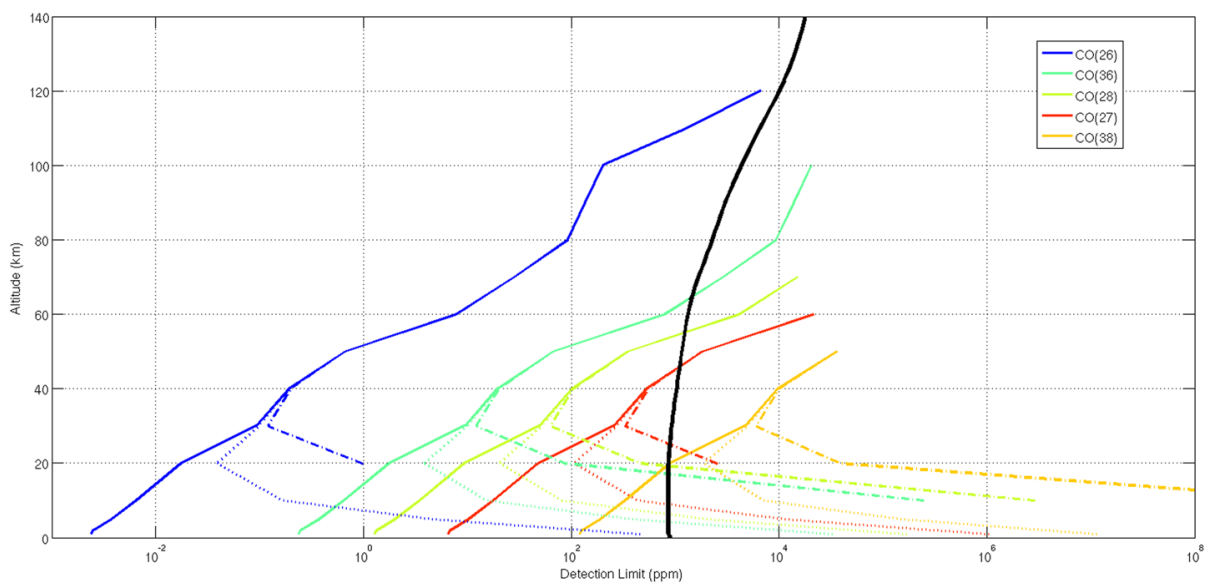

Fig. 22 Detection limits CO and its main isotopologues for several dust loadings, here expressed as aerosol optical depth: solid: $\mathrm{AOD}=0.0$, dotted: $\mathrm{AOD}=0.1$, and dash-dotted: $\mathrm{AOD}=1.0$

trace gases for different dust loading (aerosol optical depth of 0 -no dust, 0.1 and 1.0). Dust in solar occultations has the effect of reducing the radiation reaching the detector. The extinction due to the dust is the principal process, as the change in signal through scattering is negligible in this geometry. The impact is more pronounced below $30 \mathrm{~km}$ tangent height, and can even prevent detection below $20 \mathrm{~km}$ for the higher loadings (Fedorova et al. 2018).

One of the key objectives of NOMAD is the detection of isotopologues. The high spectral resolution of the IR spectrometers will ensure the high sensitivity requested for the search of trace gases and isotopologues. Figure 26 illustrates the capability of NOMAD to observe different isotopologues of water. We show in Figs. 20 (Panel A), 21, 22 and 23 the detection limits at different altitudes and for different dust loadings for the isotopologues of $\mathrm{CH}_{4}$, $\mathrm{H}_{2} \mathrm{O}, \mathrm{CO}$ and $\mathrm{CO}_{2}$ respectively. The detection limits of the isotopologues are corrected 


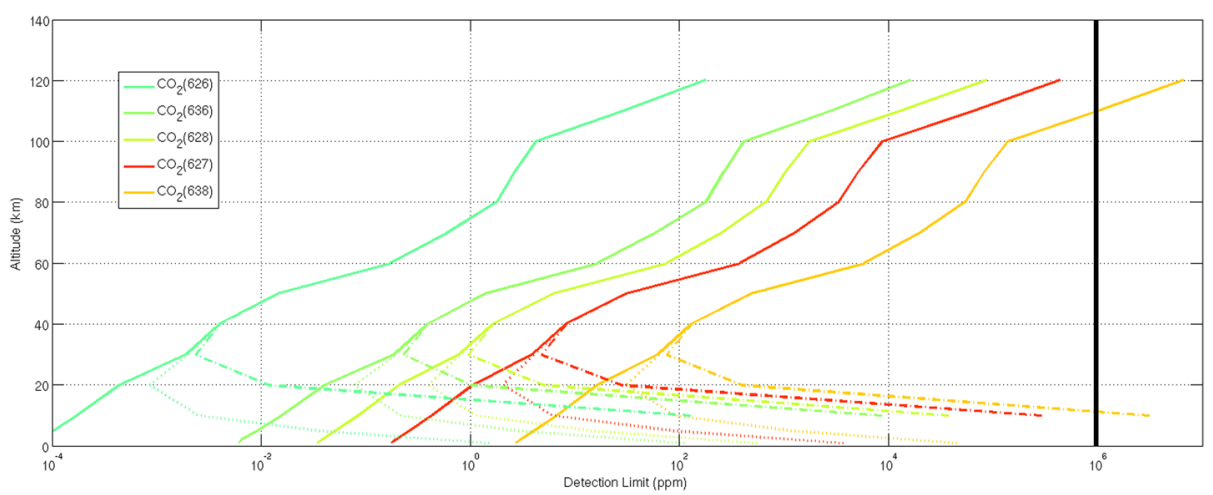

Fig. 23 Detection limits $\mathrm{CO}_{2}$ and its main isotopologues for several dust loadings, here expressed as aerosol optical depth: solid: $\mathrm{AOD}=0.0$, dotted: $\mathrm{AOD}=0.1$, and dash-dotted: $\mathrm{AOD}=1.0$
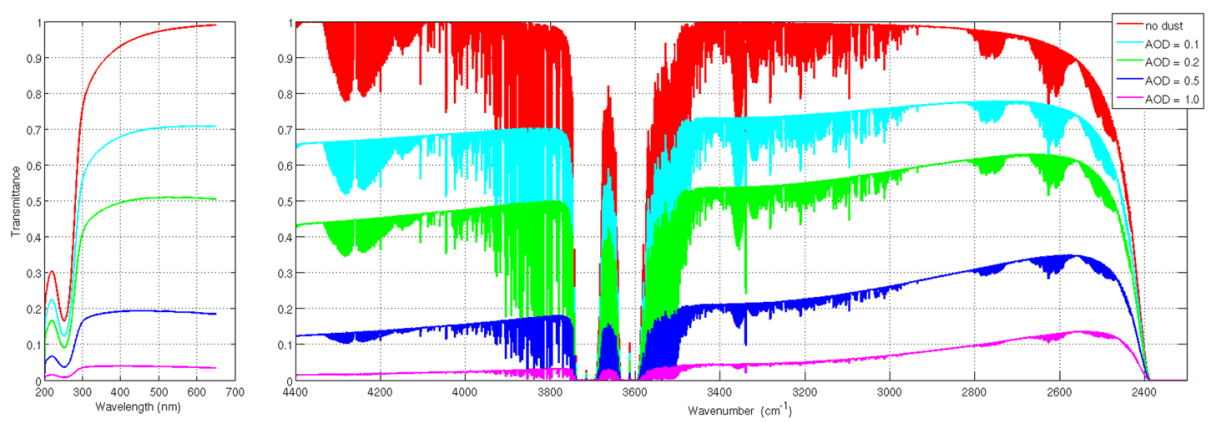

Fig. 24 Effect of dust on the transmittances observed at a tangent height of $20 \mathrm{~km}$, with Aerosol Optical Depth (AOD) of 0 (no dust), 0.2, 0.5, and 1.0 respectively

for the isotopic ratio. In the case of $\mathrm{CH}_{4}, \mathrm{CO}$ and $\mathrm{CO}_{2}$ we considered values of isotopic ratios identical to the ones on Earth, while for HDO we corrected the value by a factor of 5.6 to take into account the higher abundance of $\mathrm{HDO}$ relative to $\mathrm{H}_{2} \mathrm{O}$ on Mars. As can be inferred from Fig. 21, NOMAD will be able to provide $\mathrm{H}_{2} \mathrm{O}$ and $\mathrm{HDO}$ vertical profiles even above $40 \mathrm{~km}$ of altitude. SPICAM/MEx observed detached layers of water at higher altitudes peaking between 60 and $70 \mathrm{~km}$, with abundances varying between 50 and $100 \mathrm{ppm}$ (Maltagliati et al. 2013). These detached layers were observed in the southern hemisphere at $L_{\mathrm{S}}=205-210^{\circ}$. NOMAD will also be able to detect such increase of water abundance, and with concurrent observation of $\mathrm{H}_{2} \mathrm{O}$ and $\mathrm{HDO}$, NOMAD will deliver D/H vertical profiles up to the higher layers of the atmosphere. Combining these observations with MAVEN measurements of D and H Ly $\alpha$ emissions (Clarke et al. 2017), will allow a global view and understanding of the variability of the $\mathrm{D} / \mathrm{H}$ ratio within the Martian atmosphere from the surface up to the highest layers of the atmosphere, giving some insights on the history of water on planet Mars. Moreover, NOMAD will enable us to derive temperatures from the $\mathrm{CO}_{2}$ density measurements (see for example Mahieux et al. 2012 for similar results from the SOIR observations of Venus). Associated with the $\mathrm{H}_{2} \mathrm{O}$ profiles, these measurements will allow NOMAD to investigate in depth the supersaturation issue of water vapor in the Martian atmosphere. 


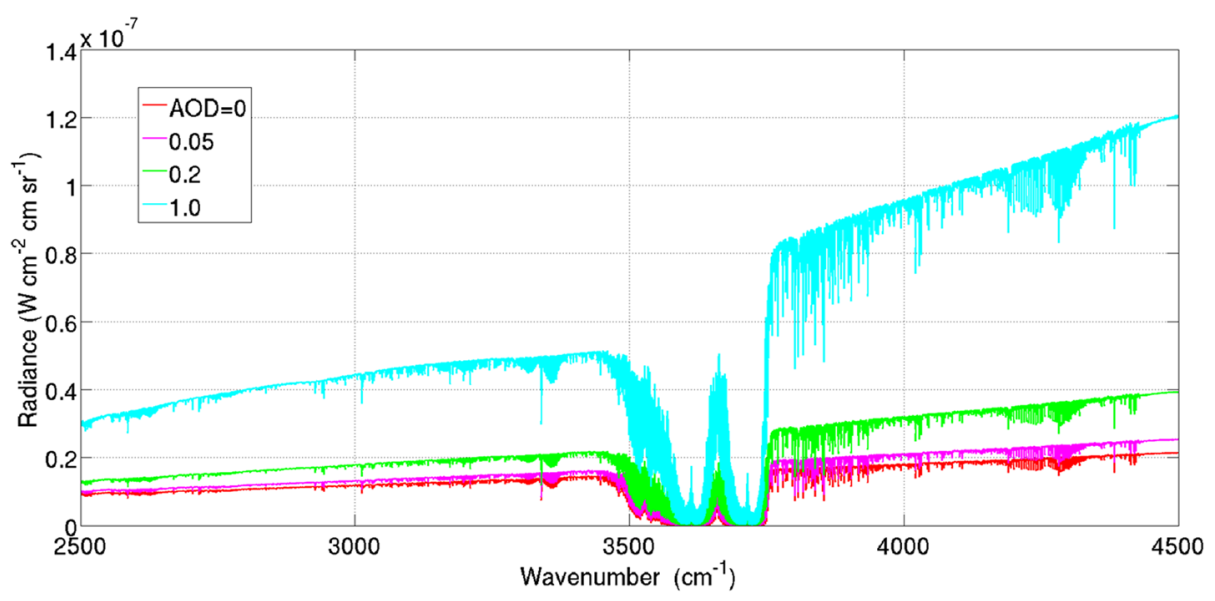

Fig. 25 Effect of dust on the nadir observations. Typical spectra are shown for different Aerosol Optical Depth (AOD) of 0 (no dust), 0.05, 0.2, and 1.0
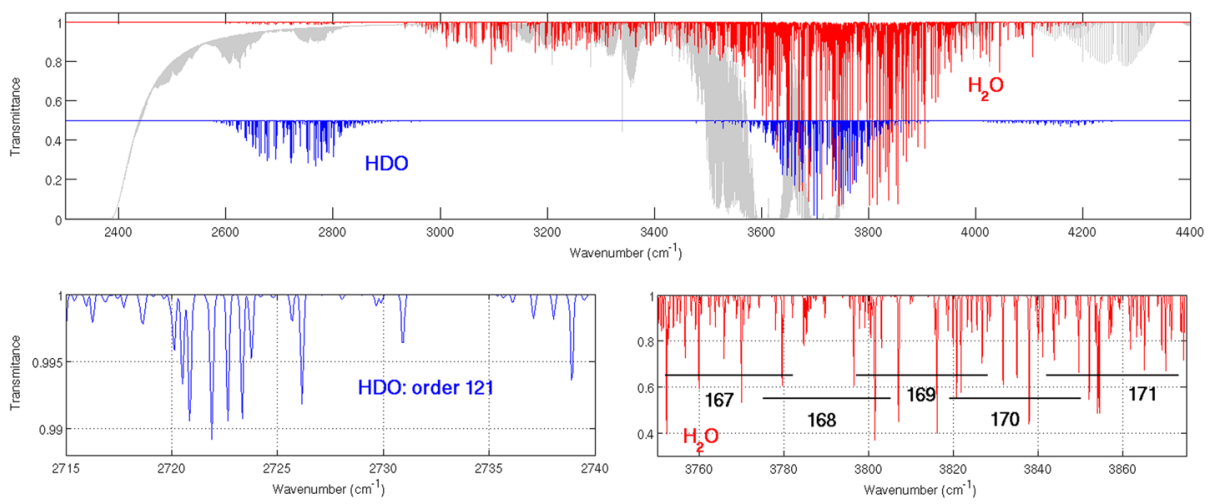

Fig. 26 NOMAD will be sensitive to the main isotopologue of water vapor (red) and HDO (blue). This is shown here (top panel) on a simulated solar occultation spectrum corresponding to a tangent height of $20 \mathrm{~km}$ (gray: all species included). HDO is shifted vertically to show the location of its main absorption lines. Bottom panels: zooms on the regions where $\mathrm{HDO}$ (left) and $\mathrm{H}_{2} \mathrm{O}$ (right) will be measured. In the case of $\mathrm{H}_{2} \mathrm{O}$ several orders can be selected (here orders 167 to 171 are shown)

$\mathrm{CO}_{2}$ density will be measured during all solar occultations. At least one order (of the 6 available) will be devoted to $\mathrm{CO}_{2}$. With the possibility to have different settings (i.e. selection of orders or spectral regions recorded) for the lower and upper parts of the atmosphere, NOMAD will ensure that a complete $\mathrm{CO}_{2}$ vertical profile is obtained from the highest altitudes probed down to the surface. Indeed, selecting strong absorption lines will provide $\mathrm{CO}_{2}$ abundance in the highest layers, while weaker lines will be used to probe the lower altitudes, where the stronger lines would be saturated. Figure 23 shows that NOMAD will be able to separate the contribution from the different isotopologues of $\mathrm{CO}_{2}$. This will lead to the determination and validation of the ${ }^{13} \mathrm{C} /{ }^{12} \mathrm{C},{ }^{17} \mathrm{O} /{ }^{16} 0$, and ${ }^{18} \mathrm{O} /{ }^{16} \mathrm{O}$ isotopic ratios.

One of the key targets for vertical profiling is $\mathrm{CO}$ for which such information is still missing today. Using absorption lines of different strength, NOMAD will be able to derive the $\mathrm{CO}$ profile from the surface (in clear sky conditions) up to the highest layers. $\mathrm{CO}$ iso- 
topologues will also be detectable and will provide information on the ${ }^{13} \mathrm{C} /{ }^{12} \mathrm{C},{ }^{17} \mathrm{O} /{ }^{16} 0$, and ${ }^{18} \mathrm{O} /{ }^{16} \mathrm{O}$ isotopic ratios.

NOMAD will also improve the detection of a series of trace gases, sometimes allowing the first potential detection ever (Fig. 20). Formaldehyde $\left(\mathrm{H}_{2} \mathrm{CO}\right)$ is produced during the oxidation of methane, and could also be released through biogenic processes. Previous detection limit of $4.5 \mathrm{ppb}$ and $3.9 \mathrm{ppb}$ were reported by Krasnopolsky et al. (1997) and Villanueva et al. (2013) respectively. Figure 20 (Panel C) shows that NOMAD is able to observe $\mathrm{H}_{2} \mathrm{CO}$ up to $40 \mathrm{~km}$ altitude. Measurement of $\mathrm{C}_{2} \mathrm{H}_{2}, \mathrm{C}_{2} \mathrm{H}_{4}$ and $\mathrm{C}_{2} \mathrm{H}_{6}$ will help to identify the origin of $\mathrm{CH}_{4}$. On Earth, thermogenic sources are characterized by low $\mathrm{CH}_{4} / \mathrm{C}_{2} \mathrm{H}_{6}$ ratios, while biogenic sources of $\mathrm{CH}_{4}$ correspond to high values (Allen et al. 2006). Detection of $\mathrm{C}_{2} \mathrm{H}_{6}$ would indicate a geochemical origin of $\mathrm{CH}_{4}$, assuming that no ethane-producing microbes exist on Mars (Etiope 2018). Moreover, these compounds are also produced by photo-dissociation and oxidation of $\mathrm{CH}_{4}$ (Wong et al. 2004), so that their detection would be an indirect confirmation of the presence of methane. A recent study (Villanueva et al. 2013) reported upper limits of 6,4 , and $0.7 \mathrm{ppb}$ for $\mathrm{C}_{2} \mathrm{H}_{2}, \mathrm{C}_{2} \mathrm{H}_{4}$, and $\mathrm{C}_{2} \mathrm{H}_{6}$ respectively, which could be measured by NOMAD up to $50 \mathrm{~km}$ altitude (see Fig. 20-Panel C). $\mathrm{HO}_{2}$ has been predicted by models (Lefèvre et al. 2004) and Fig. 20-Panel E compares the results from the GEM-Mars model with the expected sensitivity of NOMAD. No sulfur-bearing species has been detected to date in the Martian atmosphere. Both Encrenaz et al. (2011) and Nakagawa et al. (2009) reported an upper limit of 2 ppb of $\mathrm{SO}_{2}$, while recent groundbased observations of the Tharsis region revealed upper limits of $1.1 \mathrm{ppb}$ (Khayat et al. 2015). $\mathrm{HCl}$ is probably the most abundant reservoir of chlorine on Mars. Early volcanic activity could have produced $\mathrm{HCl}$ later converted into perchlorates. Uplifting of perchlorates to higher altitudes would allow photo-chemical reactions providing a source of chlorine in the atmosphere. An upper limit of $0.6 \mathrm{ppb}$ of $\mathrm{HCl}$ was reported by Villanueva et al. (2013), which would be detected by NOMAD up to altitude of $20 \mathrm{~km}$ under clear sky conditions (see Fig. 20-Panel C).

Aerosol slant optical depths and extinction are derived routinely from solar occultation observations, as was demonstrated with SOIR/VEX (Wilquet et al. 2012). Measurement of the aerosol opacity simultaneously across a wide wavelength range (i.e. UVIS, SO and LNO, and if possible ACS/NIR) also allows the optical properties, composition and size distribution of the suspended aerosols to be derived or constrained through Mie-modeling of the wavelength dependence of the extinction (Luginin et al. 2016; Wilquet et al. 2009).

Combining UV (NOMAD/UVIS), NIR (ACS) and IR (NOMAD/SO and LNO) spectral ranges will allow a thorough investigation of the dust and clouds in the Martian atmosphere. Because of the very wide spectral range observed, it will be possible to constrain the micro-physical properties of the Martian aerosols. In addition, through a careful selection of adequate spectral orders in the $2.5-3.5 \mu \mathrm{m}$ spectral window it could even be possible to distinguish between dust and $\mathrm{H}_{2} \mathrm{O}$ ice clouds (Fig. 27).

Depending on season, altitude, local solar time and location, the Mars atmospheric temperature can be cold enough for $\mathrm{CO}_{2}$ to condense and $\mathrm{CO}_{2}$ ice clouds to form. $\mathrm{CO}_{2}$ ice particles have been detected both in the lower atmosphere $(\leq 20 \mathrm{~km})$ during the polar night (Giuranna 2008; Ivanov and Muhleman 2001; Pettengill and Ford 2000) and in the mesosphere (50-100 km) at equatorial latitudes (Clancy et al. 2007; Määttänen et al. 2013; Montmessin et al. 2007).

Small $\mathrm{CO}_{2}$ ice grains might be observed with UVIS at high latitudes and altitudes while larger grains at lower altitudes and equatorial latitudes might be observed with $\mathrm{SO}$ in the IR based on the diagnostic $\mathrm{CO}_{2}$ ice $4.26 \mu \mathrm{m}$ feature, as the $\mathrm{SO}$ spectral window ends at $4.3 \mu \mathrm{m}$. Around $4.26 \mu \mathrm{m}$, there is an important increase of the $\mathrm{CO}_{2}$ ice imaginary refractive index, 


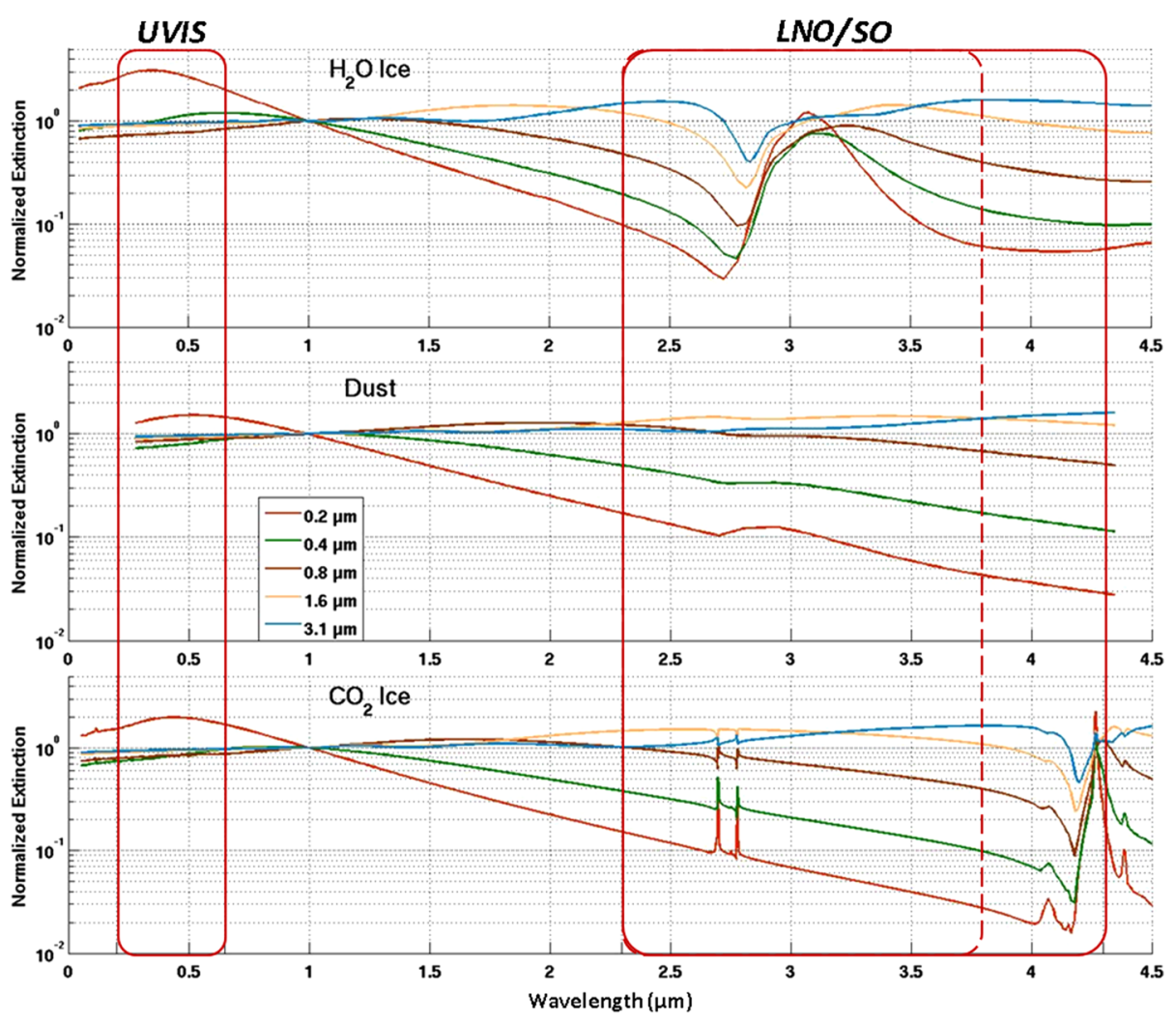

Fig. 27 Wavelength dependence of the computed normalized extinction for $\mathrm{H}_{2} \mathrm{O}$ ice (top panel), dust (middle panel) and $\mathrm{CO}_{2}$ ice (bottom panel) particles as a function of the wavelength and for different effective radii given by the color code in the middle panel. The spectral regions probed by NOMAD/UVIS, SO (red frames) and LNO (dashed line) are also indicated. The refractive indexes that are adopted for the Mie computation are from Warren and Brandt (2008) for $\mathrm{H}_{2} \mathrm{O}$ ice, from Wolff et al. (2009, 2010) for Martian dust and from Hansen $(1997,2005)$ for $\mathrm{CO}_{2}$ ice. The particle size distribution used is a log-normal distribution with $r_{\text {eff }}=0.2 \mu \mathrm{m}$

corresponding to the fundamental $v_{3}$ band of $\mathrm{CO}_{2}$ ice, that leads to a strong variation of the extinction with wavelength in the 4.0-4.5 $\mu \mathrm{m}$ region (Fig. 27).

In nadir mode, the contributions from the dust and clouds and from the surface are not easily distinguishable. Nevertheless, it is possible to retrieve information on the integrated optical depths of dust and ice clouds (Willame et al. 2017). The surface reflectivity was also considered and was retrieved in the cases where no ice clouds were present in the observed scenes, ice clouds reducing the sensitivity in the surface albedo.

The impact of the dust loading on nadir detection limits is very weak in the IR. We performed retrievals of methane using the diffraction order $134\left(3011-3036 \mathrm{~cm}^{-1}\right)$ under different conditions of dust loadings defined by the aerosol optical depths (AOD). The results for three different scenarios are given in Fig. 28. A series of spectra were simulated for different $\mathrm{CH}_{4}$ volume mixing ratio (vmr) values, ranging from 2 to $100 \mathrm{ppb}$, considering typical noise levels expected at Mars (Thomas et al. 2016). The degrees of freedom for the signal (DOFS) of the retrievals are plotted in function of different vmr values: when the $\mathrm{CH}_{4} \mathrm{vmr}$ is high, there is no problem retrieving that value, and the DOFS is close to 1; when 

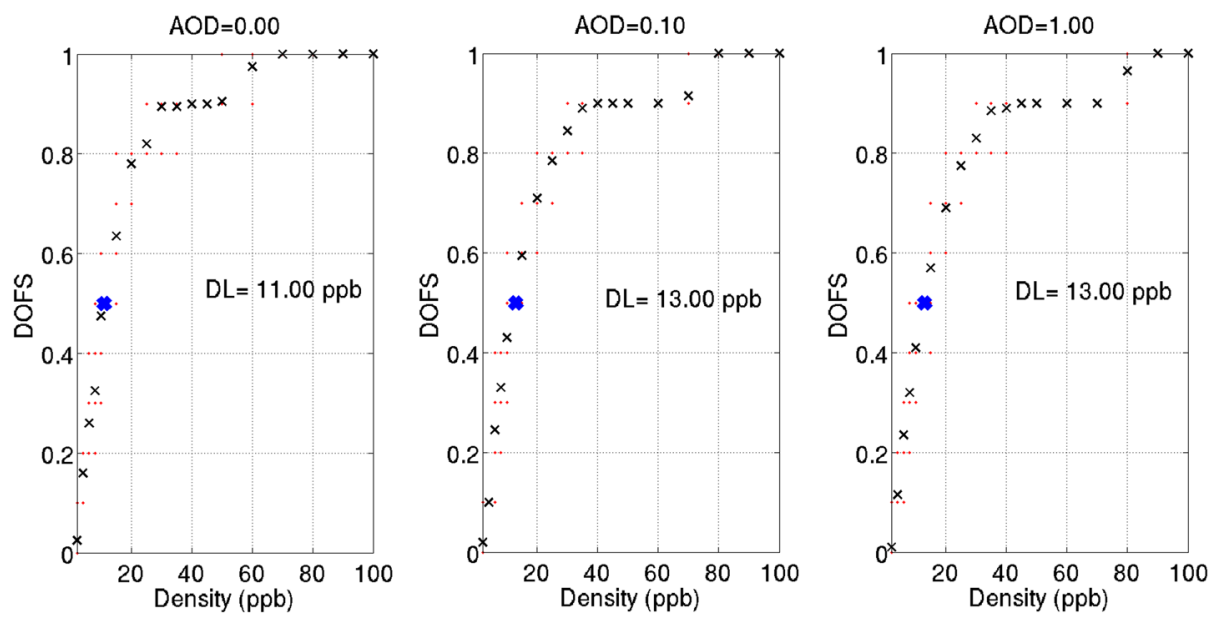

Fig. 28 Detection Limits for $\mathrm{CH}_{4}$ in three scenarios of dust: AOD $=0$ (left), AOD $=0.1$ (center) and $\mathrm{AOD}=1.0$ (right). These results were obtained by retrieving methane in the diffraction order 134 i.e. spectral interval from 3011 to $3036 \mathrm{~cm}^{-1}$. The red dots show the 20 individual results. The 18 black markers indicate the mean Degree of Freedom of the Signal (DOFS) per factor tested. The DOFS equals to 0.5 is represented by the blue marker

the injected $\mathrm{CH}_{4}$ vmr value decreases the retrieval can not distinguish the $\mathrm{CH}_{4}$ signature from the noise anymore, and the DOFS value goes to 0 . The detection limit is determined to correspond to a value of DOFS of 0.5 . While the signal increases with the dust loading as can be seen in Fig. 25, the detection limits remain of the same order, 13 ppb compared to the $11 \mathrm{ppb}$ in the case of the dust-free scenario, denoting a very weak impact of dust on the retrieval of $\mathrm{CH}_{4}$. This is entirely explained by the primary effect of dust/aerosols on the observed radiance in the IR, where the type of dust particle considered in these simulations leads to an increase of the signal reaching the instrument. In that case, the detection limit will be mostly limited by the amplitude of the absorption feature itself.

\section{Conclusions}

The NOMAD ("Nadir and Occultation for MArs Discovery") spectrometer suite will conduct a spectroscopic survey of Mars' atmosphere in the UV, visible and IR domains covering the $0.2-0.65$ and $2.3-4.3 \mu \mathrm{m}$ spectral ranges. The instrument is composed of three spectrometers: a solar occultation only spectrometer ( $\mathrm{SO}$ ) operating in the infrared wavelength domain, a second infrared spectrometer capable of doing nadir, but also solar occultation and limb observations (LNO), and an ultraviolet/visible spectrometer (UVIS) that can work in all observation modes. The spectral resolution of SO and LNO surpasses previous surveys in the infrared. NOMAD offers an integrated instrument combination of a flight-proven concept (SO is a copy of SOIR on Venus Express), and innovations based on existing and proven instrumentation (LNO is based on SOIR on board Venus Express), that will provide mapping and vertical profile information at high spatio-temporal resolution.

NOMAD will detect a large number of species, including isotopologues of the key species of the Martian atmosphere, such as $\mathrm{CO}_{2}, \mathrm{CO}, \mathrm{H}_{2} \mathrm{O}$ and even $\mathrm{CH}_{4}$. Combining $2 \mathrm{D}$-vertical sounding and mapping observations during the primary science phase, NOMAD will deliver a global $4 \mathrm{D}$ view of the atmosphere of Mars. 
The NOMAD Team-Science Team: Vandaele, Ann Carine; Lopez Moreno, Jose Juan; Bellucci, Giancarlo; Patel, Manish; Allen, Mark; Alonso-Rodrigo, Gustavo; Altieri, Francesca; Aoki, Shohei; Bolsée, David; Clancy, Todd; Cloutis, Edward; Daerden, Frank; D’Aversa, Emiliano; Depiesse, Cédric; Fedorova, Anna; Formisano, Vittorio; Funke, Bernd; Fussen, Didier; Garcia-Comas, Maya; Geminale, Anna; Gérard, Jean-Claude; Giuranna, Marco; Gonzalez-Galindo, Francisco; Hewson, Will; Ignatiev, Nicolai; Kaminski, Jacek; Karatekin, Ozgur; Kasaba, Yasumasa; Lefèvre, Franck; Lewis, Stephen; López-Puertas, Manuel; López-Valverde, Miguel; Mahieux, Arnaud; Mason, Jon; McConnel, Jack; Mumma, Mike; Neary, Lori; Neefs, Eddy; Novak, Robert; Oliva, Fabrizio; Piccialli, Arianna; Renotte, Etienne; Robert, Séverine; Sindoni, Giuseppe; Smith, Mike; Stiepen, Arnaud; Thomas, Ian R.; Trokhimovsky, Alexander; Vander Auwera, Jean; Villanueva, Geronimo; Viscardy, Sébastien; Whiteway, Jim; Willame, Yannick; Wilquet, Valerie; Wolff, Mike-Tech Team: Aparicio del Moral, Beatriz; Barzin, Pascal; BenMoussa, Ali; Berkenbosch, Sophie; Biondi, David; Bonnewijn, Sabrina; Candini, Gian Paolo; Clairquin, Roland; Cubas, Javier; Delanoye, Sofie; Drummond, Rachel; Giordanengo, Boris; Gissot, Samuel; Gomez, Alejandro; Hetey, Laszlo; Leese, Mark; Maes, Jeroen; Mazy, Emmanuel; Mazzoli, Alexandra; Meseguer, Jose; Morales, Rafael; Orban, Anne; Pastor-Morales, Maria del Carmen; PerezGrande, Isabel; Queirolo, Claudio; Ristic, Bojan; Rodriguez-Gomez, Julio; Saggin, Bortolino; Samain, Valérie; Sanz Andres, Angel; Sanz, Rosario; Simar, Juan-Felipe; Thibert, Tanguy; Zafra, Jose Jeronimo.

Acknowledgements The NOMAD experiment is led by the Royal Belgian Institute for Space Aeronomy (IASB-BIRA), assisted by Co-PI teams from Spain (IAA-CSIC), Italy (INAF-IAPS), and the United Kingdom (Open University). This project acknowledges funding by the Belgian Science Policy Office (BELSPO), with the financial and contractual coordination by the ESA Prodex Office (PEA 4000103401, 4000121493), by Spanish MICINN through its Plan Nacional and by European funds under grant ESP2015-65064-C21-P (MINECO/FEDER), as well as by UK Space Agency through grants ST/R005761/1, ST/P001262/1, ST/R001405/1 and ST/R001405/1 and Italian Space Agency through grant 2018-2-HH.0. The research was performed as part of the "Excellence of Science" project "Evolution and Tracers of Habitability on Mars and the Earth" (30442502). SA acknowledge support from the FNRS, Be.

Open Access This article is distributed under the terms of the Creative Commons Attribution 4.0 International License (http://creativecommons.org/licenses/by/4.0/), which permits unrestricted use, distribution, and reproduction in any medium, provided you give appropriate credit to the original author(s) and the source, provide a link to the Creative Commons license, and indicate if changes were made.

\section{References}

M.A. Allen, B. Sherwood Lollar, B. Runnegar, D.Z. Oehler, J.R. Lyons, C.E. Manning, M.E. Summers, Is Mars alive? EOS. Trans. Am. Geophys. Union 87, 433-439 (2006)

S. Aoki, H. Nakagawa, H. Sagawa, M. Giuranna, G. Sindoni, A. Aronica, Y. Kasaba, Seasonal variation of the $\mathrm{HDO} / \mathrm{H}_{2} \mathrm{O}$ ratio in the atmosphere of Mars at the middle of northern spring and beginning of northern summer. Icarus 260, 7-22 (2015)

M. Bauwens, T. Stavrakou, J.F. Müller, I. De Smedt, M. Van Roozendael, G.R. Van der Werf, C. Wiedinmyer, J. Kaiser, K. Sindelarova, A. Guenther, Nine years of global hydrocarbon emissions based on source inversion of OMI formaldehyde observations. Atmos. Chem. Phys. 16, 10133-10158 (2016)

J.L. Bertaux, F. Montmessin, Isotopic fractionation through water vapor condensation: The deuteropause, a cold trap for deuterium in the atmosphere of Mars. J. Geophys. Res. 106, 32879-32883 (2001)

D. Bolsée, N. Pereira, D. Gillotay, P. Pandey, G. Cessateur, T. Foujols, S. Bekki, A. Hauchecorne, M. Meftah, L. Damé, M. Hersé, A. Michel, C. Jacobs, A. Sela, SOLAR/SOLSPEC mission on ISS: In-flight performance for SSI measurements in the UV. Astron. Astrophys. 600, A21 (2017)

D. Catling, M.W. Claire, K. Zahnle, R. Quinn, B. Clark, M. Hecht, S. Kounaves, Atmospheric origins of perchlorate on Mars and in the Atacama. J. Geophys. Res. 115, E00E11 (2010) 
M.S. Chaffin, J. Deighan, N.M. Schneider, A.I.F. Stewart, Elevated atmospheric escape of atomic hydrogen from Mars induced by high-altitude water. Nat. Geosci. 10, 174-178 (2017)

R.T. Clancy, H. Nair, Annual (perihelion-aphelion) cycles in the photochemical behavior of the global Mars atmosphere. J. Geophys. Res. 101, 12785-12790 (1996)

R.T. Clancy, A.W. Grossman, M.J. Wolff, P.B. James, D.J. Rudy, Y.N. Billawala, B.J. Sandor, S.W. Lee, D.O. Muhleman, Water vapor saturation at low latitudes around aphelion: A key to Mars climate? Icarus 122, 36-62 (1996)

R.T. Clancy, M.J. Wolff, P.R. Christensen, Mars aerosol studies with the MGS TES emission phase function observations: Optical depths, particle sizes, and ice cloud types versus latitude and solar longitude. J. Geophys. Res. 108, 5098 (2003)

R.T. Clancy, M.J. Wolff, B. Whitney, B.A. Cantor, M. Smith, Mars equatorial mesospheric clouds: Global occurrence and physical properties from Mars global surveyor TES and MOC limb observations. J. Geophys. Res. 112, E04004 (2007)

R. Clancy, M. Wolff, F. Lefèvre, B. Cantor, M.C. Malin, M. Smith, Daily global mapping of Mars ozone column abundances with MARCI UV band imaging. Icarus 266, 112-133 (2016)

R.T. Clancy, M.D. Smith, F. Lefèvre, T.H. McConnochie, B.J. Sandor, M.J. Wolff, S.W. Lee, S.L. Murchie, A.D. Toigo, H. Nair, T. Navarro, Vertical profiles of Mars $1.27 \mu \mathrm{m} \mathrm{O}_{2}$ dayglow from MRO CRISM limb spectra: Seasonal/global behaviors, comparisons to LMDGCM simulations, and a global definition for Mars water vapor profiles. Icarus 293, 132-156 (2017)

J.T. Clarke, M. Mayyasi, D. Bhattacharyya, N.M. Schneider, W.E. McClintock, J.I. Deighan, A.I.F. Stewart, J.-Y. Chaufray, M.S. Chaffin, S.K. Jain, A. Stiepen, M. Crismani, G.M. Holsclaw, F. Montmessin, B.M. Jakosky, Variability of D and $\mathrm{H}$ in the Martian upper atmosphere observed with the MAVEN IUVS echelle channel. J. Geophys. Res. 122, 2336-2344 (2017)

M. Czerny, A.F. Turner, On the astigmatism of mirror spectrometers. Z. Phys. 61, 792-797 (1930)

F. Daerden, J.A. Whiteway, R. Davy, C. Verhoeven, L. Komguem, C. Dickinson, P.A. Taylor, N. Larsen, Simulating observed boundary layer clouds on Mars. Geophys. Res. Lett. 37, L04203 (2010)

F. Daerden, J.A. Whiteway, L. Neary, L. Komguem, M.T. Lemmon, N.G. Heavens, B. Cantor, E. Hébrard, M.D. Smith, A solar escalator on Mars: Self-lifting of dust layers by radiative heating. Geophys. Res. Lett. 42, 7319-7326 (2015)

R. Drummond, A.C. Vandaele, F. Daerden, D. Fussen, A. Mahieux, L. Neary, E. Neefs, S. Robert, Y. Willame, V. Wilquet, Studying methane and other trace species in the Mars atmosphere using a SOIR instrument. Planet. Space Sci. 59, 292-298 (2011)

T. Encrenaz, T. Greathouse, M. Richter, J. Lacy, T. Fouchet, B. Bézard, F. Lefèvre, F. Forget, S. Atreya, A stringent upper limit to $\mathrm{SO}_{2}$ in the Martian atmosphere. Astron. Astrophys. 530, A37 (2011)

F. Esposito, M. Giuranna, A. Maturilli, E. Palomba, L. Colangeli, V. Formisano, Albedo and photometric study of Mars with the planetary Fourier spectrometer on-board the Mars express mission. Icarus 186, 527-546 (2007)

G. Etiope, Understanding the origin of methan on Mars through isotopic and molecular data from the ExoMars orbiter. Planet. Space Sci. 159, 93-96 (2018)

A. Fedorova, O. Korablev, A.C. Vandaele, J.-L. Bertaux, D. Belyaev, A. Mahieux, E. Neefs, V. Wilquet, R. Drummond, F. Montmessin, E. Villard, $\mathrm{HDO}$ and $\mathrm{H}_{2} \mathrm{O}$ vertical distributions and isotopic ratio in the Venus mesosphere by solar occultation at infrared spectrometer onboard Venus express. J. Geophys. Res. 113, E00B22 (2008)

A. Fedorova, J.L. Bertaux, D.S. Betsis, F. Montmessin, O. Korablev, L. Maltagliati, J. Clarke, Water vapor in the middle atmosphere of Mars during the 2007 global dust storm. Icarus 300, 440-457 (2018)

S. Fonti, G.A. Marzo, Mapping the methane on Mars. Astron. Astrophys. 512, A51 (2010)

V. Formisano, S.K. Atreya, T. Encrenaz, N.I. Ignatiev, M. Giuranna, Detection of methane in the atmosphere of Mars. Science 306, 1758-1761 (2004)

A. Garcia Munoz, J.C. McConnell, I.C. McDade, S.M.L. Melo, Airglow on Mars: Some model expectations for the $\mathrm{OH}$ Meinel bands and the $\mathrm{O}_{2}$ IR atmospheric band. Icarus 176, 75-95 (2005)

A. Geminale, V. Formisano, G. Sindoni, Mapping methane in Martian atmosphere with PFS-MEX data. Planet. Space Sci. 59, 137-148 (2011)

M. Giuranna, Composition and mechanisms of accumulation of ices over the martian polar caps through analysis of PFS/MEX observations. Università degli studi di Padova. (2008)

R.M. Haberle, R.T. Clancy, F. Forget, M.D. Smith, R.W. Zurek, The Atmosphere and Climate of Mars (Cambridge University Press, Cambridge, 2017)

G.B. Hansen, The infrared absorption spectrum of carbon dioxide ice from 1.8 to $333 \mu \mathrm{m}$. J. Geophys. Res. 102, 21569-21587 (1997)

G.B. Hansen, Ultraviolet to near-infrared absorption spectrum of carbon dioxide ice from 0.174 to $1.8 \mu \mathrm{m}$. J. Geophys. Res. 110, E11003 (2005) 
P. Hartogh, C. Jarchow, E. Lellouch, M. De Val-Borro, M. Rengel, R. Moreno, A.S. Medvedev, H. Sagawa, B.M. Swinyard, T. Cavalié, D.C. Lis, M.I. Blecka, M. Banaszkiewicz, D. Bockelée-Morvan, J. Crovisier, T. Encrenaz, M. Küppers, L.-M. Lara, S. Szutowicz, B. Vandenbussche, F. Bensch, E.A. Bergin, F. Billebaud, N. Biver, G.A. Blake, J.A.D.L. Blommaert, J. Cernicharo, L. Decin, P. Encrenaz, H. Feuchtgruber, T. Fulton, T. De Graauw, E. Jehin, M. Kidger, R. Lorente, D.A. Naylor, G. Portyankina, M. Sanchez-Portal, R. Schieder, S. Sidher, N. Thomas, E. Verdugo, C. Waelkens, N. Whyborn, D. Teyssier, F. Helmich, P. Roelfsema, J. Stutzki, H.G. LeDuc, J.A. Stern, Herschel/HIFI observations of Mars: First detection of $\mathrm{O}_{2}$ at submillimetre wavelengths and upper limits on $\mathrm{HCl}$ and $\mathrm{H}_{2} \mathrm{O}_{2}$. Astron. Astrophys. 521, L49 (2010)

J.A. Holmes, S.R. Lewis, M.R. Patel, Analysing the consistency of martian methane observations by investigation of global methane transport. Icarus 257, 23-32 (2015)

J.A. Holmes, M.R. Patel, S.R. Lewis, The vertical transport of methane from different potential emission types on Mars. Geophys. Res. Lett. (2017). https://doi.org/10.1002/2017GL074613

R. Hu, A. Bloom, P. Gao, C. Miller, Y. Yung, Hypotheses for near-surface exchange of methane on Mars. Astrobiology 16, 539-550 (2016)

A.B. Ivanov, D.O. Muhleman, Cloud reflection observations: Results from the Mars orbiter laser altimeter. Icarus 154, 190-206 (2001)

A. Khayat, G. Villanueva, M. Mumma, A. Tokunaga, A search for $\mathrm{SO}_{2}, \mathrm{H}_{2} \mathrm{~S}$ and $\mathrm{SO}$ above Tharsis and Syrtis volcanic districts on Mars using ground-based high-resolution submillimeter spectroscopy. Icarus 253, 130-141 (2015)

S. Knak-Jensen, J. Skibsted, H. Jakobsen, I. ten Kate, H. Gunnlauggson, J. Merrison, K. Finster, E. Bak, J. Iversen, J. Kondrup, P. Nornberg, A sink for methane on Mars? The answer is blowing in the wind. Icarus 236, 24-27 (2014)

O. Korablev, F. Montmessin, A. Trokhimovskiy, A. Fedorova, A.V. Shakun, A.V. Grigoriev, B.E. Moshkin, N.I. Ignatiev, F. Forget, F. Lefèvre, K. Anufreychik, A.Y. Titov, A.V. Stepanov, A.V. Zharkov, A. Semenov, D. Patsaev, F. Martynovich, A. Sidorov, A. Viktorov, D. Timonin, O. Sazonov, V. Shashkin, A. Santos-Skripko, I. Maslov, I. Dzuban, I. Stupin, D. Merzlyakov, V. Makarov, Y. Nikolskiy, F. Altieri, G. Arnold, D.A. Belyaev, D.S. Betsis, J.L. Bertaux, N. Duxbury, T. Encrenaz, J.C. Gerard, S. Guerlet, D. Grassi, T. Fouchet, P. Hartogh, Y. Kasaba, I. Khatuntsev, V.A. Krasnopolsky, R.O. Kuzmin, E. Lellouch, M.A. Lopez-Valverde, M. Luginin, A. Määtänen, E. Marcq, J. Martin Torres, A. Medvedev, E. Millour, V.I. Shematovich, K. Olsen, M. Patel, C. Quantin-Nataf, A.V. Rodin, I. Thomas, N. Thomas, L. Vazquez, M. Vincendon, V. Wilquet, C. Wilson, L.V. Zasova, L.M. Zelenyi, M.-P. Zorzano, The Atmospheric Chemistry Suite (ACS) of three spectrometers for the ExoMars 2016 Trace Gas Orbiter. Space Sci. Rev. 214, 7 (2018). https://doi.org/10.1007/s11214-017-0437-6

S. Kounaves, M. Hecht, J. Kapit, K. Gospodinova, L. DeFlores, R. Quinn, W.V. Boynton, B. Clark, D. Catling, P. Hredzak, D. Ming, Q. Moore, J. Shusterman, S. Stroble, S. West, S. Young, Wet chemistry experiments on the 2007 Phoenix Mars scout lander mission: Data analysis and results. J. Geophys. Res. 115, E00E10 (2010)

V.A. Krasnopolsky, A sensitive search for $\mathrm{SO}_{2}$ in the martian atmosphere: Implications for seepage and origin of methane. Icarus 178, 487-492 (2005)

V.A. Krasnopolsky, Long-term spectroscopic observations of Mars using IRTF/CSHELL: Mapping of $\mathrm{O}_{2}$ dayglow, $\mathrm{CO}$, and search for $\mathrm{CH}_{4}$. Icarus 190, 93-102 (2007)

V.A. Krasnopolsky, Search for methane and upper limits to ethane and $\mathrm{SO}_{2}$ on Mars. Icarus 217, 144-152 (2012)

V.A. Krasnopolsky, G.L. Bjoraker, M.J. Mumma, D.E. Jennings, High-resolution spectroscopy of Mars at 3.7 and 8 micron: A sensitive search for $\mathrm{H}_{2} \mathrm{O}_{2}, \mathrm{H}_{2} \mathrm{CO}, \mathrm{HCl}$, and $\mathrm{CH}_{4}$, and detection of HDO. J. Geophys. Res. 102, 6525-6534 (1997)

V.A. Krasnopolsky, J.P. Maillard, T.C. Owen, Detection of methane in the Martian atmosphere: Evidence for life? Icarus 172, 537-547 (2004)

Y. Langevin, F. Poulet, J.P. Bibring, B. Gondet, Sulfates in the North polar region of Mars detected by OMEGA/Mars express. Science 307, 1584-1586 (2005)

F. Lefèvre, F. Forget, Observed variations of methane on Mars unexplained by known atmospheric chemistry and physics. Nature 460, 720-723 (2009)

F. Lefèvre, S. Lebonnois, F. Montmessin, F. Forget, Three-dimensional modeling of ozone on Mars. J. Geophys. Res. 109, E07004 (2004)

F. Lefèvre, J.L. Bertaux, R.T. Clancy, T. Encrenaz, K. Fast, F. Forget, S. Lebonnois, F. Montmessin, S. Perrier, Heterogeneous chemistry in the atmosphere of Mars. Nature 454, 971-975 (2008)

S.R. Lewis, P.L. Read, B.J. Conrath, J.C. Pearl, M.D. Smith, Assimilation of thermal emission spectrometer atmospheric data during the Mars global surveyor aerobraking period. Icarus 192, 327-347 (2007)

K. Lodders, B. Fegley, An oxygen isotope model for the composition of Mars. Icarus 126, 373-394 (1997) 
M. Luginin, A. Fedorova, D. Belyaev, F. Montmessin, V. Wilquet, O. Korablev, J.-L. Bertaux, A.C. Vandaele, Aerosol properties in the upper haze of Venus from SPICAV IR data. Icarus 277, 154-170 (2016)

A. Määttänen, C. Listowski, F. Montmessin, L. Maltagliati, A. Reberac, L. Joly, J.L. Bertaux, A complete climatology of the aerosol vertical distribution on Mars from MEx/SPICAM UV solar occultations. Icarus 223, 892-941 (2013)

J.B. Madeleine, F. Forget, E. Millour, T. Navarro, A. Spiga, The influence of radiatively active water ice clouds on the Martian climate. Geophys. Res. Lett. 39, L23302 (2012)

W.C. Maguire, Martian isotopic ratios and upper limits for possible minor constituents as derived from Mariner 9 infrared spectrometer data. Icarus 32, 85-97 (1977)

A. Mahieux, S. Berkenbosch, R. Clairquin, D. Fussen, N. Mateshvili, E. Neefs, D. Nevejans, B. Ristic, A.C. Vandaele, V. Wilquet, D. Belyaev, A. Fedorova, O. Korablev, E. Villard, F. Montmessin, J.L. Bertaux, In-flight performance and calibration of SPICAV/SOIR on-board Venus express. Appl. Opt. 47, 22522265 (2008)

A. Mahieux, A.C. Vandaele, S. Robert, V. Wilquet, R. Drummond, F. Montmessin, J.L. Bertaux, Densities and temperatures in the Venus mesosphere and lower thermosphere retrieved from SOIR on board Venus express: Carbon dioxide measurements at the Venus terminator. J. Geophys. Res. 117, E07001 (2012)

L. Maltagliati, F. Montmessin, A. Fedorova, O. Korablev, F. Forget, J.L. Bertaux, Evidence of water vapor in excess of saturation in the atmosphere of Mars. Science 333, 1868-1871 (2011)

L. Maltagliati, F. Montmessin, O. Korablev, A. Fedorova, F. Forget, A. Maattanen, F. Lefèvre, J.L. Bertaux, Annual survey of water vapor vertical distribution and water-aerosol coupling in the martian atmosphere observed by SPICAM/MEx solar occultations. Icarus 223, 942-962 (2013)

M. Mellon, W.C. Feldman, T. Prettyman, The presence and stability of ground ice in the southern hemisphere of Mars. Icarus 169, 324-340 (2004)

M. Mellon, R. Arvidson, H. Sizemore, M. Searls, D. Blaney, S.C. Cull, M. Hecht, T. Heet, H. Keller, M. Lemmon, W. Markiewicz, D. Ming, R. Morris, W. Pike, A. Zent, Ground ice at the Phoenix landing site: Stability state and origin. J. Geophys. Res. 114, E00E07 (2009)

L. Montabone, F. Forget, E. Millour, R.J. Wilson, S. Lewis, B. Cantor, D. Kass, A. Kleinbohl, M. Lemmon, M. Smith, M. Wolff, Eight-year climatology of dust optical depth on Mars. Icarus 251, 65-95 (2015)

F. Montmessin, F. Lefèvre, Transport-driven formation of a polar ozone layer on Mars. Nat. Geosci. 6, 930933 (2013)

F. Montmessin, F. Forget, P. Rannou, M. Cabane, R.M. Haberle, Origin and role of water ice clouds in the Martian water cycle as inferred from a general circulation model. J. Geophys. Res. 109, E10004 (2004)

F. Montmessin, B. Gondet, J.P. Bibring, Y. Langevin, P. Drossart, F. Forget, T. Fouchet, Hyperspectral imaging of convective $\mathrm{CO} 2$ ice clouds in the equatorial mesosphere of Mars. J. Geophys. Res. 112, E11S90 (2007)

M.J. Mumma, G.L. Villanueva, R.E. Novak, T. Hewagama, B.P. Bonev, M.A. DiSanti, A.M. Mandell, M.D. Smith, Strong release of methane on Mars in northern summer 2003. Science 323, 1041-1045 (2009)

H. Nakagawa, Y. Kasaba, H. Maezawa, A. Hashimoto, H. Sagawa, I. Murata, S. Okano, S. Aoki, N. Moribe, A. Mizuno, M. Momose, T. Ohnishi, N. Mizuno, T. Nagahama, Search of $\mathrm{SO}_{2}$ in the Martian atmosphere by ground-based submillimeter observation. Planet. Space Sci. 57, 2123-2127 (2009)

E. Neefs, A.C. Vandaele, R. Drummond, I.R. Thomas, S. Berkenbosch, R. Clairquin, S. Delanoye, B. Ristic, J. Maes, S. Bonnewijn, G. Pieck, E. Equeter, C. Depiesse, F. Daerden, E. Van Ransbeeck, D. Nevejans, J. Rodriguez, J.-J. Lopez-Moreno, R. Sanz, R. Morales, G.P. Candini, C. Pastor, B. Aparicio del Moral, J.M. Jeronimo, J. Gomez, I. Perez, F. Navarro, J. Cubas, G. Alonso, A. Gomez, T. Thibert, M.R. Patel, G. Belucci, L. De Vos, S. Lesschaeve, N. Van Vooren, W. Moelans, L. Aballea, S. Glorieux, A. Baeke, D. Kendall, J. De Neef, A. Soenen, P.Y. Puech, J. Ward, J.F. Jamoye, D. Diez, A. Vicario, M. Jankowski, NOMAD spectrometer on the ExoMars trace gas orbiter mission: Part 1-Design, manufacturing and testing of the infrared channels. Appl. Opt. 54, 8494-8520 (2015)

G. Neukum, R. Jaumann, H. Hoffmann, E. Hauber, J.W. Head, A. Basilevsky, B. Ivanov, S.C. Werner, S. Van Gasselt, J.B. Murray, T.B. McCord, Recent and episodic volcanic and glacial activity on Mars revealed by the high resolution stereo camera. Nature 432, 971-979 (2004)

D. Nevejans, E. Neefs, E. Van Ransbeeck, S. Berkenbosch, R. Clairquin, L. De Vos, W. Moelans, S. Glorieux, A. Baeke, O. Korablev, I. Vinogradov, Y. Kalinnikov, B. Bach, J.P. Dubois, E. Villard, Compact highresolution space-borne echelle grating spectrometer with AOTF based on order sorting for the infrared domain from 2.2 to 4.3 micrometer. Appl. Opt. 45, 5191-5206 (2006)

G. Nikolakakos, J. Whiteway, Laboratory investigation of perchlorate deliquescence at the surface of Mars with a Raman scattering lidar. Geophys. Res. Lett. 42, 7899-7906 (2015)

G. Nikolakakos, J. Whiteway, Laboratory study of adsorption and deliquescence on the surface of Mars. Icarus 308, 221-229 (2018). https://doi.org/10.1016/j.icarus.2017.05.006

M.E. Ockert-Bell, J.F. Bell III., J.B. Pollack, C.P. McKay, F. Forget, Absorption and scattering properties of the Martian dust in the solar wavelengths. J. Geophys. Res. 102, 9039-9050 (1997) 
D.Z. Oehler, G. Etiope, Methane seapage on Mars: Where to look and why. Astrobiology 17 (2017). https:// doi.org/10.1089/ast.2017.1657

L. Ojha, M.B. Wilhelm, S.L. Murchie, A.S. McEwen, J.J. Wray, J. Hanley, M. Massé, M. Chojnacki, Spectral evidence for hydrated salts in recurring slope lineae on Mars. Nat. Geosci. 8, 829-832 (2015)

T.C. Onstott, D. McGown, J. Kessler, B. Sherwood Lollar, K. Lehmann, S.M. Clifford, Martian $\mathrm{CH}_{4}$ : Sources, flux, and detection. Astrobiology 6, 377-395 (2006)

T. Owen, K. Biemann, D.R. Rushnek, J.E. Biller, D.W. Howarth, A.L. Lafleur, The composition of the atmosphere at the surface of Mars. J. Geophys. Res. 82, 4635-4639 (1977)

M.R. Patel, P. Antoine, J. Mason, M. Leese, B. Hathi, A. Stevens, D. Dawson, J. Gow, T. Ringrose, J. Holmes, S. Lewis, D. Beghuin, P. Van Donink, R. Ligot, J.-L. Dewandel, D. Hu, D. Bates, R. Cole, R. Drummond, I.R. Thomas, C. Depiesse, E. Neefs, E. Equeter, B. Ristic, S. Berkenbosch, D. Bolsée, Y. Willame, A.C. Vandaele, S. Lesschaeve, L. De Vos, N. Van Vooren, T. Thibert, E. Mazy, J. Rodriguez-Gomez, R. Morales, G.P. Candini, C. Pastor-Morales, R. Sanz, B. Aparicio del Moral, J.-M. Jeronimo-Zafra, J.M. Gomez-Lopez, G. Alonso-Rodrigo, I. Pérez-Grande, J. Cubas, A. Gomez-Sanjuan, F. Navarro-Medina, A. Ben Moussa, B. Giordanengo, S. Gissot, G. Bellucci, J.J. Lopez-Moreno, The NOMAD spectrometer on the ExoMars trace gas orbiter mission: Part 2-Design, manufacturing and testing of the ultraviolet and visible channel. Appl. Opt. 56, 2771-2782 (2017)

S. Perrier, J.-L. Bertaux, F. Lefèvre, S. Lebonnois, O. Korablev, A. Fedorova, F. Montmessin, Global distribution of total ozone on Mars from SPICAM/MEX UV measurements. J. Geophys. Res. 11, E09S06 (2006)

G.H. Pettengill, P.G. Ford, Winter clouds over the North Martian polar cap. Geophys. Res. Lett. 27, 609-612 (2000)

S. Robert, A.C. Vandaele, I.R. Thomas, Y. Willame, F. Daerden, S. Delanoye, C. Depiesse, R. Drummond, E. Neefs, L. Neary, B. Ristic, J. Mason, J.J. Lopez-Moreno, J.F. Rodriguez-Gomez, M.R. Patel, G. Bellucci, t.N. Team, Expected performances of the NOMAD/ExoMars instrument. Planet. Space Sci. 124, 94-104 (2016)

M.D. Smith, Interannual variability in TES atmospheric observations of Mars during 1999-2003. Icarus 167, 148-165 (2004)

M.D. Smith, THEMIS observations of Mars aerosol optical depth from 2002-2008. Icarus 202, 444-452 (2009)

P.H. Smith, L. Tamppari, R.F. Arvidson, D. Bass, D. Blaney, W. Boynton, A.I. Carswell, D.C. Catling, B. Clark, T. Duck, E. DeJong, D. Fisher, W. Goetz, H. Gunnlauggson, M. Hecht, V. Hipkin, J. Hoffman, S.F. Hviid, H.U. Keller, S. Kounaves, C. Lange, M. Lemmon, M. Madsen, M.C. Malin, W. Markiewicz, B.T. Marshall, C.P. McKay, M. Mellon, D. Michelangeli, D. Ming, R.V. Morris, N. Renno, W. Pike, U. Staufer, C. Stoker, P.A. Taylor, J.A. Whiteway, S. Young, A. Zent, $\mathrm{H}_{2} \mathrm{O}$ at the Phoenix landing site. Science 325, 58-61 (2009a)

M. Smith, M.J. Wolff, R.T. Clancy, S.L. Murchie, Compact reconnaissance imaging spectrometer observations of water vapor and carbon monoxide. J. Geophys. Res. 114, E00D03 (2009b)

M. Smith, F. Daerden, L. Neary, A. Khayat, The climatology of carbon monoxide and interannual variation of water vapor on Mars as observed by CRISM and modeled by the GEM-Mars general circulation model. Icarus 301, 117-131 (2018). https://doi.org/10.1016/j.icarus.2017.09.027

A. Sprague, W.V. Boynton, K.E. Kerry, D.M. Janes, D.M. Hunten, K. Kim, R.C. Reedy, A. Metzger, Mars' South polar Ar enhancement: A tracer for South polar seasonal meridional mixing. Science 306, 13641367 (2004)

T. Stavrakou, J.F. Müller, I. De Smedt, M. Van Roozendael, M. Kanakidou, M. Vrekoussis, F. Wittrock, A. Richter, J. Burrows, The continental source of glyoxal estimated by the synergistic use of spaceborne measurements and inverse modelling. Atmos. Chem. Phys. 9, 8431-8446 (2009)

L. Steele, S. Lewis, M. Patel, F. Montmessin, F. Forget, M.D. Smith, The seasonal cycle of water vapour on Mars from assimilation of thermal emission spectrometer data. Icarus 237, 97-115 (2014)

M.E. Summers, B.J. Lieb, E. Chapman, Y.L. Yung, Atmospheric biomarkers of subsurface life on Mars. Geophys. Res. Lett. 29, 2171 (2002)

H. Svedhem, Space Sci. Rev. (2017, this issue)

I.R. Thomas, A.C. Vandaele, S. Robert, E. Neefs, R. Drummond, F. Daerden, S. Delanoye, C. Depiesse, B. Ristic, A. Mahieux, L. Neary, Y. Willame, V. Wilquet, L. Aballea, W. Moelans, L. De Vos, S. Lesschaeve, N. Van Vooren, J.J. Lopez-Moreno, M.R. Patel, G. Bellucci, t.N. Team, Optical and radiometric models of the NOMAD instrument-Part II: The IR channels—SO and LNO. Opt. Express 24, 37903805 (2016)

D.V. Titov, H. Svedhem, D. McCoy, J.P. Lebreton, S. Barabash, J.L. Bertaux, P. Drossart, V. Formisano, B. Haeusler, O.I. Korablev, W. Markiewicz, D. Neveance, M. Petzold, G. Piccioni, T.L. Zhang, F.W. Taylor, E. Lellouch, D. Koschny, O. Witasse, M. Warhaut, A. Accomazzo, J. Rodrigues-Cannabal, J. Fabrega, T. Schirmann, A. Clochet, M. Coradini, Venus express: Scientific goals, instrumentation and scenario of the mission. Cosm. Res. 44, 334-348 (2006) 
M.C. Towner, M.R. Patel, T.J. Ringrose, J.C. Zarnecki, D. Pullan, M.R. Sims, S. Haapanala, A.-M. Harri, J. Polkko, C.F. Wilson, A.P. Zent, R.C. Quinn, F.J. Grunthaner, M.H. Hecht, J.R.C. Garry, The Beagle 2 environmental sensors: Science goals and instrument description. Planet. Space Sci. 52, 1141-1156 (2004)

L. Trompet, A. Mahieux, B. Ristic, S. Robert, V. Wilquet, I.R. Thomas, A.C. Vandaele, J.L. Bertaux, Improved algorithm for the transmittance estimation of spectra obtained with SOIR/Venus express. Appl. Opt. 55, 9275-9281 (2016)

A.C. Vandaele, M. De Mazière, R. Drummond, A. Mahieux, E. Neefs, V. Wilquet, O. Korablev, A. Fedorova, D. Belyaev, F. Montmessin, J.L. Bertaux, Composition of the Venus mesosphere measured by SOIR on board Venus express. J. Geophys. Res. 113, E00B23 (2008)

A.C. Vandaele, E. Neefs, R. Drummond, I.R. Thomas, F. Daerden, J.-J. Lopez-Moreno, M. Patel, G. Bellucci, M. Allen, F. Altieri, D. Bolsee, T. Clancy, E. Cloutis, S. Delanoye, C. Depiesse, E. Cloutis, A. Fedorova, V. Formisano, B. Funke, D. Fussen, A. Geminale, J.-C. Gérard, M. Giuranna, N. Ignatiev, J. Kaminski, O. Karatekin, F. Lefèvre, M. López-Puertas, M. López-Valverde, A. Mahieux, J.M. Connell, M. Mumma, L. Neary, E. Renotte, B. Ristic, S. Robert, M. Smith, S. Trokhimovsky, G. Villanueva, J. Whiteway, V. Wilquet, M. Wolff, t.N. Team, Science objectives and performances of NOMAD, a spectrometer suite for the ExoMars TGO mission. Planet. Space Sci. 119, 233-249 (2015a)

A.C. Vandaele, Y. Willame, C. Depiesse, I. Thomas, S. Robert, M.R. Patel, P. Mason, M. Leese, S. Lesschaeve, P. Antoine, F. Daerden, S. Delanoye, R. Drummond, E. Neefs, B. Ristic, J.J. Lopez-Moreno, G. Bellucci, t.N. Team, Optical and radiometric models of the NOMAD instrument part I: The UVIS channel. Opt. Express 23, 30028-30042 (2015b)

S. Vandenbussche, S. Kochenova, A.C. Vandaele, N. Kumps, M. De Mazière, Retrieval of desert dust aerosol vertical profiles from IASI measurements in the TIR atmospheric window. Atmos. Meas. Tech. 6, 25772591 (2013)

G.L. Villanueva, M.J. Mumma, R.E. Novak, Y.L. Radeva, H.U. Käufl, A. Smette, A. Tokunaga, A. Khayat, T. Encrenaz, P. Hartogh, A sensitive search for organics $\left(\mathrm{CH}_{4}, \mathrm{CH}_{3} \mathrm{OH}, \mathrm{H}_{2} \mathrm{CO}, \mathrm{C}_{2} \mathrm{H}_{6}, \mathrm{C}_{2} \mathrm{H}_{2}, \mathrm{C}_{2} \mathrm{H}_{4}\right)$, hydroperoxyl $\left(\mathrm{HO}_{2}\right)$, nitrogen compounds $\left(\mathrm{N}_{2} \mathrm{O}, \mathrm{NH}_{3}, \mathrm{HCN}\right)$ and chlorine species $\left(\mathrm{HCl}, \mathrm{CH}_{3} \mathrm{Cl}\right)$ on Mars using ground-based high-resolution infrared spectroscopy. Icarus 223, 11-27 (2013)

G. Villanueva, M. Mumma, R. Novak, H.U. Käufl, P. Hartogh, P. Encrenaz, A. Tokunaga, A. Khayat, M.D. Smith, Strong water isotopic anomalies in the martian atmosphere: Probing current and ancient reservoirs. Science 348, 218-221 (2015)

S. Viscardy, F. Daerden, L. Neary, Formation of layers of methane in the atmosphere of Mars after surface release. Geophys. Res. Lett. 43, 1868-1875 (2016)

S.G. Warren, R.E. Brandt, Optical constants of ice from the ultraviolet to the microwave: A revised compilation. J. Geophys. Res. 113, D14220 (2008)

C. Webster, P. Mahaffy, S.K. Atreya, G. Flesch, K. Farley, Low upper limit to methane abundance on Mars. Science 342, 355-357 (2013)

C. Webster, P. Mahaffy, S.K. Atreya, G. Flesch, M. Mischna, P.-Y. Meslin, K. Farley, P. Conrad, L. Christensen, A. Pavlov, J. Martín-Torres, M. Zorzano, T. McConnochie, T. Owen, J. Eigenbrode, D. Glavin, A. Steele, C. Malespin, P. Archer, B. Sutter, P. Coll, C. Freissinet, C. McKay, J. Moores, S. Schwenzer, J. Bridges, R. Navarro-González, R. Gellert, M. Lemmon, Mars methane detection and variability at Gale crater. Science 347, 415-417 (2015)

J.A. Whiteway, L. Komguem, C. Dickinson, C. Cook, M. Illnicki, J. Seabrook, V. Popovici, T.J. Duck, R. Davy, P.A. Taylor, J. Pathak, D. Fisher, A.I. Carswell, M. Daly, V. Hipkin, L. Tamppari, N. Renno, J. Moores, M. Lemmon, F. Daerden, H. Smith, Mars water ice clouds and precipitation. Science 325, 68-70 (2009)

Y. Willame, A.C. Vandaele, C. Depiesse, F. Lefèvre, V. Letocart, D. Gillotay, F. Montmessin, Retrieving cloud, dust and ozone abundances in the Martian atmosphere using SPICAM/UV nadir spectra. Planet. Space Sci. 142, 9-25 (2017)

V. Wilquet, A. Fedorova, F. Montmessin, R. Drummond, A. Mahieux, A.C. Vandaele, E. Villard, O. Korablev, J.L. Bertaux, Preliminary characterization of the upper haze by SPICAV/SOIR solar occultation in UV to mid-IR onboard Venus express. J. Geophys. Res. 114, E00B42 (2009)

V. Wilquet, R. Drummond, A. Mahieux, S. Robert, A.C. Vandaele, S.W. Bougher, A. Brecht, C. Parkinson, in Combination of SOIR/VEX Observations and VTGCM Simulations to Decipher the Mesosphere and Lower Thermosphere of Venus, European Planetary Science Congress, vol. 7, EPSC2012-243 2012, Madrid, Spain (2012)

M.J. Wolff, M.D. Smith, R.T. Clancy, R. Arvidson, M. Kahre, F. Seelos, S. Murchie, H. Savijarvi, Wavelength dependence of dust aerosol single scattering albedo as observed by CRISM. J. Geophys. Res. 114, E00D04 (2009)

M.J. Wolff, R.T. Clancy, J.D. Goguen, M.C. Malin, B.A. Cantor, Ultraviolet dust aerosol properties as observed by MARCI. Icarus 208, 143-155 (2010) 
A.-S. Wong, S.K. Atreya, T. Encrenaz, Chemical markers of possible hot spots on Mars. J. Geophys. Res. 108, 5026 (2003)

A.S. Wong, S.K. Atreya, V. Formisano, T. Encrenaz, N.I. Ignatiev, Atmospheric photochemistry above possible martian hot spots. Adv. Space Res. 33, 2236-2239 (2004)

K. Zahnle, R.S. Freedman, D.C. Catling, Is there methane on Mars? Icarus 212, 493-503 (2011)

R.W. Zurek, A. Chicarro, M.A. Allen, J.L. Bertaux, R.T. Clancy, F. Daerden, V. Formisano, J. Garvin, G. Neukum, M.A. Smith, Assessment of a 2016 mission concept: The search for trace gases in the atmosphere of Mars. Planet. Space Sci. 59, 284-291 (2011) 